\title{
The Effect of Milk on the Deodorization of Malodorous Breath after Garlic Ingestion
}

\section{THESIS}

Presented in Partial Fulfillment of the Requirements for the Degree Master of

Science in the Graduate School of The Ohio State University

$$
\text { By }
$$

Areerat Hansanugrum

Graduate Program in Food Science and Technology

The Ohio State University

2010

Master's Examination Committee:

Professor Sheryl A. Barringer, Advisor

Adjunct Professor Dr. John H. Litchfield

Associate Professor Dr. V.M. (Bala) Balasubramaniam 
Copyright by

Areerat Hansanugrum

2010 


\begin{abstract}
The effect of milk and milk components on the deodorization of diallyl disulfide, allyl methyl disulfide, allyl mercaptan, allyl methyl sulfide, and methyl mercaptan in the headspace of garlic as well as in the mouth- and nose-space after garlic ingestion was investigated using a selected ion flow tube-mass spectrometry (SIFT-MS). Fat-free and whole milk significantly reduced the head-, mouth-, and nose-space concentrations of all volatiles. Water was the major component in milk responsible for the deodorization of volatiles. Due to its higher fat content, whole milk was more effective than fat-free milk in the deodorization of the more hydrophobic volatiles diallyl disulfide and allyl methyl disulfide. Milk was more effective than water and $10 \%$ sodium caseinate in the deodorization of allyl methyl sulfide, a persistent garlic odor, in the mouth after garlic ingestion. Addition of milk to garlic before ingestion had a higher deodorizing effect on the volatiles in the mouth than drinking milk after consuming garlic.
\end{abstract}




\section{PRACTICAL APPLICATIONS}

Ingesting beverages or foods with high water and/or fat content such as milk may help reduce the malodorous odor in breath after garlic ingestion and mask the garlic flavor during eating. To enhance the deodorizing effect, deodorant foods should be mixed with garlic before ingestion. 


\section{ACKNOWLEDGEMENTS}

I would like to thank:

My advisor, Dr. Sheryl A. Barringer, for her advice, support, and time on my research and thesis writing. It had been a great experience working with her.

My parents, Mr. Nuttawat and Ms. Surata Hansanugrum, for their love, financial support, and advices.

Dr. James W. Harper for allowing me to use the SIFT-MS machine

Cheryl Wick for her SIFT-MS support.

My committee members, Dr. John H. Litchfield and Dr. V.M. (Bala)

Balasubramaniam, for serving on my graduate committee.

Ms. Monchaya Rattanaprasert for her advice and encouragement during writing my thesis.

Ms. Wannasawat Ratphitagsanti, Xiaojing Li, Nutsuda Sumonsiri, and all my lab mates for their friendship and encouragement. 


\title{
VITA
}

\author{
May $9,1982 \ldots \ldots \ldots \ldots \ldots \ldots \ldots \ldots \ldots \ldots \ldots \ldots \ldots \ldots \ldots \ldots$ Born-Bangkok, Thailand

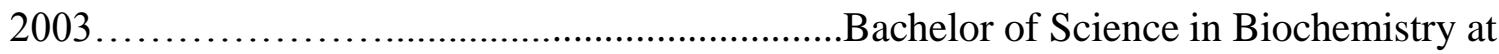 \\ University of California, Los Angeles

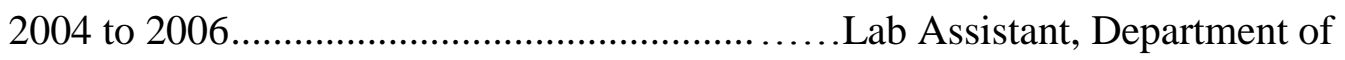 \\ Molecular, Cell, and Developmental \\ Biology, UCLA \\ 2006 to 2008 \\ Teaching Lab Assistant, Department of \\ Microbiology, Immunology, and \\ Molecular Genetics, UCLA
}

\section{FIELDS OF STUDY}

Major Field: Food Science and Technology 


\section{TABLE OF CONTENTS}

\section{Page}

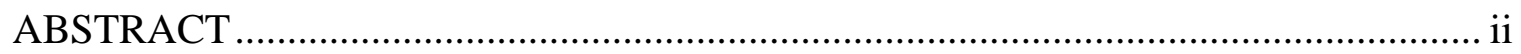

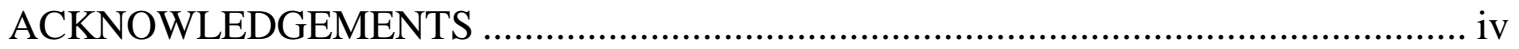

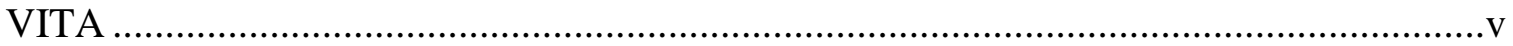

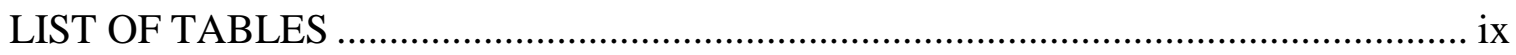

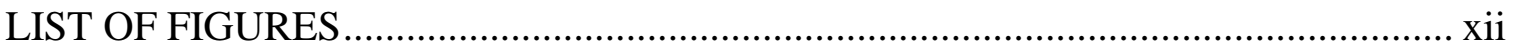

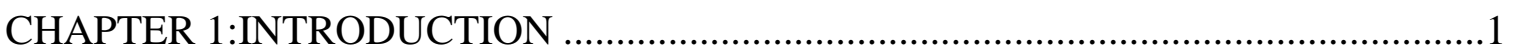

CHAPTER 2:LITERATURE REVIEW ..............................................................4

2.1. Garlic .......................................................................................

2.1.1. Identification of garlic volatiles....................................................... 
2.2. Garlic breath

2.2.1. Identification of volatiles in garlic breath........................................... 14

2.2.2. Deodorization of volatile sulfur compounds in garlic breath .....................15

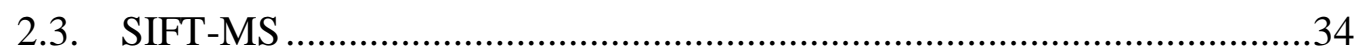

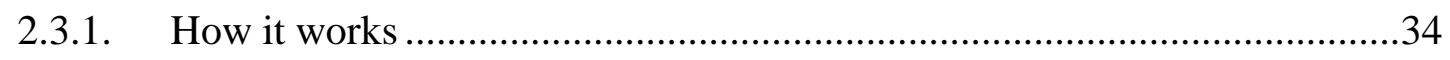

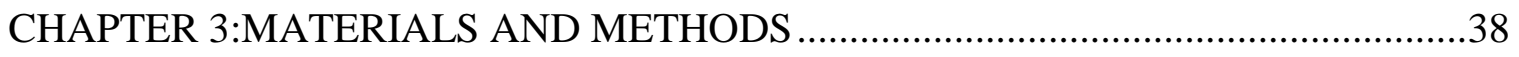

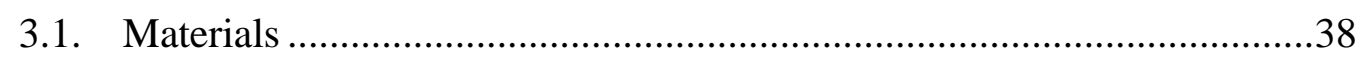

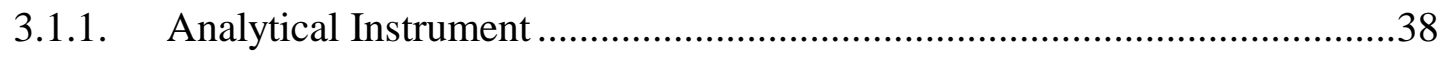

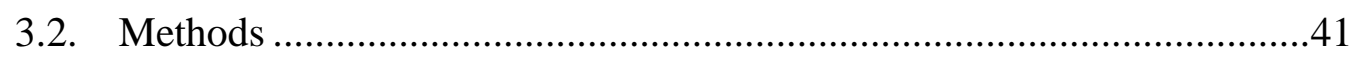

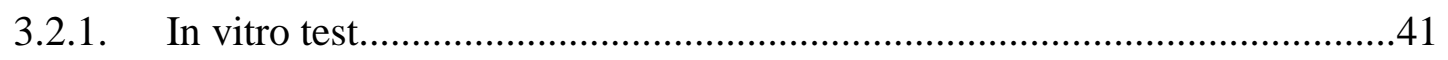

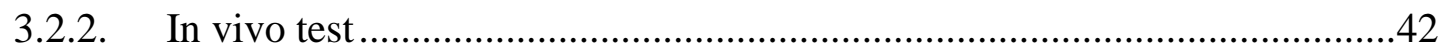

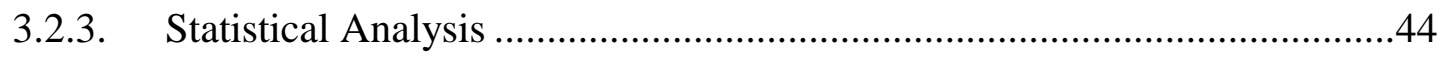

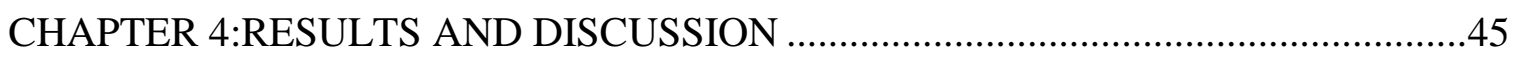

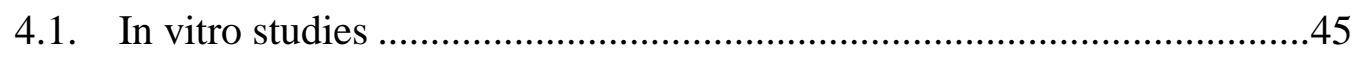


4.1.1. Effect of food components on the deodorization of the volatiles in the headspace of chopped garlic

4.1.2. Effect of milk and similar solutions on the deodorization of volatiles in the headspace of chopped garlic

4.2. In vivo studies

4.2.1. Quantification of the major volatiles in the breath after garlic ingestion ....59

4.2.2. Effect of milk and similar solutions on the deodorization of malodorous breath after garlic ingestion.

4.3. Conclusion

REFERENCES

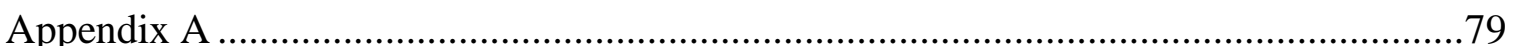




\section{LIST OF TABLES}

Table 2.1 Aroma descriptions and odor thresholds of garlic volatiles 12

Table 2.2 Deodorizing effect of foods and beverages on volatile sulfur compounds in the

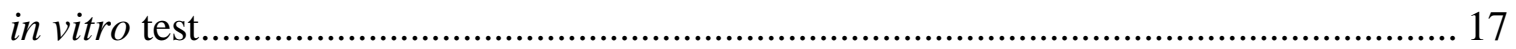

Table 3.1 Volatile sulfur compounds measured in the SIM scan ................................. 39

Table A.1 Concentrations of diallyl disulfide (DADS), allyl methyl sulfide (AMS), allyl methyl disulfide (AMDS), allyl mercaptan (AM), and methyl mercaptan (MM) in the headspace of chopped unblanched garlic..

Table A.2 Concentrations of diallyl disulfide (DADS), allyl methyl sulfide (AMS), allyl methyl disulfide (AMDS), allyl mercaptan (AM), and methyl mercaptan (MM) in the headspace of chopped blanched garlic.

Table A.3 Concentrations of diallyl disulfide (DADS), allyl methyl sulfide (AMS), allyl methyl disulfide (AMDS), allyl mercaptan (AM), and methyl mercaptan (MM) in the headspace of chopped unblanched garlic..

Table A.4 Concentrations of diallyl disulfide (DADS), allyl methyl sulfide (AMS), allyl methyl disulfide (AMDS), allyl mercaptan (AM), and methyl mercaptan (MM) in the headspace of chopped blanched garlic. 
Table A.5 Effect of sodium caseinate concentrations on the reduction of diallyl disulfide (DADS), allyl methyl sulfide (AMS), allyl methyl disulfide (AMDS), allyl mercaptan (AM), and methyl mercaptan (MM) in the headspace of chopped unblanched garlic..... 90 Table A.6 Effect of sodium caseinate concentrations on the reduction of diallyl disulfide (DADS), allyl methyl sulfide (AMS), allyl methyl disulfide (AMDS), allyl mercaptan $(\mathrm{AM})$, and methyl mercaptan (MM) in the headspace of chopped blanched garlic. 90 Table A.7 Effect of lactose concentrations on the reduction of diallyl disulfide (DADS), allyl methyl sulfide (AMS), allyl methyl disulfide (AMDS), allyl mercaptan (AM), and methyl mercaptan (MM) in the headspace of chopped unblanched garlic.

Table A.8 Effect of lactose concentrations on the reduction of diallyl disulfide (DADS), allyl methyl sulfide (AMS), allyl methyl disulfide (AMDS), allyl mercaptan (AM), and methyl mercaptan (MM) in the headspace of chopped blanched garlic.... 92 Table A.9 Effect of milk on the reduction of diallyl disulfide (DADS), allyl methyl sulfide (AMS), allyl methyl disulfide (AMDS), allyl mercaptan (AM), and methyl mercaptan (MM) in the headspace of chopped unblanched garlic. 95 Table A.10 Concentration of diallyl disulfide (DADS) in the mouth for 60 minutes after ingestion of garlic or chopped garlic in water, fat-free milk, whole milk, or $10 \%$ casein 
Table A.11 Concentration of allyl mercaptan (AM) in the mouth for 60 minutes after ingestion of garlic or chopped garlic in water, fat-free milk, whole milk, or $10 \%$ casein.. 96 Table A.12 Concentration of allyl methyl disulfide (AMDS) in the mouth for 60 minutes after ingestion of garlic or chopped garlic in water, fat-free milk, whole milk, or $10 \%$ casein.. 96

Table A.13 Concentration of allyl methyl sulfide (AMS) in the mouth for 60 minutes after ingestion of garlic or chopped garlic in water, fat-free milk, whole milk, or $10 \%$ casein..

Table A.14 Concentration of diallyl disulfide (DADS) in the mouth for 60 minutes after ingestion of garlic followed by $2 \%$ fat milk, green tea, or none.

Table A.15 Concentration of allyl mercaptan (AM) in the mouth for 60 minutes after ingestion of garlic followed by $2 \%$ fat milk, green tea, or none. 98 Table A.16 Concentration of allyl methyl disulfide (AMDS) in the mouth for 60 minutes after ingestion of garlic followed by $2 \%$ fat milk, green tea, or none. 98 Table A.17 Concentration of allyl methyl sulfide (AMS) in the mouth for 60 minutes after ingestion of garlic followed by $2 \%$ fat milk, green tea, or none. 99 


\section{LIST OF FIGURES}

Figure 2.1 Formation of thiosulfinates from S-alkylcysteine sulfoxides by the action of

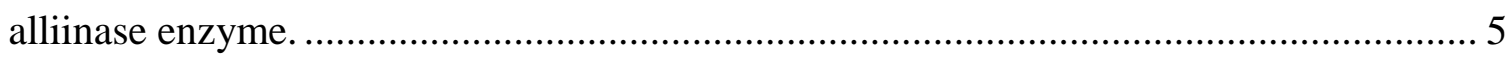

Figure 2.2 Formation of allicin after maceration of garlic. ...................................... 6 Figure 2.3 Proposed mechanism of enzymatic deodorization by fruits, vegetables, and

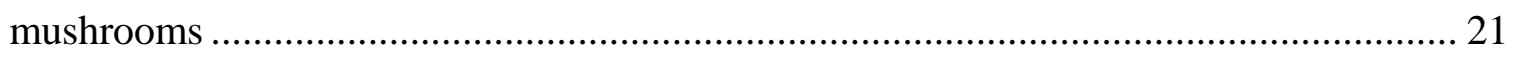

Figure 2.4 A schematic diagram of the Voice 100 SIFT-MS instrument....................... 36

Figure 4.1 Effect of blanching on the concentrations of diallyl disulfide (DADS), allyl methyl disulfide (AMDS), allyl mercaptan (AM), allyl methyl sulfide (AMS), and methyl mercaptan $(\mathrm{MM})$ in the headspace of chopped garlic

Figure 4.2 Effect of water and oil on the concentrations of diallyl disulfide (DADS), allyl methyl disulfide (AMDS), allyl mercaptan (AM), allyl methyl sulfide (AMS), and methyl mercaptan (MM) in the headspace of chopped unblanched garlic.

Figure 4.3 Effect of canola oil concentration in oil-in-water emulsions on diallyl disulfide (DADS), allyl methyl disulfide (AMDS), allyl mercaptan (AM), allyl methyl sulfide (AMS), and methyl mercaptan (MM) in the headspace of chopped unblanched garlic 
Figure 4.4 Effect of sodium caseinate concentration on diallyl disulfide (DADS), allyl methyl disulfide (AMDS), allyl mercaptan (AM), allyl methyl sulfide (AMS), and methyl mercaptan (MM) in the headspace of unblanched chopped garlic in aqueous solutions

Figure 4.5 Effect of milk and similar solutions on the concentrations of diallyl disulfide (DADS), allyl methyl disulfide (AMDS), allyl mercaptan (AM), allyl methyl sulfide (AMS), and methyl mercaptan (MM) in the headspace of chopped unblanched garlic... 58 Figure 4.6 Concentrations of diallyl disulfide (DADS), allyl mercaptan (AM), allyl methyl sulfide (AMS), and allyl methyl disulfide (AMDS) in the mouth- and nose-space after garlic ingestion 62

Figure 4.7 Concentration of diallyl disulfide (DADS) and allyl methyl disulfide (AMDS) in the mouth for 60 minutes after ingestion of garlic alone or in water, fat-free milk, whole milk, or $10 \%$ casein.

Figure 4.8 Concentration of allyl mercaptan (AM) and allyl methyl sulfide (AMS) in the mouth for 60 minutes after ingestion of garlic alone or in water, fat-free milk, whole milk, or $10 \%$ casein.

Figure 4.9 Concentrations of diallyl disulfide (DADS) and allyl methyl disulfide (AMDS) in the mouth for 60 minutes after ingestion of garlic, garlic in fat-free or whole milk, or garlic followed by fat-free or whole milk. 
Figure 4.10 Concentrations of allyl mercaptan (AM) and allyl methyl sulfide (AMS) in the mouth for 60 minutes after ingestion of garlic, garlic in fat-free or whole milk, or garlic followed by fat-free or whole milk

Figure A.1 Concentrations of A) diallyl disulfide (DADS), B) allyl methyl sulfide (AMS), allyl methyl disulfide (AMDS), allyl mercaptan (AM), and methyl mercaptan $(\mathrm{MM})$ in the headspace of chopped unblanched garlic

Figure A.2 Concentrations of A) diallyl disulfide (DADS), B) allyl methyl disulfide (AMDS), C) allyl methyl sulfide (AMS), allyl mercaptan (AM), and methyl mercaptan (MM) in the headspace of chopped blanched garlic.

Figure A.3 Concentrations of A) diallyl disulfide (DADS), allyl methyl disulfide (AMDS), allyl mercaptan (AM), B) allyl methyl sulfide (AMS), and methyl mercaptan (MM) in the headspace of chopped unblanched garlic. 85

Figure A.4 Concentrations of A) diallyl disulfide (DADS), allyl methyl disulfide (AMDS), B) allyl methyl sulfide (AMS), allyl mercaptan (AM), and methyl mercaptan (MM) in the headspace of chopped blanched garlic.

Figure A.5 Effect of solutions with different polarity on the concentrations of A) diallyl disulfide (DADS), allyl methyl disulfide (AMDS), B) allyl methyl sulfide (AMS), allyl mercaptan (AM), and methyl mercaptan (MM) in the headspace of chopped blanched garlic 
Figure A.6 Effect of canola oil concentration on the concentrations of A) diallyl disulfide (DADS), allyl methyl disulfide (AMDS), B) allyl methyl sulfide (AMS), allyl mercaptan (AM), and methyl mercaptan (MM) in the headspace of chopped blanched garlic in oilin-water emulsions.

Figure A.7 Effect of sodium caseinate on the concentrations of the more hydrophobic compounds: diallyl disulfide (DADS) and allyl methyl disulfide (AMDS) and the more hydrophilic compounds: allyl methyl sulfide (AMS), allyl mercaptan (AM), and methyl mercaptan (MM) in the headspace of blanched chopped garlic in aqueous solutions. .... 91 Figure A.8 Effect of lactose on the concentrations of A) diallyl disulfide (DADS), allyl methyl disulfide (AMDS), B) allyl mercaptan (AM), allyl methyl sulfide (AMS), and methyl mercaptan (MM) in the headspace of chopped unblanched garlic in aqueous solutions

Figure A.9 Effect of lactose on the concentrations of A) diallyl disulfide (DADS), allyl methyl disulfide (AMDS), B) allyl methyl sulfide (AMS), allyl mercaptan (AM), and methyl mercaptan (MM) in the headspace of chopped blanched garlic in aqueous solutions 


\section{CHAPTER 1}

\section{INTRODUCTION}

Garlic, Allium sativum L., has been widely used as food and medicine around the world for thousands of years. It contains a high amount of sulfur compounds, which are responsible for the characteristic odor and flavor of garlic (Lawson 1996). Garlic has many health benefits. It is an excellent source of magnesium, vitamin B6, vitamin $\mathrm{C}$, and selenium. It helps in lowering blood pressure and cholesterol and also reduces the risk of cancer (Block and others 1992; Yeh and Liu 2001). However, the consumption of garlic causes bad breath and body odor which can last from several hours to days (Haggard and Greenberg 1935).

The major volatile compounds responsible for garlic breath are allyl mercaptan, diallyl disulfide, methyl mercaptan, and allyl methyl sulfide (Laakso and others 1989; Minami and others 1989; Suarez and others 1999; Tamaki and Sonoki 1999; Tamaki and others 2008). The first three volatiles are found at a high concentration in the breath immediately after ingestion whereas allyl methyl sulfide was found to be a predominant 
compound in the breath 3 hours after ingestion (Taucher and others 1996; Suarez and others 1999).

A variety of fruits, vegetables, mushrooms, and beverages have been shown to effectively remove the odor of allyl mercaptan, methyl mercaptan, and diallyl disulfide in vitro. It was reported that prune, basil, burdock, eggplant, and the mushrooms Agaricus biporus, Boletus subvelutipes, Gyrodon lividus, Hypholoma sublaterium, Russula nigricans, and Suillus grevillei could reduce the level of allyl mercaptan and methyl mercaptan by 100\% (Negishi and Negishi 1999; Negishi and others 2002). However, these fruits, vegetables, and mushrooms had a lower deodorizing activity against diallyl disulfide, which is one of the major odor components of garlic breath, compared to milk. Milk reduced the level of diallyl disulfide by $95 \%$ whereas fruits, vegetables, and mushrooms only decreased its level by 27-73\% (Negishi and others 2002). Besides diallyl disulfide, milk also showed a high deodorizing activity against many sulfide and disulfide volatiles, which are arisen from Allium plants, such as propyl mercaptan, dipropyl sulfide, diallyl sulfide, dipropyl disulfide, and dimethyl disulfide (Negishi and others 2002). Nevertheless, milk has not been tested for its capability to deodorize the malodorous odors in breath after garlic ingestion in vivo. Therefore, the objectives of this study were to investigate the effect of milk as well as the order of milk ingestion on the deodorization of malodorous odor in breath after ingestion of raw garlic and also identify 
which milk components are most important for the deodorization using selected ion flow tube mass spectrometry (SIFT-MS). 


\section{CHAPTER 2}

\section{LITERATURE REVIEW}

\subsection{Garlic}

Garlic, Allium sativum L., has been widely used as a seasoning in cooking around the world for thousands of years. Compared to other edible plants, garlic contains a high amount of sulfur compounds ( 1\% of its dry weight) (Lawson 1996). A group of sulfur compounds that are responsible for the characteristic flavor and biological properties of garlic are thiosulfinates (THS). These volatile sulfur compounds are produced from the non-volatile sulfur compounds called S-alkylcysteine sulfoxides. Garlic contains about 85\% (+)-S-2-propenyl-L-cysteine sulfoxide (alliin), 10\% (+)-S-methyl-L-cysteine sulfoxide (methiin), and 5\% (+)-S-(E)1-propenyl-L-cysteine sulfoxide (isoalliin) of the total S-alkylcysteine sulfoxides (Lawson 1996). Eight thiosulfinates can be generated from the three S-alkylcysteine sulfoxides by the action of alliinase enzyme (Figure 2.1). 
There are two types of alliinase enzyme in garlic: alliin-specific alliinase and methiin-specific alliinase. The optimal pHs for the alliin-specific and methiin- specific alliinase are 5 and 6.5-7, respectively. Under acidic condition $(\mathrm{pH}<3.5)$, the activity of both alliinase enzymes are inhibited. Moreover, the methiin-specific alliinase is more heat-labile and has a slower activity than the alliin-specific alliinase. Due to a high content of alliinase in garlic, the rate of thiosulfinate formation occurs very fast after garlic cloves are crushed (Lawson 1996).

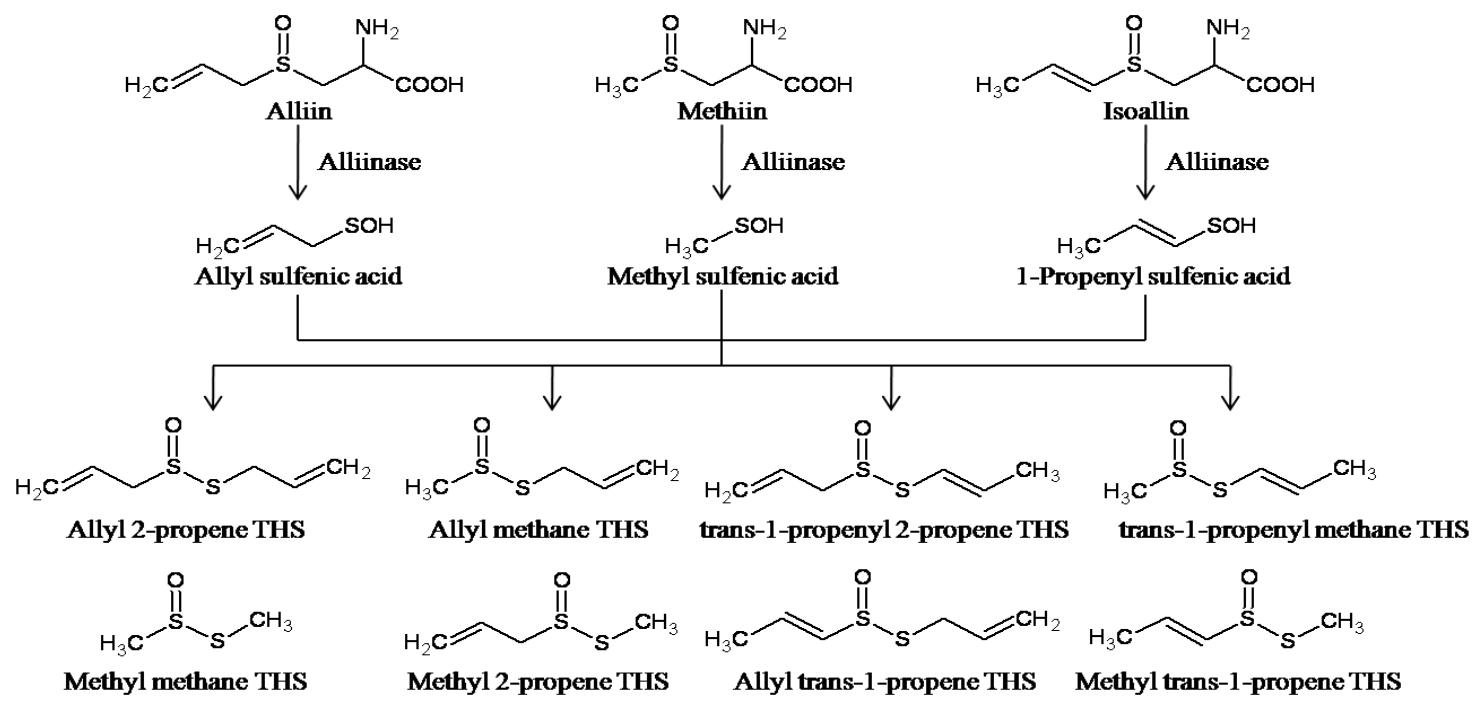

Figure 2.1 Formation of thiosulfinates from S-alkylcysteine sulfoxides by the action of alliinase enzyme (from Lawson 1996). 
Allicin is a major thiosulfinate (about $70 \%$ of total thiosulfinates) that imparts the garlic odor and antibacterial property in freshly cut garlic (Lawson 1996). It is also a precursor of other important garlic volatiles such as diallyl disulfide, diallyl trisulfide, and allyl methyl trisulfide. With the absence of allicin, the intact garlic has neither smell nor antibacterial activity (Cavallito and Bailey 1944). However, once the garlic is crushed, a C-S lyase enzyme (alliinase) is mixed with the alliin forming 2-propenesulfenic acid, pyruvate, and ammonia (Figure 2.2). The 2-propenesulfenic acids are self-condensed to form allicin (Figure 2.2).

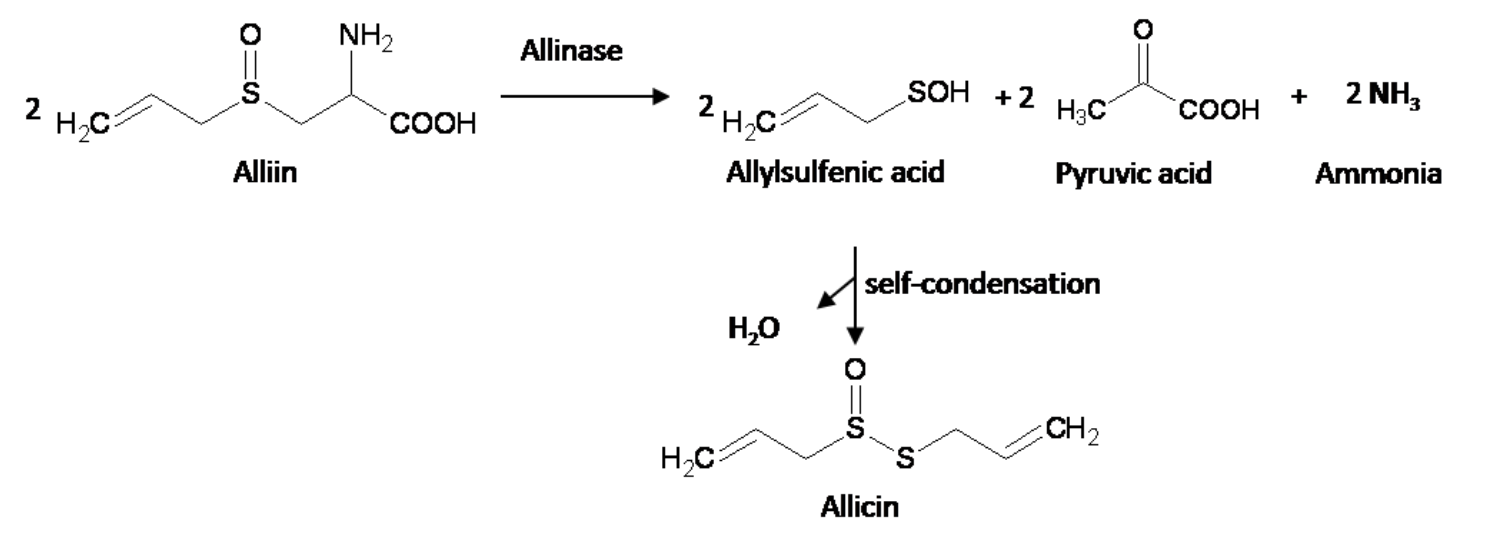

Figure 2.2 Formation of allicin after maceration of garlic (adapted from Rose and others 2005). 


\subsubsection{Identification of garlic volatiles}

The major volatiles found in garlic were diallyl disulfide (Wertheim in 1844; Semmler 1893; Vernin and others 1986; Laakso and others 1989; Yu and others 1989; Pino and others 1991; Mazza and others 1992; Kim and others 1995; Lee and others 2003), diallyl trisulfide (Semmler 1893; Vernin and others 1986; Laakso and others 1989; Yu and others 1989; Pino and others 1991; Kim and others 1995), and allyl methyl trisulfide (Vernin and others 1986; Yu and others 1989; Pino and others 1991; Kim and others 1995).

The minor components of garlic odor were diallyl sulfide (Vernin and others 1986; Yu and others 1989; Pino and others 1991; Kim and others 1995), allyl methyl sulfide (Vernin and others 1986; Laakso and others 1989; Yu and others 1989; Pino and others 1991; Kim and others 1995), allyl methyl disulfide (Vernin and others 1986; Laakso and others 1989; Yu and others 1989; Pino and others 1991; Kim and others 1995), dimethyl sulfide (Laakso and others 1989; Kim and others 1995), dimethyl disulfide (Laakso and others 1989; Yu and others 1989; Pino and others 1991), dimethyl trisulfide (Vernin and others 1986; Laakso and others 1989; Yu and others 1989; Pino and others 1991; Kim and others 1995), allyl mercaptan (or 2-propene-1-thiol) (Laakso and others 1989; Yu and others 1989; Kim and others 1995), allyl disulfide (Yu and 
others 1989), allyl tetrasulfide (Pino and others 1991), methyl propyl disulfide (Yu and others 1989), (E)-1-propenyl methyl disulfide (Yu and others 1989; Kim and others 1995), (Z)-1-propenyl methyl disulfide (Mazza and others 1992; Kim and others 1995), propyl allyl disulfide (Yu and others 1989; Kim and others 1995), propyl allyl trisulfide (Kim and others 1995), (Z)- 1-propenyl allyl disulfide (Pino and others 1991; Mazza and others 1992; Kim and others 1995), (E)- 1-propenyl allyl disulfide (Pino and others 1991; Mazza and others 1992; Kim and others 1995), 3- vinyl-4H-1,2-dithiin (or 3-vinyl-1,2dithi-5-ene) (Yu and others 1989; Pino and others 1991; Kim and others 1995), 2- vinyl4H-1,2-dithiin (Kim and others 1995), 2- vinyl-4H-1,3-dithiin (Yu and others 1989), 3vinyl-1,2-dithi-4-ene (Pino and others 1991), 1,2,3-trithi-4-ene (Pino and others 1991), 1,2-dithiocyclopent-3-ene (Pino and others 1991; Kim and others 1995), acetaldehyde (Laakso and others 1989), 2-methylbenzaldehyde (Yu and others 1989), 3-methyl thiopropanal (Kim and others 1995), allyl thiopropanal (Kim and others 1995), 2propanone (Laakso and others 1989), ethanol (Laakso and others 1989), 2-propen-1-ol (Laakso and others 1989; Yu and others 1989; Kim and others 1995), 1-hexanol (Yu and others 1989), acetic acid (Laakso and others 1989), propene (Yu and others 1989), 1,2epithiopropane (Yu and others 1989), 2,4-dimethylfuran (Yu and others 1989), tetrahydro-2,5-dimethylthiophene (Yu and others 1989), 3-methyl-2-cyclopentene-1thione ( $\mathrm{Yu}$ and others 1989), 1,3-dithiane (Yu and others 1989), aniline (Yu and others 1989), 1,2-dimercaptocyclopentane (Yu and others 1989), 4-methyl-5-vinylthiazole (Yu 
and others 1989), 3,5-diethyl-1,2,4-trithiolane (Yu and others 1989), and isobutyl isothiocyanate (Yu and others 1989).

The volatiles composition of oil obtained from garlic grown in Mexico, France, Egypt, Turkey, and China was investigated by Vernin and others in 1986 using gas chromatography with flame ionization detection (GC-FID) and gas chromatography with flame photometric detection (GC-FPD). The amounts of volatile compounds in garlic varied from country to country, but the main volatile compounds were similar. GC-FID analysis revealed that diallyl disulfide and diallyl trisulfide were the two major volatiles in garlic obtained from Mexico, France, Egypt, Turkey, and China, representing approximately $60-90 \%$ of the total composition. The range in composition of diallyl disulfide, diallyl trisulfide, allyl methyl trisulfide, allyl methyl disulfide, dimethyl trisulfide, diallyl sulfide, and allyl methyl sulfide in garlic grown in these countries were $30-50 \%, 30-42 \%, 4-14 \%, 0.6-7 \%, 0.3-4 \%, 1.6-10 \%$, and $0.4-2 \%$, respectively.

However, GC-FPD analysis showed that diallyl disulfide and diallyl trisulfide were the main components of garlic oil from France, Egypt, Turkey, and China, but allyl methyl trisulfide and diallyl disulfide were the two most abundant volatiles in garlic from Mexico. The compositional range of diallyl disulfide, diallyl trisulfide, allyl methyl trisulfide, allyl methyl disulfide, dimethyl trisulfide, diallyl sulfide, and allyl methyl 
sulfide in garlic cultivated in these countries were $20-48 \%, 6-42 \%, 2-61 \%$, traces- $6 \%$, traces- $10 \%$, traces- $7 \%$, and traces- $0.4 \%$, respectively.

The volatile constituents of young and mature garlic cultivated in Mediterranean were compared by Mazza and others (1992) using GC-FID and GC-MS. Young garlic had a higher amount of diallyl disulfide, diallyl trisulfide, allyl methyl disulfide, and allyl methyl trisulfide than mature garlic.

The volatile compositions of garlic prepared by water distillation, steam distillation, and Likens-Nicker (L-N) distillation/solvent extraction with or without steam were compared by Yu and others (1989) using GC-MS. The main volatiles in garlic oil made by water distillation, steam distillation, and Likens-Nicker (L-N) distillation/solvent extraction were diallyl trisulfide, diallyl disulfide, and allyl methyl trisulfide. They also found that garlic oil prepared by water or steam distillation had lower amounts of 2,4-dimethylfuran, 2-propen-1-ol, aniline, and 3,5-diethyl-1,2,4trithiolane than the water layer of garlic distillate and garlic oil produced by LikensNicker (L-N) distillation/solvent extraction because these compounds were more soluble in water. Moreover, the quantity of the total volatiles in water layer of garlic distillate was less than those in garlic oil obtained by water distillation, steam distillation, and Likens-Nicker (L-N) distillation/solvent extraction. 
The volatile components of garlic under different temperature were examined by Brodnitz and others (1971). They found that allyl 2-propene thiosulfinate (or allicin), a major volatile compound in garlic extract, was decomposed to diallyl disulfide (66\%), diallyl sulfide (14\%) and diallyl trisulfide (9\%) by rearrangement reactions at room temperature and to 3-vinyl-1,2-dithi-4-ene (55.4\%) and 3-vinyl-1,2-dithi-5-ene (23.5\%) under gas chromatography condition.

The aroma descriptions of 15 identified volatile compounds in garlic and odor thresholds of (z)-1-propenyl 2-propenyl disulfide, (E)-1-propenyl 2-propenyl disulfide, 1,2,3-trithi-4-ene, and allyl tetrasulide were determined by Pino and others (1991). High resolution gas chromatography (HRGC), GC-MS, and eluate sniffing method were used in analysis of garlic volatiles. A summary of aroma descriptions and odor thresholds of garlic volatiles identified in this study was given in Table 2.1. Moreover, the flavor dilution (FD) factor (aroma value) of garlic volatiles showed that diallyl trisulfide, diallyl disulfide, and allyl methyl trisulfide were "the most potent flavor compounds" in garlic oil. 
Table 2.1 Aroma descriptions and odor thresholds of garlic volatiles (Adapted from Pino and others 1991)

\begin{tabular}{|c|c|c|}
\hline Volatile compounds & Aroma description & $\begin{array}{c}\text { Odor threshold in air } \\
\text { (ppb) }\end{array}$ \\
\hline Allyl methyl sulfide & Garlic, savory & - \\
\hline Dimethyl disulfide & Vegetable, cabbage & - \\
\hline Diallyl sulfide & Pungent, garlic & - \\
\hline Allyl methyl disulfide & Garlic, savory & - \\
\hline 1,2-dithiocyclopentene & Fried garlic & - \\
\hline Dimethyl trisulfide & Onion & - \\
\hline Diallyl disulfide & Pungent, garlic & - \\
\hline (z)-1-propenyl 2-propenyl disulfide ${ }^{\mathrm{a}}$ & Boiled onion & 0.003 \\
\hline (E)-1-propenyl 2-propenyl disulfide ${ }^{\mathrm{a}}$ & Boiled onion & 0.008 \\
\hline Allyl methyl trisulfide & Garlic, savory & - \\
\hline 3-vinyl-1,2-dithi-5-ene & Fried garlic & - \\
\hline 1,2,3- trithi-4-enea & H2S-like & 0.003 \\
\hline 3-vinyl-1,2-dithi-4-ene & Fried garlic & - \\
\hline Diallyl trisulfide & Pungent, garlic & - \\
\hline Allyl tetrasulfide ${ }^{a}$ & Garlic, savory & 0.001 \\
\hline
\end{tabular}

${ }^{a}$ new garlic volatiles 
The volatile components of garlic with or without soybean oil were investigated by Laakso and others (1989) and Kim and others (1995). Laakso and others (1989) found that acetaldehyde, dimethyl sulfide, 2-propanone, 2-propene-1-thiol, ethanol, allyl methyl sulfide, dimethyl disulfide, 2-propen-1-ol, allyl methyl disulfide, acetic acid, diallyl disulfide were present in both samples with varying percentage composition. However, diallyl sulfide, dimethyl trisulfide, allyl methyl trisulfide, and diallyl trisulfide were only found in the garlic sample. The main headspace volatiles of garlic in soybean oil were ethanol (26.6\%), 2-propene-1-thiol (13\%), diallyl disulfide (12.4), and acetaldehyde (10.8\%). This result was different from that reported by Kim and others (1995). They reported that the major component of garlic in soybean oil were 2-vinyl-4H-1,2-dithiin and 3-vinyl-4H-1,2-dithiin. Also, Kim and others (1995) noticed that increasing the amount of soybean oil decreased the total volatiles and increased the levels of 1,2-dithiin and 3-vinyl-4H-1,2-dithiin. 


\subsection{Garlic breath}

Garlic has many health benefits to humans. It prevents heart disease and reduces risk of cancer (Block and others 1992; Yeh and Liu 2001). However, the consumption of garlic causes bad breath and body odor which can last from several hours to days (Haggard and Greenberg 1935). Therefore, there have been studies on identifying the compounds in breath after garlic ingestion (Laakso and others 1989; Minami and others 1989; Taucher and others 1996; Suarez and others 1999; Tamaki and Sonoki 1999; Tamaki and others 2008) and also how to deodorize these volatile compounds by foods and beverages (Ui and others 1991; Depree and Savage 1998; Negishi and Negishi 1999; Negishi and others 2002; Negishi and others 2004; Shimizu K and others 2004; Tamaki and others 2007; Lodhia and others 2008).

\subsubsection{Identification of volatiles in garlic breath}

The major volatiles found in breath immediately after ingestion of raw garlic were allyl mercaptan (Laakso and others 1989; Minami and others 1989; Suarez and others 1999; Tamaki and Sonoki 1999; Tamaki and others 2008), diallyl disulfide (Laakso and others 1989; Minami and others 1989; Tamaki and Sonoki 1999; Tamaki and others 2008), and methyl mercaptan (Suarez and others 1999; Tamaki and Sonoki 1999; Tamaki 
and others 2008). In addition, allyl mercaptan and methyl mercaptan were also the major components of garlic breath after ingesting heat-treated garlic (Tamaki and Sonoki 1999; Tamaki and others 2008) or rinsing the mouth with a garlic solution (Tamaki and others 2007). After 3 hours of ingestion, allyl methyl sulfide was found to be a predominant compound (Taucher and others 1996; Suarez and others 1999).

The minor components of breath after eating raw garlic were diallyl sulfide (Taucher and others 1996), diallyl trisulfide (Taucher and others 1996), allyl methyl disulfide (Taucher and others 1996; Tamaki and Sonoki 1999; Tamaki and others 2008), dimethyl sulfide (Taucher and others 1996), hydrogen sulfide (Suarez and others 1999), and 3-(allylthio) propionic acid (Tamaki and Sonoki 1999; Tamaki and others 2008).

\subsubsection{Deodorization of volatile sulfur compounds in garlic breath}

\subsubsection{Allyl mercaptan}

Allyl mercaptan was the main volatile sulfur compound found in breath immediately after ingesting raw (Laakso and others 1989; Minami and others 1989; Suarez and others 1999; Tamaki and Sonoki 1999; Tamaki and others 2008) or heattreated garlic (Tamaki and Sonoki 1999) and rinsing the mouth with a garlic solution 
(Tamaki and others 2007). It originates from the garlic particles that are trapped in the mouth and could be metabolized by liver and gut tissues of rat (Suarez and others 1999). After ingestion, allyl mercaptan reached its maximum concentration quickly, (Suarez and others 1999), decreased significantly over the first hour of the ingestion (Minami and others 1989), and became negligible in two hours (Suarez and others 1999).

Allyl mercaptan could be eliminated by a variety of fruits and vegetables (Negishi and others 2002), mushrooms (Depree and Savage 1998; Negishi and others 2002; Tamaki and others 2007), and teas (Negishi and others 2004). Negishi and others (2002) investigated the effect of various fruits and vegetables as well as polyphenols and polyphenoloxidase on elimination of allyl mercaptan. The study was conducted by using a detector tube to measure the remaining concentration of allyl mercaptan in the headspace of a mixture of allyl mercaptan and crushed food or allyl mercaptan, polyphenolic compounds and acetone powders of fruits and vegetables containing polyphenoloxidase. It was reported that prune, burdock, basil, eggplant, mushroom Agaricus biporus, Boletus subvelutipes, Gyrodon lividus, Hypholoma sublaterium, Russula nigricans, and Suillus grevillei could reduce the level of allyl mercaptan by 100\% (Table 2.2). Apple, blueberry, kiwi fruit, milk, and mushroom Lentinus edodes could reduce the level of allyl mercaptan by less than $50 \%$ (Table 2.2). And cooked rice could reduce the level of allyl mercaptan by $5 \%$ (Table 2.2). 
Table 2.2 Deodorizing effect of foods and beverages on volatile sulfur compounds in the in vitro test (adapted from Negishi and Negishi 1999; Negishi and others 2002; Negishi and others 2004)

\begin{tabular}{|c|c|c|c|c|}
\hline \multirow[b]{2}{*}{ Foods \& Beverages } & \multicolumn{4}{|c|}{ \% Deodorization } \\
\hline & $\begin{array}{c}\text { Methyl } \\
\text { mercaptan }\end{array}$ & $\begin{array}{c}\text { Allyl } \\
\text { mercaptan }\end{array}$ & $\begin{array}{c}\text { Diallyl } \\
\text { disulfide }\end{array}$ & $\begin{array}{l}\text { Diallyl } \\
\text { sulfide }\end{array}$ \\
\hline Apple & $45-100$ & 35 & 14 & 3 \\
\hline Plums & 100 & - & - & - \\
\hline Prune & 100 & 100 & 38 & 8 \\
\hline Apricot & 100 & - & - & - \\
\hline Loquat & 100 & - & - & - \\
\hline Lettuce & 100 & - & 70 & 21 \\
\hline Endive & 100 & - & - & - \\
\hline Chicory & 100 & - & - & - \\
\hline Celery (leaf) & 100 & - & - & - \\
\hline Udo & 100 & - & - & - \\
\hline Perilla & 100 & - & - & - \\
\hline Peppermint & 100 & - & - & - \\
\hline Basil & 100 & 100 & 73 & 24 \\
\hline Burdock & 100 & 100 & 33 & 27 \\
\hline Eggplant & 100 & 100 & 27 & 10 \\
\hline Cherry & 95 & - & - & - \\
\hline Peach & 93 & - & - & - \\
\hline Grape & $73-88$ & - & - & - \\
\hline Potato & 88 & - & - & - \\
\hline Blueberry & $37-76$ & 41 & 57 & 21 \\
\hline Okra & 76 & - & - & - \\
\hline Avocado & 51 & - & - & - \\
\hline Banana & 49 & - & 58 & 11 \\
\hline Red cabbage & 42 & - & - & - \\
\hline Carrot & 39 & - & - & - \\
\hline
\end{tabular}


Table 2.2 continued

\begin{tabular}{|c|c|c|c|c|}
\hline \multirow[b]{2}{*}{ Foods \& Beverages } & \multicolumn{4}{|c|}{ \% Deodorization } \\
\hline & $\begin{array}{c}\text { Methyl } \\
\text { mercaptan }\end{array}$ & $\begin{array}{c}\text { Allyl } \\
\text { mercaptan } \\
\end{array}$ & $\begin{array}{c}\text { Diallyl } \\
\text { disulfide }\end{array}$ & $\begin{array}{l}\text { Diallyl } \\
\text { sulfide } \\
\end{array}$ \\
\hline Parsley & 34 & - & 70 & 33 \\
\hline Cucumber & 34 & - & - & - \\
\hline Ginger & 29 & - & - & - \\
\hline Lemon & 27 & - & - & - \\
\hline Horseradish & 27 & - & - & - \\
\hline Melon & 27 & - & - & - \\
\hline Grapefruit & 24 & - & - & - \\
\hline Nectarine & 22 & - & - & - \\
\hline Wasabi & 17 & - & - & - \\
\hline Spinach & 15 & - & 70 & 6 \\
\hline Tomato & 15 & - & - & - \\
\hline Mandarine orange & 12 & - & - & - \\
\hline Bell pepper & 12 & - & - & - \\
\hline Radish & 7 & - & - & - \\
\hline Water melon & 7 & - & - & - \\
\hline Strawberry & 2 & - & - & - \\
\hline Pineapple & 0 & - & - & - \\
\hline Kiwi & $0-15$ & 35 & 85 & 18 \\
\hline Yam & 0 & - & 41 & 19 \\
\hline Cooked rice & 0 & 5 & 70 & 22 \\
\hline Persimmon & - & - & 12 & 0 \\
\hline Asparagus & - & - & 38 & 11 \\
\hline Cow's milk & - & 46 & 95 & 91 \\
\hline Egg & - & - & 84 & 88 \\
\hline Agaricus biporus & 100 & 100 & 58 & 5 \\
\hline Boletus subvelutipes & 100 & 100 & 63 & 18 \\
\hline Gyrodon lividus & 100 & 100 & 72 & 19 \\
\hline
\end{tabular}

Continued 
Table 2.2 continued

\begin{tabular}{|c|c|c|c|c|}
\hline & \multicolumn{4}{|c|}{ \% Deodorization } \\
\cline { 2 - 5 } Foods \& Beverages & $\begin{array}{c}\text { Methyl } \\
\text { mercaptan }\end{array}$ & $\begin{array}{c}\text { Allyl } \\
\text { mercaptan }\end{array}$ & $\begin{array}{c}\text { Diallyl } \\
\text { disulfide }\end{array}$ & $\begin{array}{c}\text { Diallyl } \\
\text { sulfide }\end{array}$ \\
\hline $\begin{array}{c}\text { Hypholoma } \\
\text { sublaterium }\end{array}$ & 100 & 100 & 59 & 21 \\
\hline Russula nigricans & 100 & 100 & 63 & 81 \\
\hline Suillus grevillei & 100 & 100 & 71 & 16 \\
\hline Lentinus edodes & 43 & 36 & 60 & 4 \\
\hline Flammulina velutipes & 27 & - & - & - \\
\hline Ku-ding-cha & 3 & 7 & - & - \\
\hline Green tea & 0 & 7 & - & - \\
\hline Black tea & 0 & 0 & - & - \\
\hline Oolong tea & 0 & 4 & - & - \\
\hline
\end{tabular}

In addition, a mixture of polyphenolic compounds and acetone powders of fruits and vegetables with a high deodorizing activity such as burdock could also reduce the level of allyl mercaptan effectively. Chlorogenic acid-burdock acetone powder, (-)epicatechin-pear acetone powder, variegatic acid- Boletus subvelutipes acetone powder, L-DOPA- Agaricus biporus acetone powder, and $\gamma$-L-glutaminyl-4-hydroxybezeneAgaricus biporus acetone powder could reduce the level of allyl mercaptan by $100 \%$ and tyrosine- Agaricus biporus acetone powder could reduce the level of allyl mercaptan by $61 \%$. Furthermore, they demonstrated that allylthiocaffeic acid was the product of the reaction between chlorogenic acid and allyl mercaptan with a presence of a burdock 
acetone powder by using HPLC and LC-MS analysis and proposed that the deodorization of allyl mercaptan by fruits and vegetables was achieved through polyphenoloxidase catalyzed addition reaction between polyphenolic compounds and allyl mercaptan (Figure 2.3).

The same mechanism of deodorization was also applied to teas (Figure 2.3; Negishi and others 2004). Negishi and others (2004) showed that ku-ding-cha tea, green tea, black tea, and oolong tea by themselves had a very low capability of deodorizing allyl mercaptan (<10\% reduction) (Table 2.2). However, when combining ku-ding-cha tea with apple acetone powder, it could reduce the level of allyl mercaptan by $100 \%$ whereas adding pear acetone powder to green tea, black tea, and oolong tea could reduce the level of allyl mercaptan by less than $45 \%$.

Similarly, 3,5-Dicaffeoylquinic acid (3,5-DiCQA) and 5-caffeoylquinic acid (5CQA) by themselves had no effect on allyl mercaptan, but when they were combined with apple acetone powder, their deodorizing activity increased. 5-CQA- apple acetone powder and 3,5-DiCQA-apple acetone powder could reduce the level of allyl mercaptan by $45 \%$ and $19 \%$, respectively.

Since ku-ding-cha tea is rich in caffeoyl quinic acid derivatives, they proposed that the deodorization of allyl mercaptan by ku-ding-cha tea was done through the 
polyphenoloxidase catalyzed addition reaction between the caffeoyl quinic acid derivatives and allyl mercaptan (Figure 2.3). Moreover, they observed that Camellia sinesis teas (e.g. green tea, black tea, and oolong tea), which are rich in catechins, had a lower deodorizing activity against allyl marcaptan than ku-ding-cha tea. And among these teas, oolong tea had the highest deodorizing activity because it had a relatively low amount of ascorbic acid.
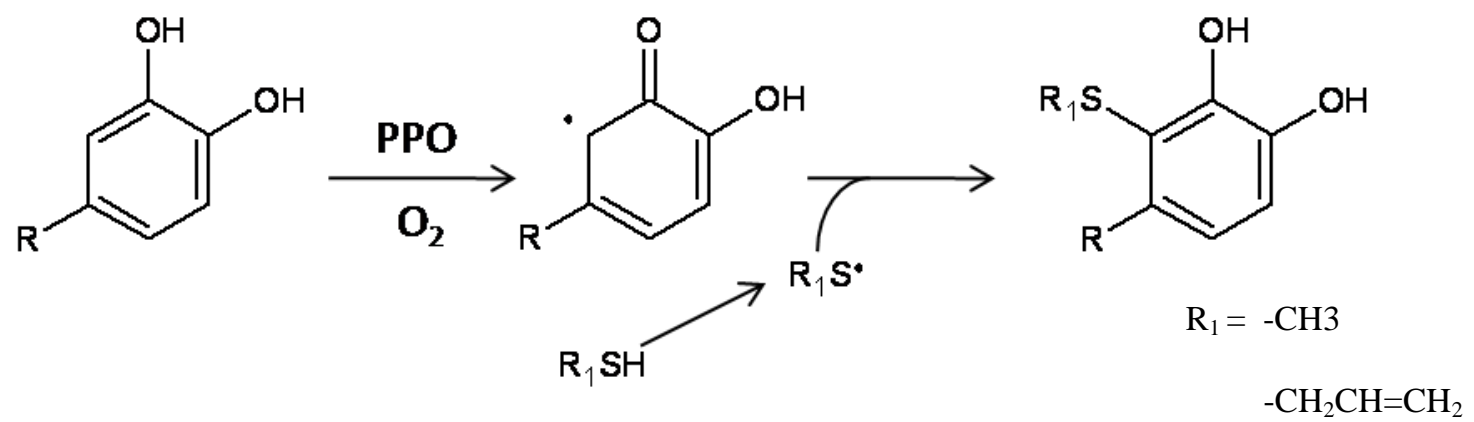

Figure 2.3 Proposed mechanism of enzymatic deodorization by fruits, vegetables, and mushrooms (from Negishi and others 2002) 
Tamaki and others (2007) demonstrated that the deodorization of allyl mercaptan by mushroom extract was not caused by the aqueous component (water) of the extract, but the polyphenols in the mushroom. Also, polar (water) and nonpolar (benzene) solvents had a little effect on elimination of allyl mercaptan. As shown in this study, the concentration of allyl mercaptan above the mushroom extract decreased rapidly over time and at 30 minutes after mixing, the concentration of allyl mercaptan declined to $0 \mathrm{ppm}$ whereas those above water and benzene were still greater than $1.3 \mathrm{ppm}$.

The effect of mushroom Agaricus bisporus at different growing stage on allyl mercaptan was investigated (Depree and Savage 1998). By using GC to measure the level of allyl mercaptan in the headspace of allyl mercaptan in a mushroom suspension, Depree and Savage (1998) found that mushroom Agaricus bisporus in the first flush had the highest deodorizing activity against allyl mercaptan.

Moreover, the deodorization of allyl mercaptan in breath after garlic ingestion was investigated by Suarez and others (1999) and Tamaki and others (2007). Suarez and others (1999) reported that brushing teeth immediately after garlic ingestion could reduce the level of allyl mercaptan in mouth by greater than $90 \%$. Also, rinsing mouth with mushroom Agaricus bisporus extract could reduce significantly the level of allyl mercaptan in mouth after garlic solution rinse (Tamaki and others 2007). 


\subsubsection{Diallyl disulfide}

Diallyl disulfide was the second (Laakso and others 1989; Minami and others 1989) or third (Tamaki and Sonoki 1999; Tamaki and others 2008) most abundant volatile sulfur compound found in breath immediately after ingestion of raw garlic. It was absent in the breath if the heat-treated garlic was consumed (Tamaki and Sonoki 1999). Diallyl disulfide originated from the garlic particles that are trapped in the mouth (Suarez and others 1999). After ingestion, diallyl disulfide rose to its maximum concentration rapidly (Taucher and others 1996; Suarez and others 1999), decreased significantly over the first hour of the ingestion (Minami and others 1989), and became negligible in two hours (Taucher and others 1996; Suarez and others 1999).

The effect of fruits and vegetables on removal of diallyl disulfide was investigated by Negishi and others (2002). The study was conducted by using GC to measure the remaining concentration of diallyl disulfide in the headspace of a mixture of diallyl disulfide and crushed foods. It was found that cow's milk, egg, and kiwi could reduce the level of diallyl disulfide by greater than $80-95 \%$ (Table 2.2). Spinach, lettuce, parsley, basil, mushroom Gyrodon lividus, and mushroom Suillus grevillei could reduce the level of diallyl disulfide by $\sim 70 \%$ (Table 2.2). Banana, blueberry, mushroom Agaricus bisporus, Boletus subvelutipes, Hypholoma sublaterium, Lentinus edodes, and Russula 
nigricans could reduce the level of allyl mercaptan by $~ 60 \%$ (Table 2.2). And apple, prune, persimmon, burdock, eggplant, asparagus, and yam could reduce the level of allyl mercaptan by less than $45 \%$ (Table 2.2).

Also, they noticed that fruits and vegetables with a high deodorization effect on allyl mercaptan such as prune, burdock, and eggplant had a low deodorization effect on diallyl disulfide. Therefore, they hypothesized that a physical and chemical interaction between diallyl disulfide and the chemical components of foods such as chlorophylls, proteins, or lipids might be responsible for the deodorization of diallyl disulfide by fruits, vegetables, and milk.

\subsubsection{Methyl mercaptan}

Methyl mercaptan was the second most abundant volatile sulfur compound found in breath after ingestion of raw (Suarez and others 1999; Tamaki and Sonoki 1999; Tamaki and others 2008) or heat-treated garlic (Tamaki and Sonoki 1999; Tamaki and others 2008) and rinsing the mouth with a garlic solution (Tamaki and others 2007). It was also one of the main components of pathological oral malodor (Ui and others 1991; Tamaki and Sonoki 1999) and present in the breath before garlic ingestion (Suarez and others 1999; Tamaki and Sonoki 1999; Tamaki and others 2007; Tamaki and others 2008). Methyl mercaptan could be originated from the garlic particles that are trapped in 
the mouth (Suarez and others 1999) or metabolic activity of oral bacteria (Tonzetich 1977) and could be rapidly metabolized by liver and gut tissues of rat (Suarez and others 1999). After ingestion, methyl mercaptan reached its maximum concentration in 5 minutes, decreased significantly over the first hour of the ingestion, and became negligible in 3 hours (Suarez and others 1999).

There have been many studies on how to eliminate methyl mercaptan both in vitro and in vivo by using fruits, vegetables, mushrooms, and beverages (Ui and others 1991; Negishi and Negishi 1999 Suarez and others 1999; Negishi and others 2002; Negishi and others 2004; Tamaki and others 2007; Lodhia and others 2008).

Negishi and Negishi (1999) and Negishi and others (2002) investigated the effect of various fruits and vegetables on the elimination of methyl mercaptan. The studies were conducted by using a detector tube to measure the remaining concentration of methyl mercaptan in the headspace of a mixture of methyl mercaptan and crushed foods. It was reported that plums, prune, apricot, loquat, lettuce, endive, chicory, celery (leaf), udo, perilla, peppermint, burdock, basil, eggplant, mushroom Agaricus biporus, Boletus subvelutipes, Gyrodon lividus, Hypholoma sublaterium, Russula nigricans, and Suillus grevillei could reduce the level of methyl mercaptan by 100\% (Table 2.2; Negishi and Negishi 1999; Negishi and others 2002). Peach, cherry, grape, blueberry, potato, and okra could reduce the level of methyl mercaptan by 75-95\% (Table 2.2; Negishi and Negishi 
1999). Banana, avocado, red cabbage, carrot, apple, blueberry, and mushroom Lentinus edodes could reduce the level of methyl mercaptan by 35-50\% (Table 2.2; Negishi and Negishi 1999; Negishi and others 2002). Nectarine, mandarine orange, lemon, grapefruit, spinach, parsley, ginger, horseradish, wasabi, tomato, bell pepper, cucumber, melon, and kiwi could reduce the level of methyl mercaptan by 10-35\% (Table 2.2; Negishi and Negishi 1999; Negishi and others 2002). And raddish, water melon, and strawberry could reduce the level of methyl mercaptan by <10\% (Table 2.2; Negishi and Negishi 1999). However, cooked rice, milk, pineapple, kiwi, and yam had no effect on methyl mercaptan (Table 2.2; Negishi and Negishi 1999; Negishi and others 2002).

Moreover, a mixture of polyphenolic compounds and acetone powders of fruits and vegetables with a high deodorizing activity such as burdock could also reduce the level of methyl mercaptan effectively (Negishi and others 2002). Chlorogenic acidburdock acetone powder, (-)- epicatechin-pear acetone powder, variegatic acid-Boletus subvelutipes acetone powder, and $\gamma$-L-glutaminyl-4-hydroxybezene- Agaricus biporus acetone powder could reduce the level of methyl mercaptan by $100 \%$. L-DOPAAgaricus biporus acetone powder and tyrosine- Agaricus biporus acetone powder could reduce the level of methyl mercaptan by $89 \%$ and $61 \%$, respectively. Furthermore, Negishi and others (2002) demonstrated that methylthiocaffeic acid was the product of the reaction between chlorogenic acid and methyl mercaptan with a presence of a 
burdock acetone powder by using HPLC and LC-MS analysis and proposed that the deodorization of methyl mercaptan by fruits and vegetables was achieved through polyphenoloxidase catalyzed free radical addition reaction between polyphenolic compounds and methyl mercaptan (Figure 2.3). Also, Negishi and Negishi (1999) found that increasing the amount of fruits and vegetables as well as the reaction time could enhance the deodorization of methyl mercaptan by fruits and vegetables.

In addition, by comparing the concentration of methyl mercaptan in the headspace of methyl mercaptan in water, benzene or mushroom Agaricus biporus extract, Tamaki and others (2007) demonstrated that the deodorization of methyl mercaptan by mushroom extract was not caused by the aqueous component (water) of the extract, but the polyphenols in the mushroom. Also, polar (water) and nonpolar (benzene) solvents had a little effect on elimination of methyl mercaptan. As shown in this study, the concentration of methyl mercaptan above the mushroom extract decreased rapidly over time and at 30 minutes after mixing, the concentration of methyl mercaptan declined to $0 \mathrm{ppm}$ whereas those above water and benzene were still greater than $4 \mathrm{ppm}$.

Furthermore, the effect of teas on elimination of methyl mercaptan was investigated by Negishi and others (2004). They showed that ku-ding-cha tea, green tea, black tea, and oolong tea by themselves had no deodorizing activity against methyl mercaptan (Table 2.2). However, when combining ku-ding-cha tea (rich in caffeoyl 
quinic acid derivatives) with apple acetone powder, it could reduce the level of methyl mercaptan by $100 \%$ whereas adding pear acetone powder to green tea, black tea, and oolong tea (rich in catechins) could reduce the level of methyl mercaptan by $~ 30 \%$. Similarly, 3,5-Dicaffeoylquinic acid (3,5-DiCQA) and 5-caffeoylquinic acid (5-CQA) by themselves had no effect on methyl mercaptan, but when they were combined with apple acetone powder, their deodorizing activity increased. 5-CQA- apple acetone powder and 3,5-DiCQA-apple acetone powder could reduce the level of methyl mercaptan by $100 \%$ and $72 \%$, respectively. Also, they proposed that the deodorization of methyl mercaptan by ku-ding-cha tea was caused by the polyphenoloxidase catalyzed addition reaction between the caffeoyl quinic acid derivatives and methyl mercaptan (Figure 2.3).

In contrast to what was reported by Negishi and others (2004), Ui and others (1991) and Lodhia and others (2008) found that green tea and green tea catechins by themselves could reduce the level of methyl mercaptan. Ui and others (1991) also reported that green tea catechins had a stronger deodorizing activity than sodium copper chlorophyllin, a common oral deodorizer used in the market and among the four components of green tea catechins, (-)-epigallocatechin gallate had the highest deodorizing activity against methyl mercaptan. Moreover, green tea (Lodhia and others 2008) and green tea catechins (Ui and others 1991) could inhibit the production of methyl mercaptan from L-methionine in saliva. 
The deodorization of methyl mercaptan in breath after garlic ingestion (Negishi and Negishi 1999; Suarez and others 1999; Tamaki and others 2007) and breath of people with halitosis (Ui and others 1991; Lodhia and others 2008) was investigated. Suarez and others (1999) reported that brushing teeth immediately after garlic ingestion could reduce the level of methyl mercaptan in mouth by greater than $90 \%$. Also, rinsing mouth with mushroom Agaricus bisporus extract could significantly reduce the level of methyl mercaptan in mouth at 10 minutes after garlic solution rinse, but the odor of methyl mercaptan came back again after 30 minutes (Tamaki and others 2007). Moreover, the odor sensor showed that eating a fresh apple after ingestion of a soup containing garlic paste could slightly reduce the level of methyl mercaptan in breath, but eating microwave-heated apple had no effect (Negishi and Negishi 1999). Also, the sensory evaluation revealed that eating fresh apple, lyophilized unripe apple, lyophilized unripe pear, and lyophilized prune could significantly remove the malodorous odor in the breath (Negishi and Negishi 1999). Further, Negishi and Negishi (1999) hypothesized that the effect of apple on deodorization of malodorous odor did not last long because the amount of polyphenols in apple was depleted by the enzymatic browning reaction. Also, it was found that chewing gum containing tea catechins (Ui and others 1991) and green tea (Lodhia and others 2008) could significantly reduce the level of methyl mercaptan in the mouth immediately after eating, but the odor of methyl mercaptan came back again after an hour (Lodhia and others 2008). Toothpaste could slightly reduce the level of methyl 
mercaptan in the mouth, but chewing gum, mints, and parsley-seed oil could not (Lodhia and others 2008). Further, Toothpaste, mints, and green could inhibit the formation of methyl mercaptan in saliva, but chewing gum and parsley-oil could not (Lodhia and others 2008).

\subsubsection{Allyl methyl sulfide}

Allyl methyl sulfide is a volatile sulfur compound responsible for the persistent garlic odor in breath after ingestion of raw (Taucher and others 1996; Suarez and others 1999; Tamaki and Sonoki 1999) or heated-treated garlic (Tamaki and Sonoki 1999). It originates from gut and could not be metabolized by liver and gut tissues of rat (Suarez and others 1999). After ingestion, it was present in mouth, nose, and urine headspace at a similar level (Suarez and others 1999). Its concentration increased slowly after ingestion (Taucher and others 1996; Suarez and others 1999) and at 3 hours it became a predominant compound in the breath (Suarez and others 1999). Also, it took more than a day for allyl methyl sulfide to decline to its baseline level (Taucher and others 1996).

Allyl methyl sulfide was not detected in urine and was present at a low level in breath only for 30 minutes if garlic was chewed but not swallowed (Suarez and others 1999). Therefore, Suarez and others (1999) hypothesized that allyl methyl sulfide was absorbed from gut to the blood circulation and transported throughout the body (e.g. lung 
and urine). Moreover, its level of $100 \mathrm{ppb}$ was still perceptible by the human nose (Suarez and others 1999).

The deodorization of allyl methyl sulfide had not been studied until 2004 (Negishi and others 2004; Shimizu and others 2004; Tamaki and others 2007). Negishi and others (2004) investigated the effect of apple (cv. Ourin), ku-ding-cha tea, and green tea on deodorization of allyl methyl sulfide in breath after garlic ingestion using GC. They reported that eating apple after garlic ingestion could reduce the level of allyl methyl sulfide during the first hour of the ingestion, but its level increased again in the next 2-4 hours. On the other hand, the effect of ku-ding-cha tea became apparent at 3-5 hours after ingestion and it could reduce the level of allyl methyl sulfide by $10 \mathrm{ppb}$ as compared to the control in which water was drunk instead. However, green tea (Negishi and others 2004) and mushroom Agaricus bisporus (Tamaki and others 2007) had no effect on deodorization of allyl methyl sulfide.

From these results, Negishi and others (2004) proposed that polyphenols was responsible for the deodorization of allyl methyl sulfide in breath by apple and ku-dingka tea. Since ku-ding-ka tea had a higher content of polyphenols than apple, it attained a longer deodorizing effect. Also, the deodorization of allyl methyl sulfide by apple during the first hour after ingestion might be caused by enzymatic deodorization of allyl mercaptan, a precursor of allyl methyl sulfide. Moreover, they recommended that in order 
to obtain a higher deodorizing effect, eating apple should be combined with drinking chlorogenic acid rich drinks such as ku-dind-ka tea, mate, or coffee and they need to be consumed frequently.

Furthermore, Shimizu and others (2004) evaluated the effect of Rubus suavissimus, Rubus idaeus, Rubus fruticosus, Eucalyptus globules, Rosmarinus officinalis, Myrica rubra, and Camellia sinensis var. sinensison on deodorization of allyl methyl sulfide in breath after garlic ingestion using GC. They reported that among these plant extracts, Rubus suavissimus had the highest deodorizing effect on allyl methyl sulfide and polyphenols was responsible for its deodorizing activity because a positive correlation between the polyphenols content in Rubus suavissimus and its deodorizaing activity was observed. Moreover, they demonstrated that allyl methylsulfoxide was a product of the reaction between allyl methyl sulfide and Rubus suavissimus and its deodorizing activity disappeared under anaerobic condition. Therefore, they proposed that the deodorization of allyl methyl sulfide by Rubus suavissimus was caused by the oxidative reaction between polyphenols and allyl methyl sulfide. 


\subsubsection{Diallyl sulfide}

Diallyl sulfide is a minor volatile sulfur compound found in breath immediately after ingestion of raw garlic (Taucher and others 1996). It reached its maximum concentration quickly and became negligible in two hours after ingestion (Taucher and others 1996). The effect of fruits and vegetables on elimination of diallyl sulfide was investigated by Negishi and others (2002). The study was conducted by using GC to measure the remaining concentration of diallyl sulfide in the headspace of a mixture of diallyl sulfide and crushed foods. It was found that cow's milk, egg, and mushroom Russula nigricans could reduce the level of diallyl sulfide by $80-90 \%$ (Table 2.2). Kiwi, banana, blueberry, burdock, eggplant, lettuce, parsley, basil, asparagus, yam, cooked rice, mushrooms Boletus subvelutipes, Gyrodon lividus, Hypholoma sublaterium, and Suillus grevillei could reduce the level of diallyl sulfide by 10-35\% (Table 2.2). Apple, prune, spinach, and mushrooms Agaricus bisporus, and Lentinus edodes could reduce the level

of diallyl sulfide by $<10 \%$ (Table 2.2). Persimmon had no effect on diallyl sulfide (Table 2.2). Also, Negishi and others (2002) proposed that the deodorization of diallyl sulfide by fruits, vegetables, and milk might be caused by a physical and chemical interaction between diallyl sulfide and the chemical components of foods such as chlorophylls, proteins, or lipids. However, in the case of the mushroom Russula nigricans, the 
deodorization of diallyl sulfide might be caused by an enzymatic reaction because its deodorizing activity decreased when the mushroom was heated.

\subsection{SIFT-MS}

\subsubsection{How it works}

In the Voice 100 SIFT-MS, shown in Figure 2.4, reagent ions with a positive charge are created in a microwave discharge ion source by ionization of a saturated mixture of air and water at $\sim 0.3$ torr (Spanel and others 1996; Francis and others 2007). From these reagent ions, the precursor ions (e.g. $\mathrm{H}_{3} \mathrm{O}^{+}, \mathrm{NO}^{+}$, and $\mathrm{O}_{2}^{+}$) are selected based on their mass-to-charge ratio using a quadrupole mass filter located in the upstream chamber at $\sim 1$ X $10^{-5}$ Torr (Spanel and others 1996; Francis and others 2007). The precursor ions are then injected against the pressure gradient into the flow tube via a venturi orifice and carried along with inert carrier gas (e.g. helium and argon) at a known velocity (Spanel and others 1996; Spanel and Smith 1999; Francis and others 2007). The sample gas (e.g. breath or air in the headspace of the sample) is introduced into the flow tube through a heated capillary $\left(120^{\circ} \mathrm{C}\right)$ and reacts with the precursor ions generating product ions (Wilson and others 2006). The products ions travel along the flow tube and enter the downstream chamber via an electrostatic orifice (Francis and others 2007). 
Based on mass, the product ions of interest are selected by a second quadrupole mass spectrometer located in the downstream chamber (at $<1 \times 10^{-5}$ Torr) and detected on a continuous dynode particle multiplier (Francis and others 2007). By knowing the rate coefficients of the reaction between the precursor ions and volatile compounds of interest as well as the flow tube parameters (e.g. flow velocity of carrier gas and length of flow tube), the concentrations of volatiles in the headspace of the sample or exhaled air can be determined using the ratios of the product to precursor ions count rates in the downstream chamber (Spanel and Smith 1999; Wilson and others 2006). 


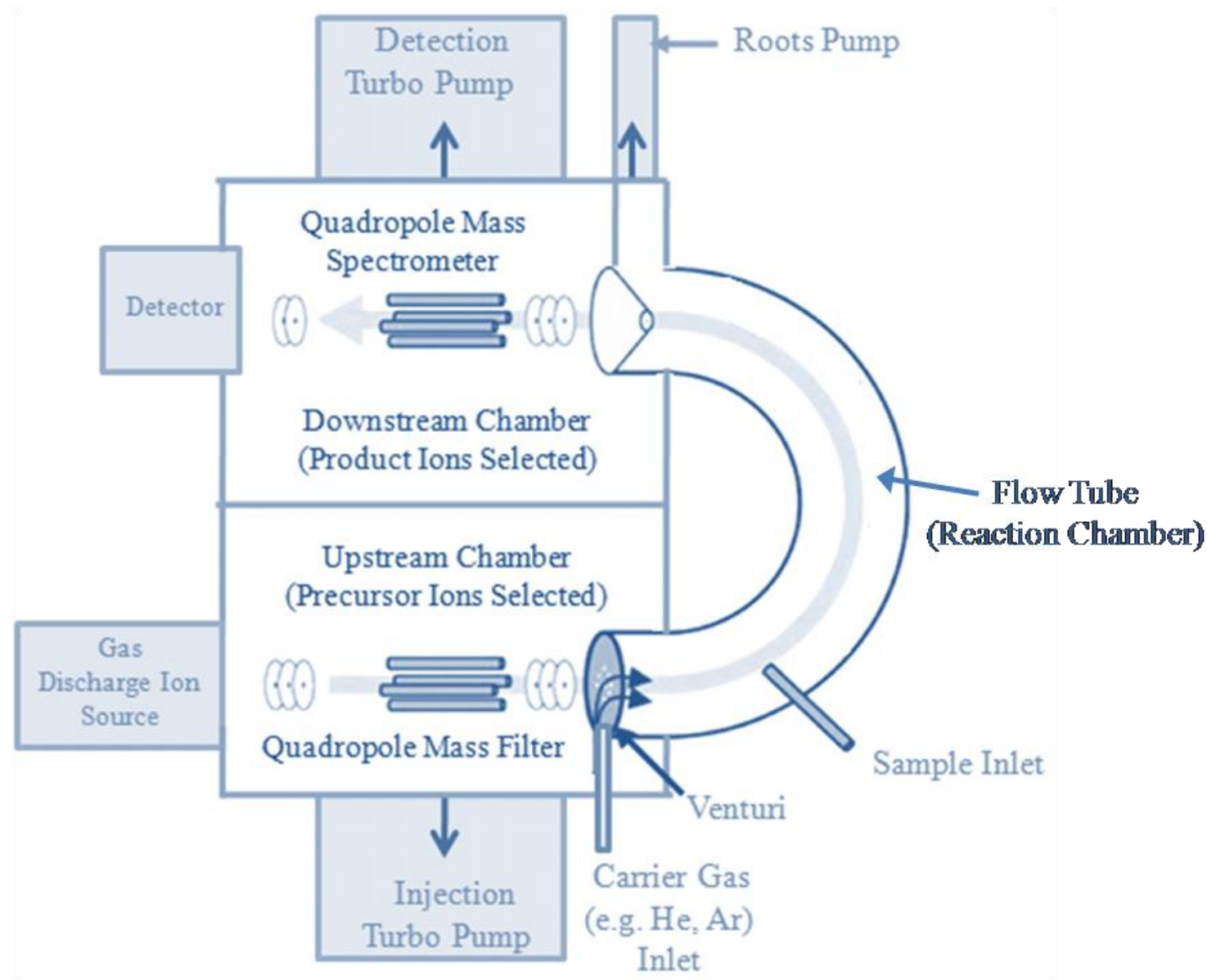

Figure 2.4 A schematic diagram of the Voice 100 SIFT-MS instrument (adapted from Francis and others 2007; Wilson and others 2006) 
There are 2 modes of operation in the SIFT detection mass spectrometer: full scan mode and selected ion monitoring mode (SIM). In the full scan mode, the mass spectrometer scans over a selected mass range in the downstream chamber to obtain the spectrum of the precursor and product ions (Spanel and Smith 1999). This mode is suitable for samples (e.g. static ambient air) in which the concentration of volatiles does not change with time (Spanel and Smith 1999). On the other hand, in the SIM scan mode, the mass spectrometer scans the chosen products by switching rapidly between the precursor and selected product ions allowing real time monitoring of the samples (e.g. breath and headspace of foods.) in which the concentration of the volatiles change over time (Spanel and Smith 1999).

In the SIFT-MS, $\mathrm{H}_{3} \mathrm{O}^{+}, \mathrm{NO}^{+}$, and $\mathrm{O}_{2}{ }^{+}$are used as precursor ions for the analysis of trace gas in the air and breath samples because they react with most volatile organic compounds and inorganic molecules at a faster rate than the major components of air and breath (e.g. $\mathrm{N}_{2}, \mathrm{O}_{2}, \mathrm{H}_{2} \mathrm{O}$, Ar, and $\mathrm{CO}_{2}$ ) (Spanel and others 1996; Spanel and Smith 1999). 


\section{CHAPTER 3}

\section{MATERIALS AND METHODS}

\subsection{Materials}

Garlic cloves, fat-free milk (Giant Eagle, $\mathrm{OH}$ ), whole milk (Giant Eagle, $\mathrm{OH}$ ), and pure canola oil (The Kroger Co., Cincinnati, $\mathrm{OH}$ ) were purchased from a local market. NZMP Sodium Caseinate was purchased from Chicago Sweeteners Distributors

of Fonterra Proteins, Des Plaines, IL. Lactose monohydrate NF 80M was purchased from Kerry, Hoffman Estates, IL. Tween80 was purchased from Sigma Chemical Co., St. Louis, MO.

\subsubsection{Analytical Instrument}

A selected ion mode (SIM) scan was made using a selected ion flow tube-mass spectrometry (SIFT-MS) (VOICE 100, Syft Technologies Ltd, Christchurch, New Zealand) instrument. Syft VOICE-100 software (v.1.4.9.17754, Syft Technologies Ltd, Christchurch, New Zealand) was used to analyze compounds of interest in the headspace 
of ground garlic as well as the breath after garlic ingestion using known kinetic parameters (Spanel and Smith 1996, 1998; Williams and others 1998). The SIM scan measured the following compounds: allyl methyl sulfide, diallyl disulfide, allyl methyl disulfide, allyl mercaptan, acetone, and methyl mercaptan (Table 3.1).

Table 3.1 Volatile sulfur compounds measured in the SIM scan

\begin{tabular}{|l|c|c|c|c|}
\hline \multicolumn{1}{|c|}{ Volatile compound } & Ion Product & Precursor Ion & $\boldsymbol{m} / \boldsymbol{z}$ & Branching ratio \\
\hline Allyl methyl sulfide & $\mathrm{C}_{4} \mathrm{H}_{8}{\mathrm{~S} . \mathrm{H}^{+}}^{+}$ & $\mathrm{H}_{3} \mathrm{O}^{+}$ & 89 & 100 \\
\hline Diallyl disulfide & $\left(\mathrm{C}_{3} \mathrm{H}_{5}\right)_{2} \mathrm{~S}_{2}^{+}$ & $\mathrm{NO}^{+}$ & 146 & 100 \\
\hline Allyl methyl disulfide & $\mathrm{C}_{4} \mathrm{H}_{8} \mathrm{~S}_{2}^{+}$ & $\mathrm{NO}^{+}$ & 120 & 100 \\
\hline Allyl mercaptan & $\mathrm{C}_{3} \mathrm{H}_{6} \mathrm{~S}^{+}$ & $\mathrm{NO}^{+}$ & 74 & 100 \\
\hline Acetone & $\mathrm{C}_{3} \mathrm{H}_{6} \mathrm{O} . \mathrm{NO}^{+}$ & $\mathrm{NO}^{+}$ & 88 & 100 \\
\hline Methyl mercaptan & $\mathrm{CH}_{4}{\mathrm{~S} . \mathrm{H}^{+}}$ & $\mathrm{H}_{3} \mathrm{O}^{+}$ & 49 & 100 \\
\hline
\end{tabular}


The flow tube was $25.8 \mathrm{~cm}$ long and $4.8 \mathrm{~cm}$ in diameter. Scan time was $95 \mathrm{sec}$. Product sample period and precursor sample period were 100 and $25 \mathrm{~ms}$, respectively. The upstream quadropole settle time and downstream quadropole settle time were 25 and $10 \mathrm{~ms}$, respectively. The electrometer polling points was 1 . The microwave power was set at $50 \mathrm{~W}$. Air was used as an ion source gas. The ion source and flow tube pressures were 0.4 and 0.040 torr, respectively. Helium and argon were used as a carrier gas and their flow rates were set at 15 and 25 torr L/s, respectively. The sample flow rate and capillary flow rate were set at 3.4 and 10 torr L/s, respectively. The inlet, flow tube, sample selection plate, and capillary temperatures were $120,33,100$, and $80^{\circ} \mathrm{C}$, respectively. Results are reported as ppb by volume. 


\subsection{Methods}

\subsubsection{In vitro test}

\subsubsection{Effect of food components and milk}

Emulsions of $0,1,3,5,10$, and $100 \%$ canola oil (v/v) were prepared with canola oil, distilled water, and $1 \mathrm{~mL}$ of emulsifier (Tween80, Sigma Chemical Co., St. Louis, MO) and stirred for 30 mins. Solutions of 1, 3, 5, and 10\% sodium casienate (w/v) were prepared with sodium caseinate (Chicago Sweeteners Distributors of Fonterra Proteins, Des Plaines, IL) and distilled water and stirred for $1 \mathrm{hr}$. Solutions of 1, 3, 5, and 10\% sugar $(\mathrm{w} / \mathrm{v})$ were prepared with lactose monohydrate NF 80M (Kerry, Hoffman Estates, IL) and distilled water and stirred for 20 mins. 3.2\% canola oil emulsion (w/w) was prepared with $1 \%$ emulsifier (Tween80, Sigma Chemical Co., St. Louis, MO) in canola oil and distilled water and stirred for 30 mins. A solution of 3.2\% sodium caseinate and $5.1 \%$ lactose (w/v) was prepared with sodium caseinate sodium caseinate, lactose monohydrate NF 80M, and distilled water and stirred for 15 mins. Distilled water was used as a control.

The garlic cloves were peeled and cut to $6.00 \pm 0.10 \mathrm{~g}$ a few minutes prior to use. Peeled garlic cloves were chopped in a $355 \mathrm{~mL}$ chopper (Black \& Decker HC306 One 
Touch Chopper, The Black \& Decker Corporation, Towson, Maryland) for $15 \mathrm{sec}$, transferred to a $500 \mathrm{~mL}$ pyrex bottle, and capped with PTDE faced silicone septa cap. The $6.00 \pm 0.10 \mathrm{~g}$ chopped garlic sample was either blanched in $99^{\circ} \mathrm{C}$ water bath for 10 min and cooled in ice for $5 \mathrm{~min}$ or equilibrated at room temperature for 15 minutes. The headspace volatiles of the blanched or unblanched chopped garlic in the $500 \mathrm{~mL}$ pyrex bottle before adding $100 \mathrm{~mL}$ treatments ( $22 \mathrm{~min}$ after chopping garlic) were measured via a 18 gauge passivated needle connected to the inlet of the SIFT-MS machine using a SIM scan. At 3 mins after adding the treatments, the headspace volatiles of the blanched or unblanched chopped garlic were measured. Three replicates were conducted.

Octanol-water partition coefficients of diallyl disulfide, allyl methyl disulfide, allyl methyl sulfide, allyl mercaptan, methyl mercaptan, water, emulsifier, and lactose were calculated from the XLogP3 method (NCBI 2009).

\subsubsection{In vivo test}

The garlic cloves were peeled and cut to a size of $3.00 \pm 0.20 \mathrm{~g}$ a few minutes prior to use. A breath sample before garlic ingestion was analyzed by the SIFT-MS and used as the background concentrations of the volatiles. The reported concentrations were obtained by subtracting the average concentrations from the background concentrations 
The subject ingested $3.00 \pm 0.20 \mathrm{~g}$ of chopped garlic in $200 \mathrm{~mL}$ of water, fat-free milk, whole milk, or $10 \%$ sodium caseinate. Alternately, the subject chewed $3.00 \pm 0.20 \mathrm{~g}$ of peeled garlic for $20 \mathrm{sec}$, swallowed, then drank $200 \mathrm{~mL}$ of fat-free milk, whole milk, or nothing (control) at $1 \mathrm{~min}$ after swallowing. During nose and mouth-space volatile measurements, the subject continuously inhaled $(3 \mathrm{sec})$ and exhaled $(7 \mathrm{sec})$ for $90 \mathrm{sec}$ into a $4 \mathrm{~cm}$ straw pierced in the middle with a 14 gauge passivated needle connected to the inlet of the SYFT-MS machine. Exhaled air from nose and mouth was measured alternately. A total of 8 exhalations, 4 from nose and 4 from mouth, were collected at each time point. New straws were used for every measurement. Measurements were taken at $3,6,9,12,15,30$, and 60 min after ingestion. The concentrations of each volatile obtained from exhalation via nose were averaged separately from those from the exhaled air from the mouth using SAS 9.1 software (SAS Institute Inc., Cary, NC). Each test was conducted on different days. Three replicates were performed for each of the in vivo tests except for the control (eight replicates) and the same subject (26 year old female) was used throughout the study. 


\subsubsection{Statistical Analysis}

For the in vitro test, analysis of covariance was performed on the compound concentration data using the Proc GLM procedure of SAS 9.1 software (SAS Institute Inc., Cary, NC). For the in vivo test, the averaged values were used in calculation of the ratios of mouthspace to nosespace concentration using analysis of variance. A p-value of 0.05 was used to determine statistical significance. 


\section{CHAPTER 4}

\section{RESULTS AND DISCUSSION}

\subsection{In vitro studies}

\subsubsection{Effect of food components on the deodorization of the volatiles in the headspace of chopped garlic}

In order to have a better understanding of the effect of milk on the deodorization

of malodorous breath after garlic ingestion, the effect of the milk components water, fat, casein, and lactose as well as the effect of fat-free and whole milk on the concentrations of diallyl disulfide, allyl methyl disulfide, allyl mercaptan, allyl methyl sulfide, and methyl mercaptan in the headspace of unblanched and blanched garlic were investigated. Diallyl disulfide, allyl methyl disulfide, allyl mercaptan, allyl methyl sulfide, and methyl mercaptan were chosen because they have been identified at high concentration in breath after consumption of garlic (Laakso and others 1989; Minami and others 1989; Suarez and others 1999; Tamaki and Sonoki 1999; Tamaki and others 2008). 
Blanching the garlic increased the headspace concentrations of diallyl disulfide, allyl methyl disulfide, allyl mercaptan, and allyl methyl sulfide by 326 to $3575 \%$ (Figure 4.1). Heating garlic causes transformation of thiosulfinates (allicin and allyl methyl thiosulfinate) to diallyl trisulfide, diallyl disulfide, and allyl methyl trisulfide; therefore increasing their levels (Lawson 1993). Since diallyl disulfide, allyl methyl disulfide, allyl mercaptan, and allyl methyl sulfide are also formed from the thiosulfinates by chemical reactions (Tamaki and Sonoki 1999), blanching garlic increased the concentrations of all of these volatiles. However, blanching decreased the concentration of methyl mercaptan by $98 \%$ (Figure 4.1). This result was opposite to what was reported by Tamaki and Sonoki (1999). They found that the concentration of methyl mercaptan in the headspace of heated grated garlic increased over time. 


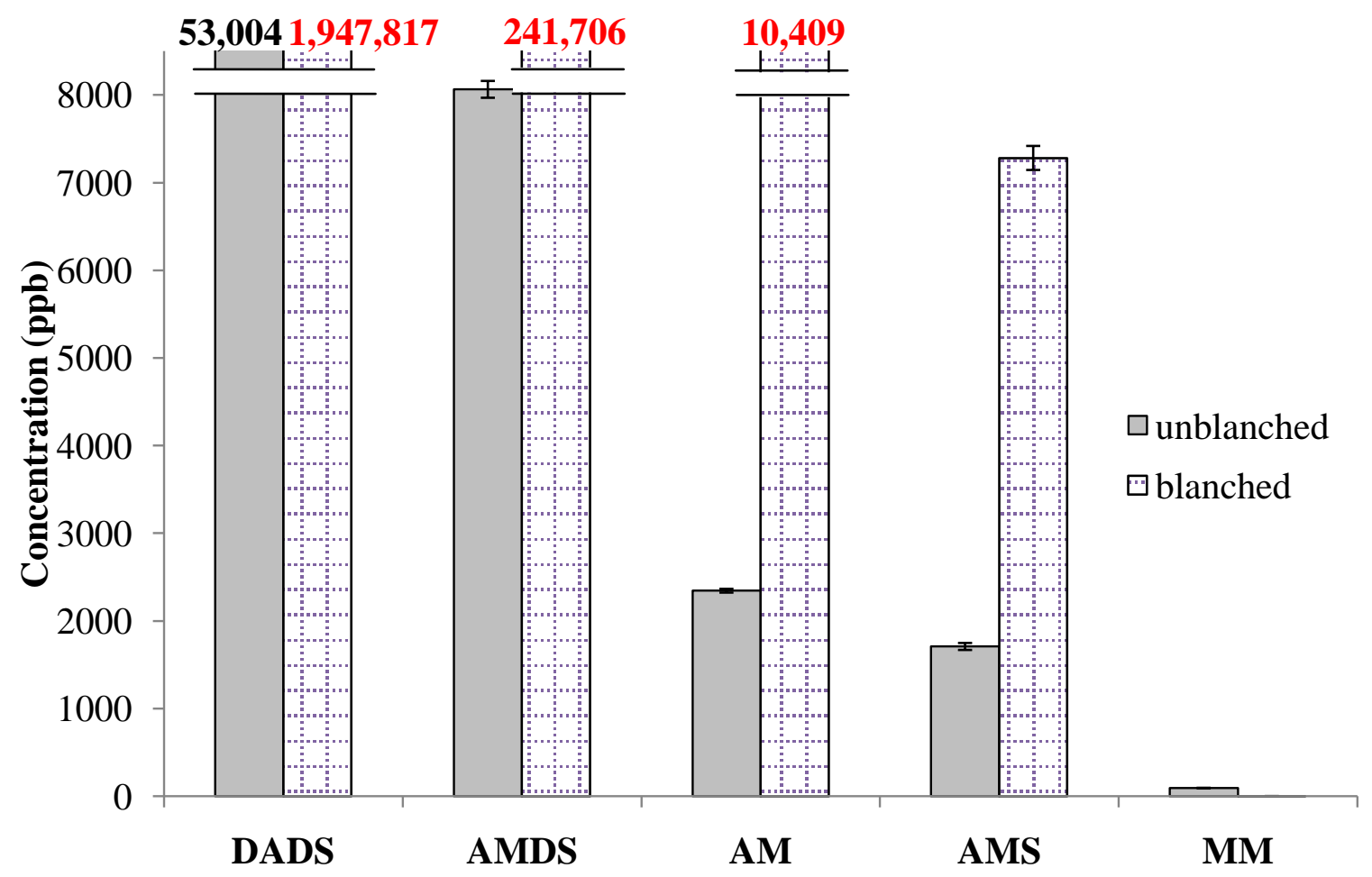

Figure 4.1 Effect of blanching on the concentrations of diallyl disulfide (DADS), allyl methyl disulfide (AMDS), allyl mercaptan (AM), allyl methyl sulfide (AMS), and methyl mercaptan (MM) in the headspace of chopped garlic 


\subsubsection{Effect of water and fat}

In this study, food components produced the same trends for blanched and unblanched garlic so only the unblanched results are presented. The blanched tests also showed that the enzymes in the garlic were not responsible for any of the interactions with the milk components causing deodorization. Water reduced the concentrations of all five volatiles in the headspace of chopped garlic by 61 to $99 \%$ (Figure 4.2). This occurs because of partitioning of volatiles between phases (Buttery and others 1973). Since the garlic volatiles in water are partitioning among garlic, water and gas phases, their headspace concentrations were lower than those of garlic, which the volatiles are only partitioning between garlic and gas phase.

Canola oil reduced the concentrations of diallyl disulfide and allyl methyl disulfide by $26 \%$ more than water (Figure 4.2). Allyl mercaptan, allyl methyl sulfide, and methyl mercaptan had slightly less reduction with oil than water. This result can be explained by the partition coefficient, $\log \mathrm{P}$. Since diallyl disulfide $(\log \mathrm{P}=2.2)$ and allyl

methyl disulfide $(\log \mathrm{P}=1.6)$ are hydrophobic, they dissolve better in oil $(\log \mathrm{P} \sim 6.1)$ than water $(\log \mathrm{P}=-0.5)$; and therefore their volatility in oil is lower than in water. On the other hand, allyl methyl sulfide $(\log \mathrm{P}=1.5)$, allyl mercaptan $(\log \mathrm{P}=1.2)$, and methyl 
mercaptan $(\log \mathrm{P}=0.5)$, are more hydrophilic and so had a higher headspace concentration in oil than in water.

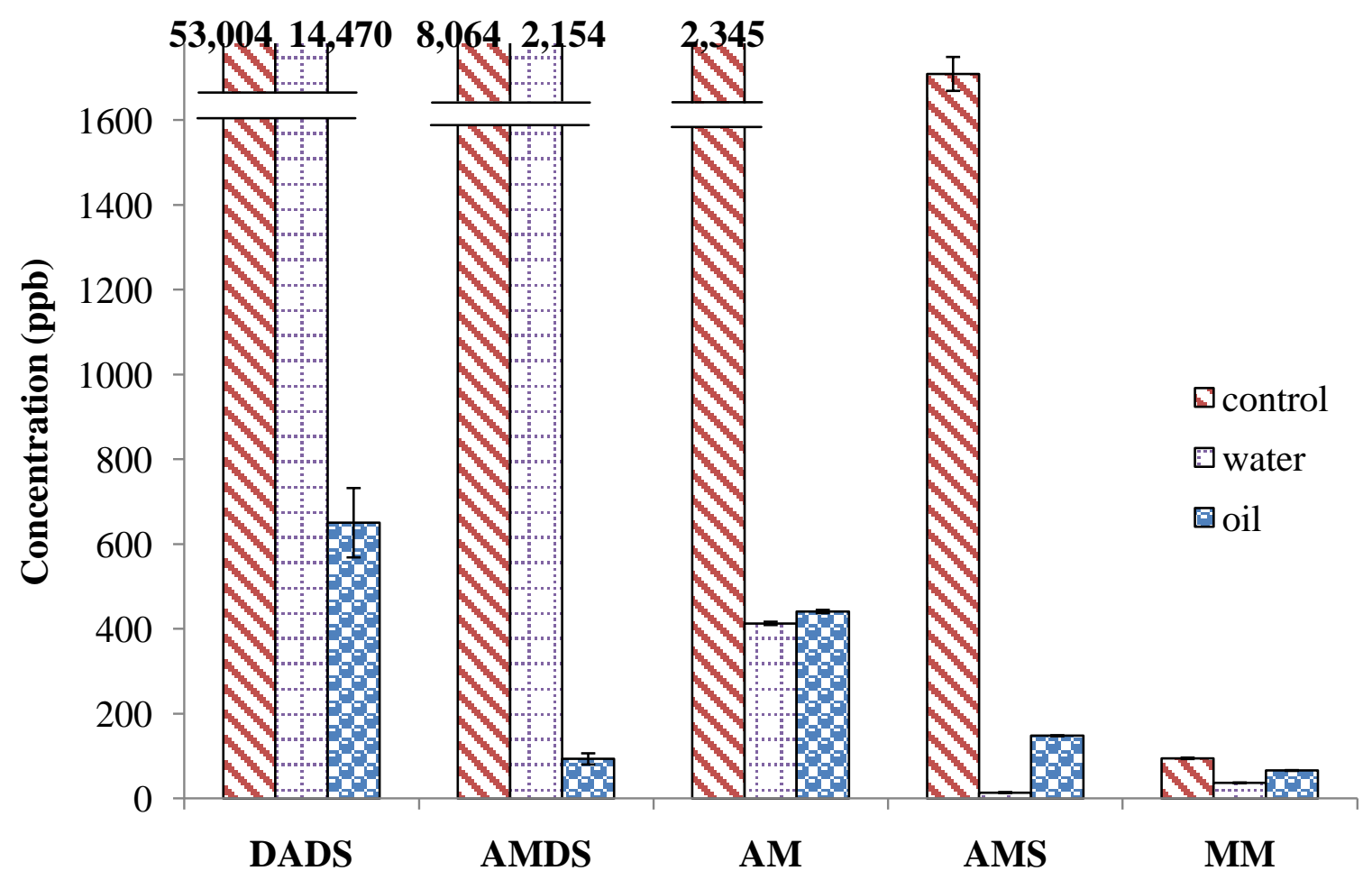

Figure 4.2 Effect of water and oil on the concentrations of diallyl disulfide (DADS), allyl methyl disulfide (AMDS), allyl mercaptan (AM), allyl methyl sulfide (AMS), and methyl mercaptan (MM) in the headspace of chopped unblanched garlic. 
Since milk contains different fat contents and both fat and water have a significant effect on the volatility of the analyzed volatile compounds, the effect of oil concentration on the headspace concentrations of these volatile compounds was also investigated. Increasing the concentration of canola oil in oil-in-water emulsions significantly decreased the concentrations of the more hydrophobic compounds diallyl disulfide and allyl methyl disulfide (Figure 4.3). As the concentration of oil increased, more oil is available for the more hydrophobic compounds diallyl disulfide and allyl methyl disulfide to dissolve in; and therefore decreased their headspace concentration. This result agrees with the finding of Phan and others (2008) who found that the headspace concentrations and the total amount of aroma release of the hydrophobic aroma compounds ethyl 3-methyl butanoate, 3-isobutyl 2-methoxy pyrazine, octanal, and linalool decreased significantly as the oil content in oil-in-water emulsions increased from 5 to $10 \%$. However, the amount of oil had no effect on the concentrations of the more hydrophilic compounds allyl mercaptan, allyl methyl sulfide, and methyl mercaptan, except at $100 \%$ oil (Figure 4.3).Since the more hydrophilic allyl mercaptan, allyl methyl sulfide, and methyl mercaptan dissolve in water better than oil, increasing the concentration of oil from 0 to $10 \%$ in oil-in-water emulsions had no significant effect on these volatiles. Only when no water was present, in $100 \%$ oil, were the volatile levels higher. Similarly, increasing the oil content up to $83 \%$ in model emulsions had no effect 
on the odor intensity of the hydrophilic compounds diacetyl and butyric acid, except at 99\% oil, where the odor intensity of these volatiles were higher (Guyot and others 1996).

Both water and oil significantly reduced the volatility of the analyzed volatile compounds in the headspace of chopped unblanched or blanched garlic. Oil decreased the volatility of the more hydrophobic compounds diallyl disulfide and allyl methyl disulfide better than water whereas water decreased the volatility of the more hydrophilic allyl mercaptan, allyl methyl sulfide, and methyl mercaptan better than oil. With water as the continuous phase, increasing oil concentration significantly decreased the headspace concentration of the hydrophobic volatile compounds diallyl disulfide and allyl methyl disulfide, but did not change the headspace concentration of the more hydrophilic compounds allyl mercaptan, allyl methyl sulfide, and methyl mercaptan until oil became the continuous phase. 

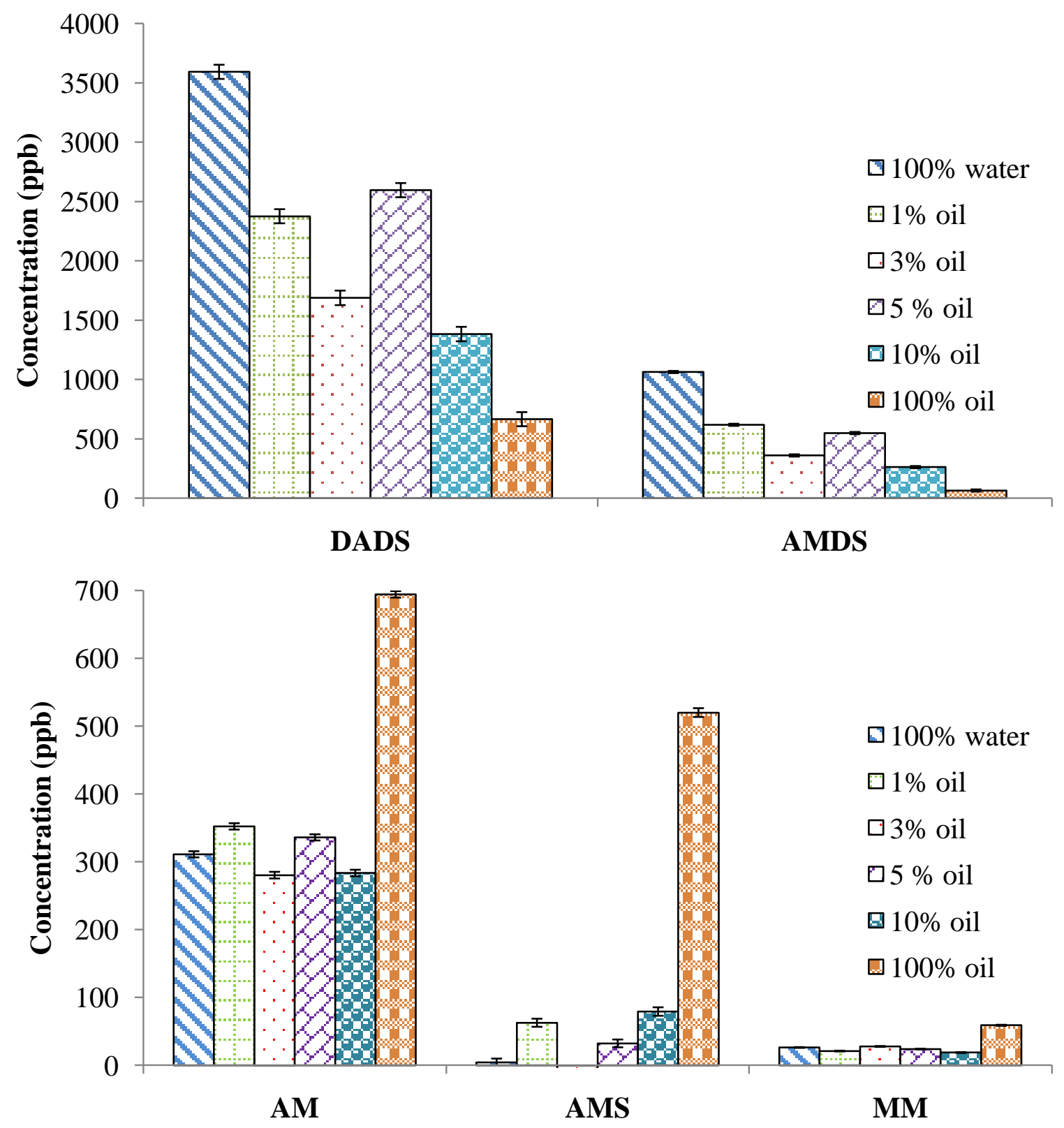

Figure 4.3 Effect of canola oil concentration in oil-in-water emulsions on diallyl disulfide (DADS), allyl methyl disulfide (AMDS), allyl mercaptan (AM), allyl methyl sulfide (AMS), and methyl mercaptan (MM) in the headspace of chopped unblanched garlic. 


\subsubsection{Effect of protein and sugar}

Since milk contains different protein and sugar contents and both components may have an effect on the volatility of the analyzed volatile compounds, the effect of protein and sugar concentrations on the headspace concentrations of these volatile compounds was also investigated. Sodium caseinate significantly reduced the concentrations of the disulfide compounds diallyl disulfide and allyl methyl disulfide in the headspace of chopped garlic in water (Figure 4.4). In the 1-10\% concentration range, sodium caseinate decreased their concentrations by up to $27 \%$ over their concentration in water. Sodium caseinate may interact with diallyl disulfide and allyl methyl disulfide via the sulfhydryl-disulfide interchange reaction (Jocelyn 1972), resulting in the reduction of the volatility of these volatile disulfide compounds. The reduction of volatile disulfides via the sulfhydryl-disulfide interchange reaction has been reported in many studies (Mottram and others 1996; Adams and others 2001). By the sulfhydryl-disulfide interchange reaction, casein reduces the headspace concentrations of bis (2-furanylmethyl disulfide and bis (2-methyl-3-furanyl) disulfide by 21-46\% (Mottram and others 1996) and egg albumin decreases the headspace concentration of diallyl disulfide by $15 \%$ (Adams and others 2001). 
On the other hand, sodium caseinate had no effect on the concentrations of the sulfide and mercaptan compounds allyl mercaptan, allyl methyl sulfide, and methyl mercaptan (Figure 4.4). These volatile sulfides should not be able to interact with sodium caseinate via the sulfhydryl-disulfide interchange reaction. Adams and others (2001) reported that diallyl sulfide cannot participate in the sulfhydryl-disulfide interchange reaction with egg albumin. Lactose had no effect on the concentrations of any of the analyzed volatile compounds in the headspace of chopped unblanched or blanched garlic in water. 

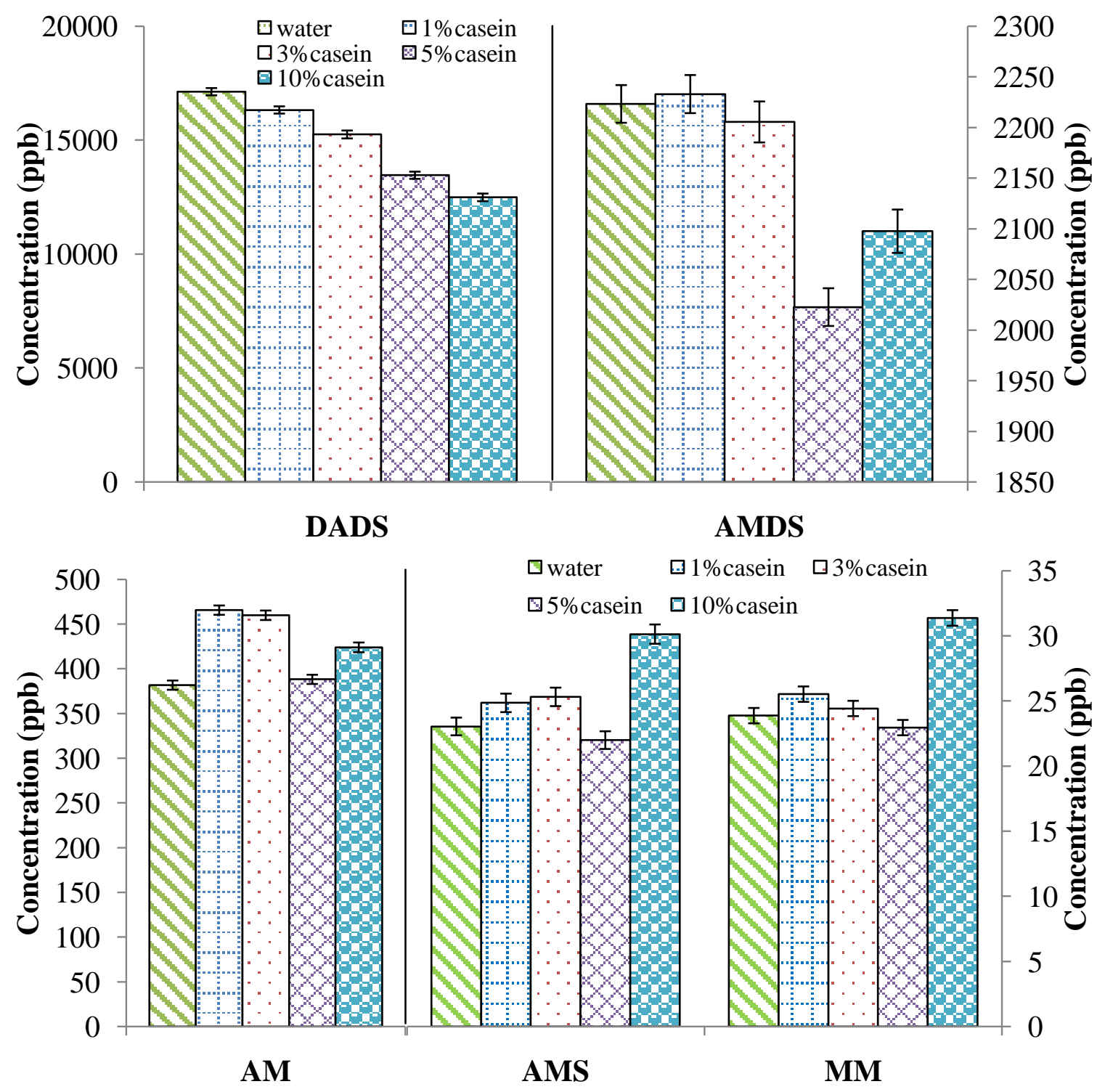

Figure 4.4 Effect of sodium caseinate concentration on diallyl disulfide (DADS), allyl methyl disulfide (AMDS), allyl mercaptan (AM), allyl methyl sulfide (AMS), and methyl mercaptan (MM) in the headspace of unblanched chopped garlic in aqueous solutions. AMDS, AMS, and MM are on the right axis. 


\subsubsection{Effect of milk and similar solutions on the deodorization of volatiles in the headspace of chopped garlic}

Both fat-free and whole milk significantly reduced the concentrations of the analyzed volatile compounds in the headspace of chopped garlic (Figure 4.5). Whole milk was more effective than fat-free milk in the reduction of the hydrophobic compounds diallyl disulfide and allyl methyl disulfide. However, there was no significant difference in the reduction of the more hydrophilic compounds allyl mercaptan, allyl methyl sulfide, and methyl mercpatn between fat-free and whole milk. This finding agrees with the study of Miettinen and others (2004) who reported that increasing the fat content in UHT milk from 0 to $5 \%$ significantly decreased the headspace concentration of the hydrophobic compound linalool, but did not affect the headspace concentration of the more hydrophilic compound cis-3-hexenol.

Water, which constitutes about $90 \%$ of fat-free milk and $88 \%$ of whole milk (USDA 2009), is a major factor in the deodorization of these volatiles, as shown earlier. Water reduced the concentrations of the volatiles by 68 to $99 \%$ (Figure 4.5). Compared to water, a solution of $3.2 \%$ sodium caseinate and $5.1 \%$ lactose, which resembles the content of casein and lactose in fat-free and whole milk had no effect on the more hydrophobic volatiles diallyl disulfide and allyl methyl disulfide, and slightly increased 
the concentrations of the more hydrophilic compounds allyl mercaptan, allyl methyl sulfide, and methyl mercaptan (Figure 4.5). Fat-free milk had the same effect on these volatiles as the $3.2 \%$ sodium caseinate and $5.1 \%$ lactose solution (Figure 4.5). Therefore, it can be concluded that water is the major component in fat-free milk that is responsible for the deodorization of the volatiles in the headspace of chopped garlic.

The 3.2\% oil-in-water emulsion, which imitates the fat content in whole milk, further decreased the concentrations of the hydrophobic volatiles diallyl disulfide and allyl methyl disulfide, and had no effect on the hydrophilic volatiles allyl mercaptan, allyl methyl sulfide, and methyl mercaptan compared to $3.2 \%$ sodium caseinate and $5.1 \%$ lactose solution (Figure 4.5). Whole milk had a similar effect on these volatiles as the $3.2 \%$ oil-in-water emulsion. Thus, in addition to water, milk fat is another component in whole milk that can further reduce the headspace concentration, but only for the hydrophobic volatiles. The whole milk result is consistent with the finding of Negishi and others (2002) who reported that milk (3.5\% fat) reduces the headspace concentration of a diallyl disulfide solution by $96 \%$. 

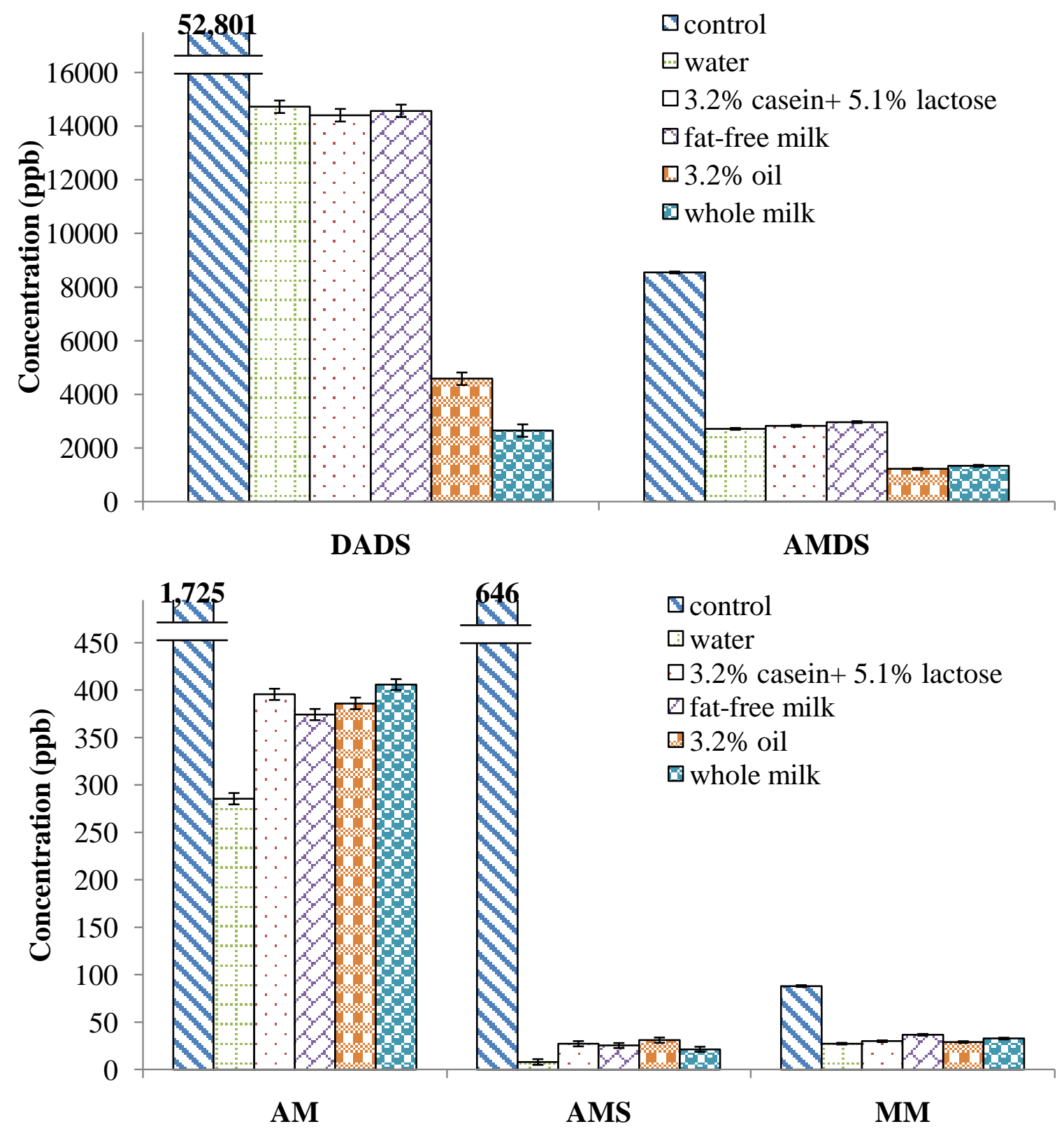

Figure 4.5 Effect of milk and similar solutions on the concentrations of diallyl disulfide (DADS), allyl methyl disulfide (AMDS), allyl mercaptan (AM), allyl methyl sulfide (AMS), and methyl mercaptan (MM) in the headspace of chopped unblanched garlic. 


\subsection{In vivo studies}

\subsubsection{Quantification of the major volatiles in the breath after garlic ingestion}

Since the metabolism of garlic inside the body is different from the chemical reactions that occur outside the body and milk shows a significant deodorizing effect against all analyzed volatiles in the in vitro test, the effect of milk on the deodorization of the garlic volatiles in breath after garlic ingestion was also investigated.

The concentrations of diallyl disulfide, allyl methyl disulfide, allyl mercaptan, allyl methyl sulfide, and methyl mercaptan were measured in the mouth- and nose-space for 60 mins after garlic ingestion. In the first 30 mins after ingestion, diallyl disulfide and allyl mercaptan were the two major volatile compounds in the mouth-space whereas allyl methyl sulfide and allyl methyl disulfide were minor volatiles (Figure 4.6). Methyl mercaptan, which was reported to be the second most abundant volatile sulfur compound found in the breath after garlic ingestion (Suarez and others 1999; Tamaki and Sonoki 1999; Tamaki and others 2008), was present at a lower level than the detection limit of the SIFT-MS. It is possible that the high level of methyl mercaptan in the breath reported in previous studies (Suarez and others 1999; Tamaki and Sonoki 1999; Tamaki and others 2008) might come from the metabolism of sulfur-containing proteins by oral 
microorganisms (Tonzetich 1977), not the garlic itself. Allyl mercaptan and diallyl disulfide have been identified as the major volatiles found in breath immediately after ingestion of raw garlic in many studies (Laakso and others 1989; Minami and others 1989; Suarez and others 1999; Tamaki and Sonoki 1999; Tamaki and others 2008).

Since diallyl disulfide, allyl mercaptan, and allyl methyl disulfide come from the garlic particles retained in the oral cavity (e.g. teeth, tongue, etc.) (Haggard and Greenberg 1935; Suarez and others 1999), their concentrations in the mouth and nose decreased significantly after swallowing garlic. Also, the concentrations of these volatiles in the mouth were higher than those in the nose. At 30 mins after ingestion, only $\sim 10$ $15 \%$ of the initial concentrations of diallyl disulfide, allyl mercaptan, and allyl methyl disulfide were present in the nose- and mouth-space. The nose- to mouth-space ratios of diallyl disulfide, allyl mercaptan, and allyl methyl disulfide were 1:11, 1:10, and 1:6, respectively.

Allyl methyl sulfide was a major volatile in the nose after garlic ingestion (Figure 4.6). Allyl methyl sulfide originates from the gut and is transferred to different parts of the body via the blood stream (Suarez and others 1999). Its concentration in the mouth and nose decreased gradually after swallowing garlic. At 30 mins after ingestion, 60$70 \%$ of the initial concentration of allyl methyl sulfide was still retained in the nose- and mouth-space and this compound became the predominant compound in the mouth at 60 
mins after ingestion. The nose- to mouth-space ratio of allyl methyl sulfide was $1: 1$. At 60 mins after ingestion, the concentrations of diallyl disulfide, allyl mercaptan, and allyl methyl disulfide in the nose- and mouth-space were $\sim 2-8 \%$ of their initial concentrations whereas the concentration of allyl methyl sulfide was $\sim 50 \%$ of its initial concentration. Three hours after ingestion, allyl methyl sulfide has been reported to still be a predominant compound in breath (Taucher and others 1996; Suarez and others 1999). 

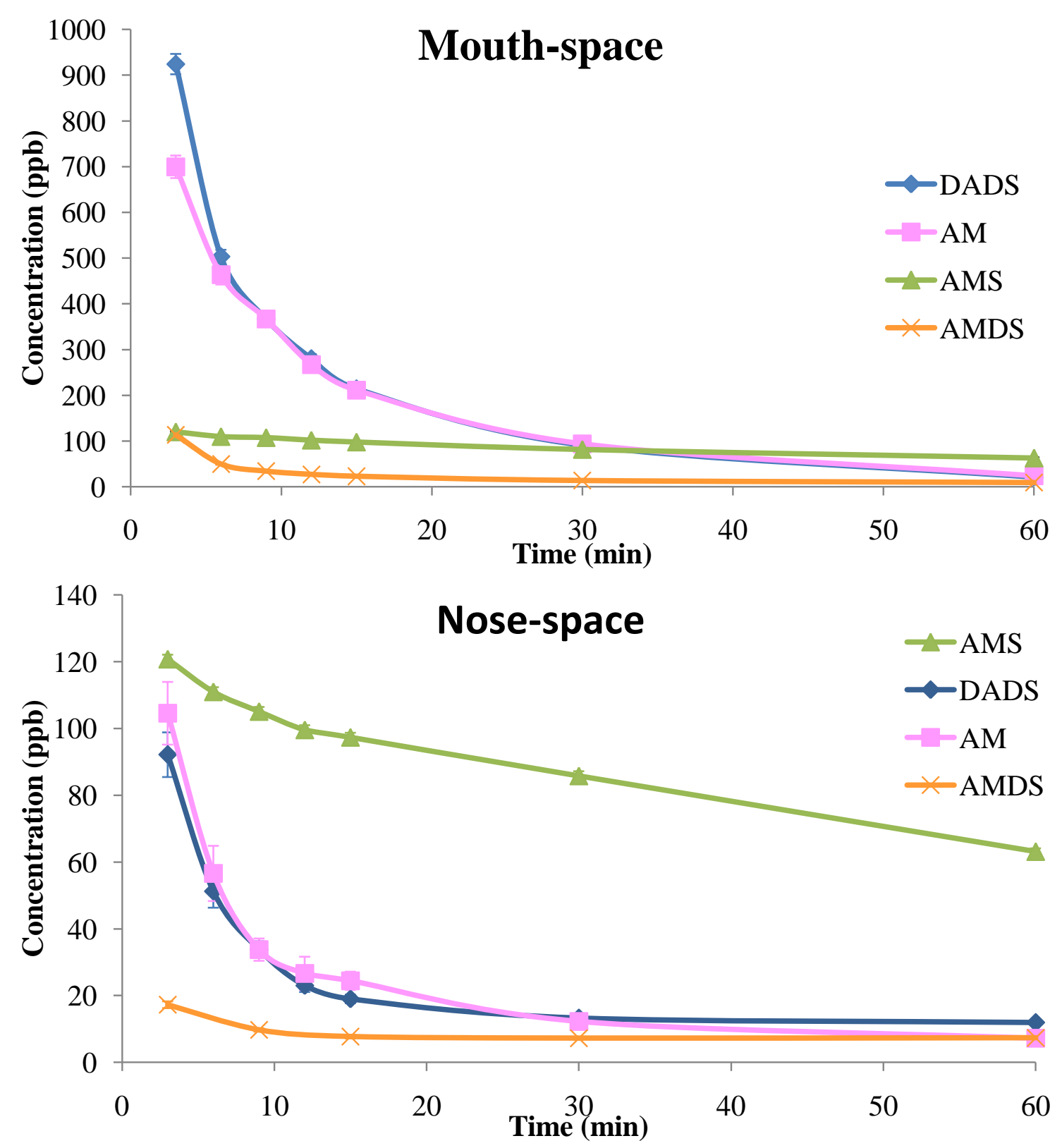

Figure 4.6 Concentrations of diallyl disulfide (DADS), allyl mercaptan (AM), allyl methyl sulfide (AMS), and allyl methyl disulfide (AMDS) in the mouth- and nose-space after garlic ingestion. 


\subsubsection{Effect of milk and similar solutions on the deodorization of malodorous breath after garlic ingestion}

\subsubsection{Ingestion of garlic + treatments}

Addition of water, fat-free milk, whole milk, or $10 \%$ sodium caseinate to chopped garlic before ingestion significantly reduced the concentrations of all analyzed volatile compounds in the mouth for the 60 mins after ingestion of the garlic mixture (Figure 4.7 and 4.8). Since milk produced the same trends for mouth-space and nose-space volatiles, only the mouth-space results are presented. Compared to garlic with nothing added before ingestion, water reduced the concentrations of diallyl disulfide, allyl methyl disulfide, allyl mercaptan, and allyl methyl sulfide in the mouth during the 3-60 mins after ingestion by 94-96, 92-56, 92-97, and 65-20\%, respectively (Figure 4.7 and 4.8). As shown in the previous section, water is capable of deodorizing both hydrophobic (diallyl disulfide and allyl methyl disulfide) and hydrophilic volatiles (allyl mercaptan and allyl methyl sulfide) in the headspace of chopped garlic (Figure 4.2 and 4.6) so it is logical this would also be effective in the mouth. For diallyl disulfide, allyl methyl disulfide, and allyl mercaptan, there were few differences between water, fat-free milk, whole milk, and $10 \%$ casein, likely because water is the major factor. 
Allyl methyl sulfide is produced in the gut (Suarez and others 1999) so it behaves differently from the other volatiles. At 60 mins after ingestion, the concentrations of diallyl disulfide, allyl mercaptan, and allyl methyl disulfide in the nose- and mouth-space were $\sim 2-8 \%$ of their initial concentrations whereas the concentration of allyl methyl sulfide was $\sim 50 \%$ of its initial concentration (Figure 4.7 and 4.8). Milk reduced the concentration of allyl methyl sulfide, which causes a persistent garlic odor, in the mouth after garlic ingestion better than water and $10 \%$ sodium caseinate. In the liver, allyl methyl sulfide is produced from diallyl disulfide by methylating and breaking the disulfide bond of diallyl disulfide via the action of the phase II enzyme glutathione (Sheen and others 1999; Rosen and others 2000, 2001). Since allyl methyl sulfide is one of the metabolites of diallyl disulfide, reducing the availability of diallyl disulfide to interact with the phase II enzyme glutathione (Rosen and others 2000) in the body by physical and chemical interaction with milk (Negishi and others 2002) would result in decreasing the level of allyl methyl sulfide in the mouth after ingestion of garlic. Thus, addition of milk to chopped garlic before ingestion may help deodorize allyl methyl sulfide, a persistent garlic odor, in breath. 

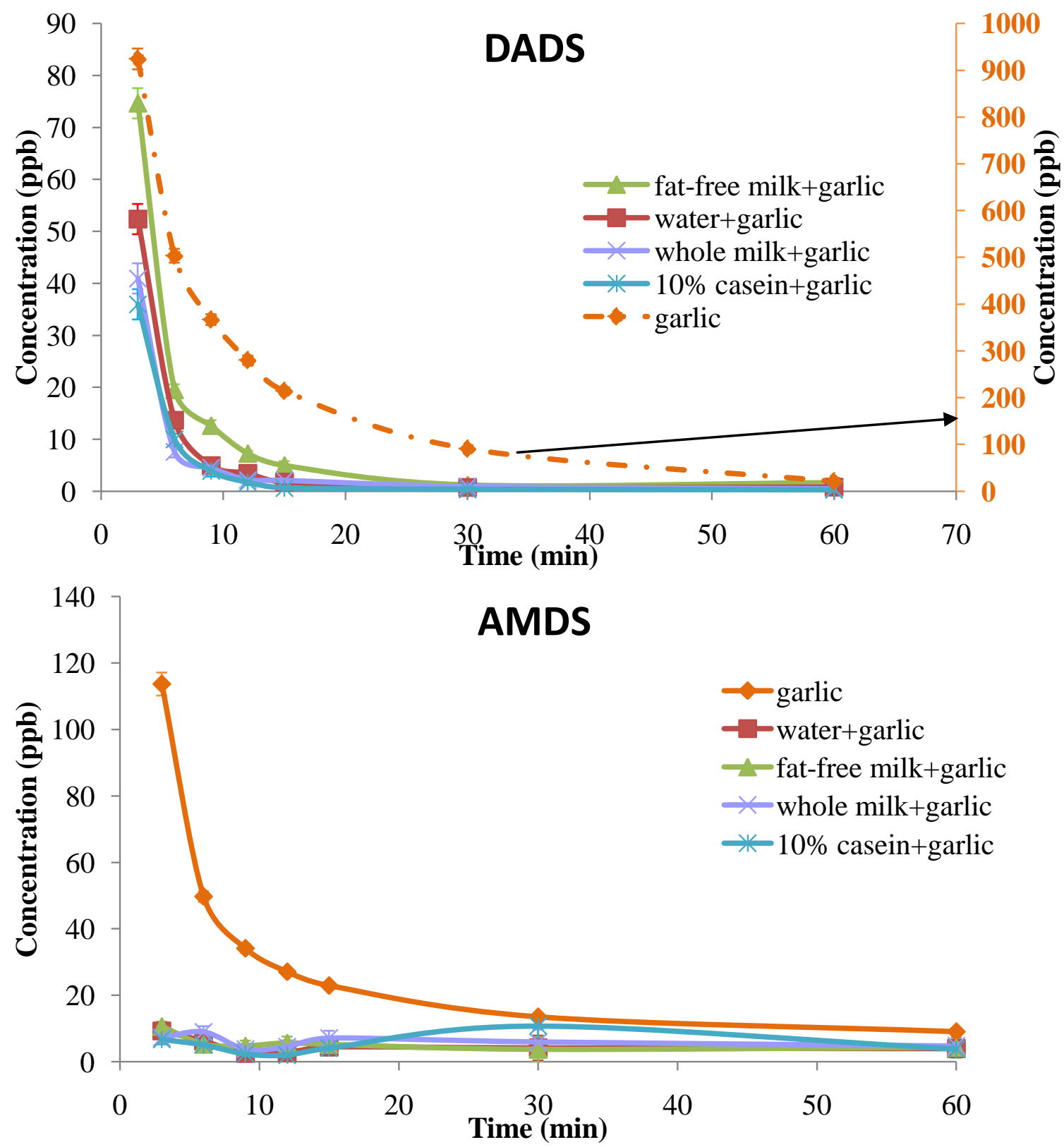

Figure 4.7 Concentration of diallyl disulfide (DADS) and allyl methyl disulfide (AMDS) in the mouth for 60 minutes after ingestion of garlic alone or in water, fat-free milk, whole milk, or $10 \%$ casein. The dashed line of DADS is on right hand y-axis. 

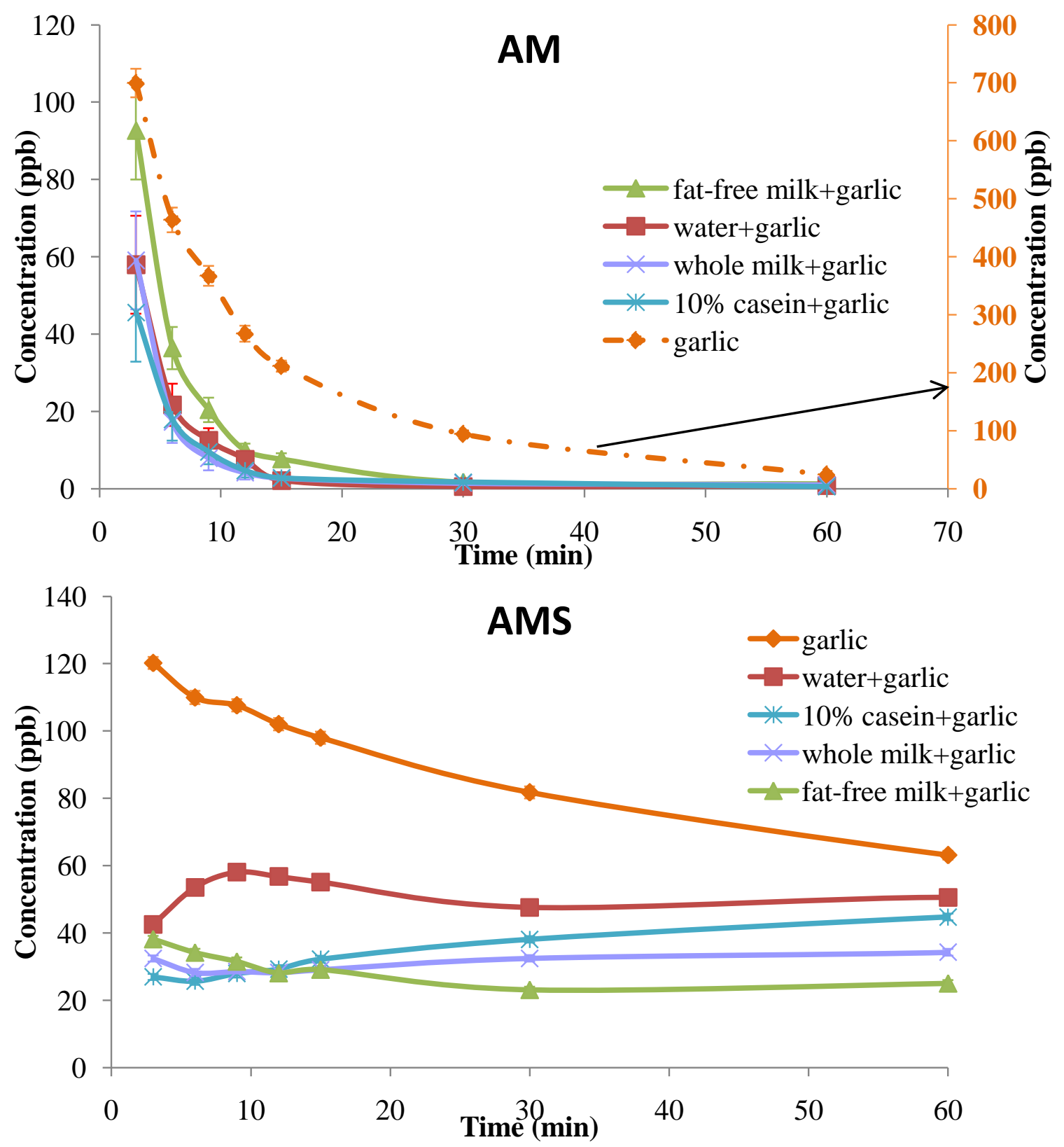

Figure 4.8 Concentration of allyl mercaptan (AM) and allyl methyl sulfide (AMS) in the mouth for 60 minutes after ingestion of garlic alone or in water, fat-free milk, whole milk, or $10 \%$ casein. Dashed line of AM is on right hand y-axis. 


\subsubsection{Effect of order of milk consumption on the deodorization of malodorous breath after garlic ingestion}

Consumption of fat-free or whole milk after consuming garlic significantly reduced the concentrations of diallyl disulfide, allyl methyl disulfide, allyl mercaptan, and allyl methyl sulfide in the mouth (Figure 4.9 and 4.10). However, consumption of fat-free or whole milk mixed with garlic reduced the concentrations of these volatiles more than consumption of fat-free or whole milk after garlic (Figure 4.9 and 4.10). There was no significant difference between consumption of fat-free and whole milk after garlic ingestion. When milk is consumed after garlic, it rinses the volatiles in the mouth and also reacts with the garlic metabolites inside the body. However, when milk is mixed together with garlic, additional reactions may occur. Negishi and others (2002) reported that milk (3.5\% fat) effectively reduces the headspace concentration of diallyl disulfide and diallyl sulfide solutions by physical and chemical interaction between the volatile sulfur compounds and the food components (protein or lipid). The deodorizing effect of milk mixed with garlic may be due to direct reactions with garlic. Therefore, adding treatments to garlic before ingestion had a higher deodorizing effect on these volatiles than eating treatments after garlic. 

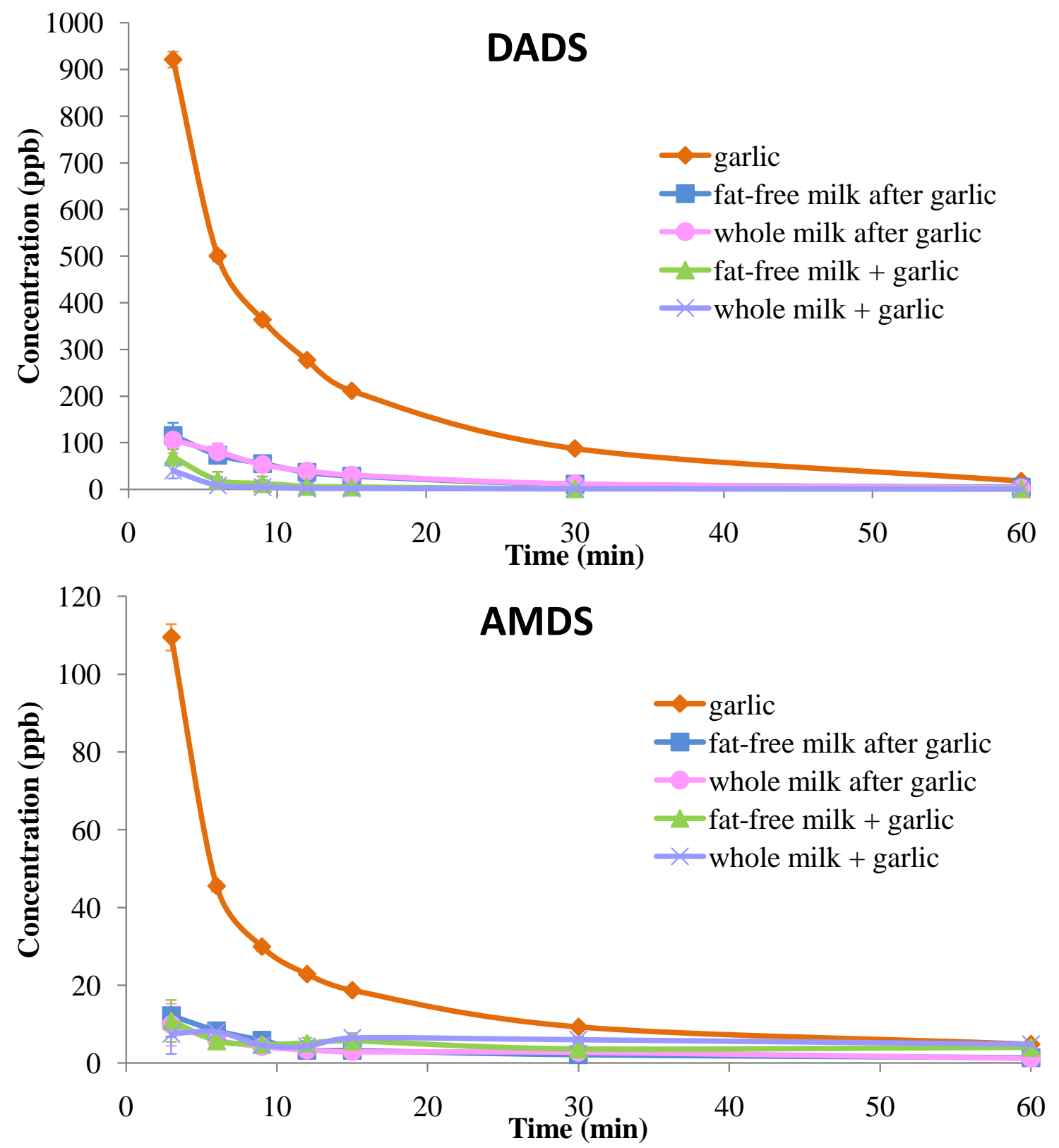

Figure 4.9 Concentrations of diallyl disulfide (DADS) and allyl methyl disulfide (AMDS) in the mouth for 60 minutes after ingestion of garlic, garlic in fat-free or whole milk, or garlic followed by fat-free or whole milk. 

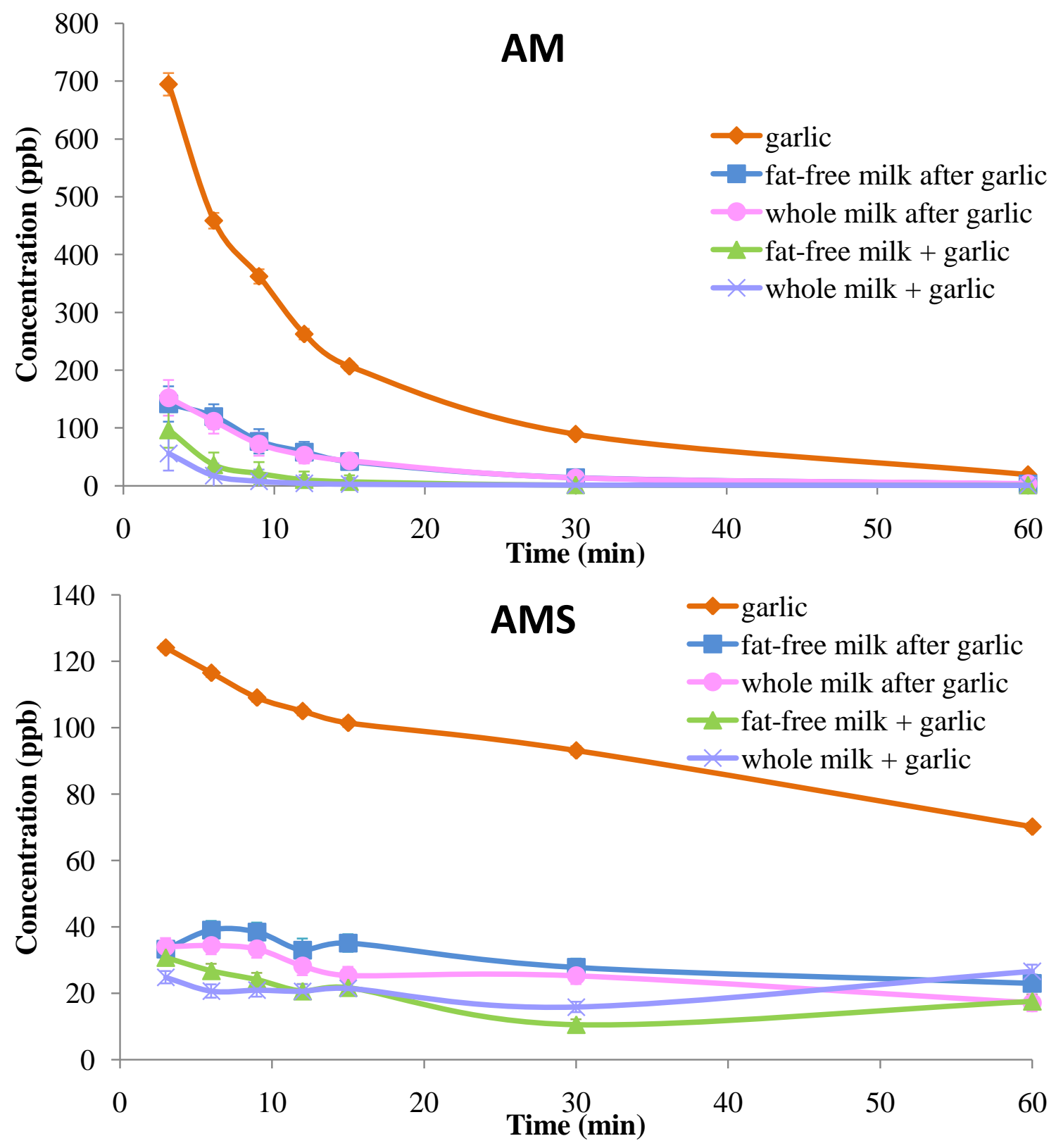

Figure 4.10 Concentrations of allyl mercaptan (AM) and allyl methyl sulfide (AMS) in the mouth for 60 minutes after ingestion of garlic, garlic in fat-free or whole milk, or garlic followed by fat-free or whole milk. 


\subsection{Conclusion}

Fat-free and whole milk significantly reduced the head-, mouth-, and nose-space concentrations of the major odor components of garlic breath diallyl disulfide, allyl methyl disulfide, allyl mercaptan, allyl methyl sulfide, and methyl mercaptan. Water was the major component in fat-free and whole milk that was responsible for the deodorization of all volatiles. Due to its higher fat content, whole milk was more effective than fat-free milk in the deodorization of the more hydrophobic volatiles diallyl disulfide and allyl methyl disulfide. In water, casein reduced the disulfides volatiles diallyl disulfide and allyl methyl disulfide, but lactose had no effect on any volatiles. Also, fat-free and whole milk was more effective than water and $10 \%$ sodium caseinate in the deodorization of allyl methyl sulfide, a persistent garlic odor, in the mouth-space after garlic ingestion. The order of milk ingestion also had a significant effect on the deodorization of volatiles in the mouth after garlic ingestion. Drinking milk after garlic ingestion had a lower deodorizing effect than drinking milk mixed with garlic. The results suggest that drinking beverages or foods with high water and/or fat content such as milk may help reduce the malodorous odor in breath after consumption of garlic and mask the garlic flavor during eating. 


\section{REFERENCES}

Adams RL, Mottram DS, Parker JK, Brown HM. 2001. Flavor-protein binding: disulfide interchange reactions between ovalbumin and volatile disulfides. J. Agric. Food Chem. 49: 4333-4336.

Block G, Patterson B, Subar A. 1992. Fruit, vegetables, and cancer prevention: a review of the epidemiological evidence. Nutr. Cancer. 18(1):1-29.

Brodnitz MH, Pascale JV, Derslice LV. 1971. Flavor components of garlic extract. J Agr Food Chem 19 (2): 273-275.

Buttery RG, Guadagri DG, Ling LC. 1973 Flavor compounds: volatilities in vegetable oil and oil-water mixtures. Estimation of odor thresholds. J Agr Food Chem 21: 198-201.

Cavallito CJ, Bailey JH. 1944. Allicin, the antibacterial principle of Allium sativum. I. isolation, physical properties and antibacterial action. J Am Chem Soc. 66: 1950-1951.

Depree JA, Savage GP. 1998. Variation in deodorant content of the cultivated mushroom Agaricus bisporus. Proceedings of the Nutrition Society of New Zealand 23: 48-52. 
Francis GJ, Wilson PF, Milligan DB, Langford VS, McEwan MJ. 2007. GeoVOC: A SIFT-MS method for the analysis of small linear hydrocarbons of relevance to oil exploration. International Journal of Mass Spectrometry 268: 38-46.

Guyot C, Bonnafont C, Lesschaeve I, Issanchou S, Voilley A, Spinnler HE. 1996. Effect of fat content on odor intensity of three aroma compounds in model emulsions: $\delta$ decalactone, diacetyl, and butyric acid. J. Agric. Food Chem. 44: 2341-2348.

Haggard HW, Greenberg LA. 1935. Breath odors from alliaceous substance. Cause and remedy. Journal of the American Medical Association 104: 2160-2163.

Jocelyn PC. 1972. Biochemistry of the SH group. New York: Academic Press INC. 404 p.

Kim SM, Wu CM, Kubota K, Kobayashi A. 1995. Effect of soybean oil on garlic volatile compounds isolated by distillation. J Agric Food Chem 43: 449-452.

Laakso I, Seppane-Laakso T, Hiltunen R, Muller B, Jansen H, Knobloch K. 1989. Volatile garlic odor components: gas phases and adsorbed exhaled air analyzed by headspace gas chromatography-mass spectrometry. Planta Med 55: 257-261. 
Lawson LD. 1993. Bioactive organosulfur compounds of garlic and garlic products; role in reducing blood lipids. ACS Symposium Series 534: 306-330. American Chemical Society, Washington DC.

Lawson LD. 1996. The composition and chemistry of garlic cloves and processed garlic. In Garlic: The Science and Therapeutic Application of Allium sativum L. and Related Species. Maryland: Williams \& Wilkins pp 37-107.

Lee S, Kim N, Lee D. 2003. Comparative study of extraction techniques for determination of garlic flavor components by gas chromatography-mass spectrometry. Anal Bioanal Chem 377: 749-756.

Lodhia P, Yaegaki K, Khakbaznejad A, Imai T, Sato T, Tanaka T, Murata T, Kamoda T. 2008. Effect of green tea on volatile sulfur compounds in mouth air. J. Nutr. Sci. Vitaminol. 54: 89-94.

Mazza G, Ciaravolo S, Chiricosta G, Celli S. 1992. Volatile flavor components from ripening and mature garlic bulbs. Flavour Fragrance J 7:111-116.

Miettinen SM, Hyvonen L, Linforth RST, Taylor AJ, Tuorila H. 2004. Temporal aroma delivery from milk systems containing 0-5\% added fat, observed by free choice profiling, time intensity, and atmospheric pressure chemical ionization-mass spectrometry techniques. J. Agric. Food Chem. 52: 8111-8118. 
Minami T, Boku T, Inada K, Morita M, Okazaki Y. 1989. Odor components of human breath after the ingestion of grated raw garlic. Journal of Food Science 54 (3): 763-765.

Mottram DS, Szauman-Szumski C, Dodson A. 1996. Interaction of thios and disulfide flavor compounds with food components. J. Agric. Food Chem. 44: 2349-2351.

NCBI. 2009. PubChem [online]. Maryland: National center for biotechnology information, U.S. National Libery of Medicine, 2004 [cited 1 January 2010]. Available from World Wide Web: http://pubchem.ncbi.nlm.nih.gov/

Negishi O, Negishi Y. 1999. Enzymatic deodorization with raw fruits, vegetables and mushrooms. Food Sci. Technol. Res. 5 (2): 176-180.

Negishi O, Negishi Y, Ozawa T. 2002. Effects of food materials on removal of Alliumspecific volatile sulfur compounds. J. Agric. Food Chem. 50: 3856-3861.

Negishi O, Negishi Y, Yamaguchi F, Sugahara T. 2004. Deodorization with Ku-ding-cha containing a large amount of caffeoyl quinic acid derivatives. J. Agric. Food Chem. 52: 5513-5518.

Phan VA, Liao YC, Antille N, Sagalowicz L, Robert F, Godinot N. 2008. Delayed volatile compound release properties of self-assembly structures in emulsions. J. Agric. Food Chem. 56: 1072-1077. 
Pino J, Rosado A, Gonzalez A. 1991. Volatile flavor components of garlic essential oil. Acta Alimentaria 20 (3-4):163-171.

Rose P, Whiteman M, Moore PK, Zhu YZ. 2005. Bioactive $S$-alk(en)yl cysteine sulfoxide metabolites in the genus Allium: the chemistry of potential therapeutic agents. Nat Prod Rep 22: 351-368.

Rosen RT, Hiserodt RD, Fukuda EK, Ruiz RJ, Zhou Z, Lech J, Rosen SL, Hartman TG. 2000. The determination of metabolites of garlic preparations in breath and human plasma. Biofactors 13: 241-249.

Rosen RT, Hiserodt RD, Fukuda EK, Ruiz RJ, Zhou Z, Lech J, Rosen SL, Hartman TG. 2001. Determination of allicin, S-allylcysteine and volatile metabolites of garlic in breath, plasma or simulated gastric fluids. J. Nutr. 131: 968S-971S.

Semmler FW. 1893. Essential oil of garlic (allium sativum). Arch. Pharm. 230: 434-443.

Sheen LY, Wu CC, Lii CK, Tsai SJ. 1999. Metabolites of diallyl disulfide and diallyl sulfide in primary rat hepatocytes. Food and Chemical Toxicology 37: 1139-1146.

Shimizu K, Maeda Y, Osawa K, Shimura S. 2004. Deodorizing effect of Rubus suavissimus extract against allyl methyl sulfide. Nippon Shokuhin Kagaku Kogaku Kaishi 51 (4): 205-209. 
Spanel P, Rolfe P, Rajan B, Smith D. 1996. The selected ion flow tube (SIFT) - A novel technique for biological monitoring. Ann. Occup. Hyg. 40 (6): 615-626.

Spanel P, Smith D. 1996. A selected ion flow tube study of the reactions of $\mathrm{NO}^{+}$and $\mathrm{O}_{2}{ }^{+}$ ions with some organic molecules: The potential for trace gas analysis of air. J. Chem. Phys. 104 (5): 1893-1899.

Spanel P, Smith D. 1998. Selected ion flow tube studies of the reactions of $\mathrm{H}_{3} \mathrm{O}^{+}, \mathrm{NO}^{+}$, and $\mathrm{O}_{2}{ }^{+}$with some organosulfur molecules. International Journal of Mass Spectrometry 176: $167-176$.

Spanel P, Smith D. 1999. Selected ion flow tube- mass spectrometry: detection and realtime monitoring of flavors released by food products. Rapid Commun. Mass Spectrom. 13: 585-596.

Suarez F, Springfield J, Furne J, Levitt M. 1999. Differentiation of mouth versus gut as site of origin of odoriferous breath gases after garlic ingestion. Am J Physiol 276: G425G430.

Tamaki T, Sonoki S. 1999. Volatile sulfur compounds in human expiration after eating raw or heat-treated garlic. J Nutr Sci Vitaminol 45: 213-222. 
Tamaki K, Sonoki S, Tamaki T, Ehara K. 2008. Measurement of odour after in vitro or in vivo ingestion of raw or heated garlic, using electronic nose, gas chromatography and sensory analysis. International Journal of Food Science and Technology 43: 130-139.

Tamaki K, Tamaki T, Yamazaki T. 2007. Studies on the deodorization by mushroom (Agaricus bisporus) extract of garlic extract-induced oral malodor. J. Nutr. Sci.

Vitaminol. 53: 277-286.

Taucher J, Hansel A, Jordan A, Lindinger W. 1996. Analysis of Compounds in Human Breath after Ingestion of Garlic Using Proton-Transfer-Reaction Mass Spectrometry. J. Agric. Food Chem. 44: 3778-3782.

Tonzetich J. 1977. Production and origin of oral malodor: a review of mechanisms and methods of analysis. Journal of Periodontology 48 (1): 13-20.

Ui M, Yasuda H, Shibata M, Maruyama T, Horita H, Hara T, Yasuda T. 1991. Effect of tea catechins for halitosis and their application to chewing gum. Nippon Shokuhin Kogyo Gakkaishi 38 (12): 1098-1102.

USDA. 2009. National nutrient database for standard reference [online]. Maryland: USDA-ARS, Nutrient data laboratory, 2009 [cited 12 February 2010]. Available from World Wide Web: http://www.nal.usda.gov/fnic/foodcomp/search/ 
Vernin G, Metzger J, Fraisse D, Scharff C. 1986. GC-MS (EI, PCI, NCI) computer analysis of volatile sulfur compounds in garlic essential oils. Application of the mass fragmentometry SIM technique. Planta Med 52: 96-101.

Wertheim T. 1844. Investigation of garlic oil. Justus Liebigs Ann Chem 51: 289-315. Williams TL, Adams NG, Babcock LM. 1998. Selected ion flow tube studies of $\mathrm{H}_{3} \mathrm{O}^{+}$ $\left(\mathrm{H}_{2} \mathrm{O}\right)_{0,1}$ reactions with sulfides and thiols. International Journal of Mass Spectrometry and Ion Processes 172: 149-159.

Wilson PF, Prince BJ, McEwan MJ. 2006. Application of selected-ion flow tube mass spectrometry to the real-time detection of triacetone triperoxide. Anal Chem 78: 575-579.

Yeh YY, Liu L. 2001. Cholesterol-lowering effect of garlic extracts and organosulfur compounds: human and animal studies. Journal of Nutrition 131: 989S-993S.

Yu TH, Wu CM, Liou YC. 1989. Volatile compounds from garlic. J Agric Food Chem 37: 725-730. 


\section{Appendix A}

Table A.1 Concentrations of diallyl disulfide (DADS), allyl methyl sulfide (AMS), allyl methyl disulfide (AMDS), allyl mercaptan (AM), and methyl mercaptan (MM) in the headspace of chopped unblanched garlic. 1\% Tween 80 was added in all oil-in-water emulsions. Distilled water and pure canola oil were used as controls. Values represent least square mean \pm standard error $(n=3)$.

\begin{tabular}{|c|c|c|c|c|c|}
\hline \multirow{2}{*}{ Treatments } & \multicolumn{5}{|c|}{ Concentration (ppb) } \\
\cline { 2 - 6 } & DADS & AMS & AMDS & AM & MM \\
\hline water & $14470.31 \pm 79.69$ & $14.23 \pm 1.18$ & $2154.04 \pm 13.89$ & $413.26 \pm 3.90$ & $37.13 \pm 0.91$ \\
\hline $\mathbf{1 \%}$ oil in water emulsion & $2476.95 \pm 79.20$ & $13.03 \pm 1.20$ & $534.66 \pm 13.01$ & $340.88 \pm 4.09$ & $30.31 \pm 0.91$ \\
\hline 3\%oil in water emulsion & $1558.27 \pm 79.22$ & $12.95 \pm 1.16$ & $290.43 \pm 13.05$ & $330.39 \pm 3.91$ & $28.47 \pm 0.91$ \\
\hline $\mathbf{5 \%}$ oil in water emulsion & $1247.95 \pm 80.64$ & $11.90 \pm 1.17$ & 158.4613 .07 & $327.19 \pm 3.91$ & $28.98 \pm 0.91$ \\
\hline $\mathbf{1 0 \%}$ il in water emulsion & $1115.70 \pm 80.15$ & $15.65 \pm 1.17$ & $184.66 \pm 13.41$ & $288.70 \pm 4.00$ & $17.79 \pm 0.91$ \\
\hline oil & $650.62 \pm 81.77$ & $148.23 \pm 1.17$ & $93.63 \pm 13.18$ & $441.22 \pm 3.92$ & $66.31 \pm 0.91$ \\
\hline
\end{tabular}



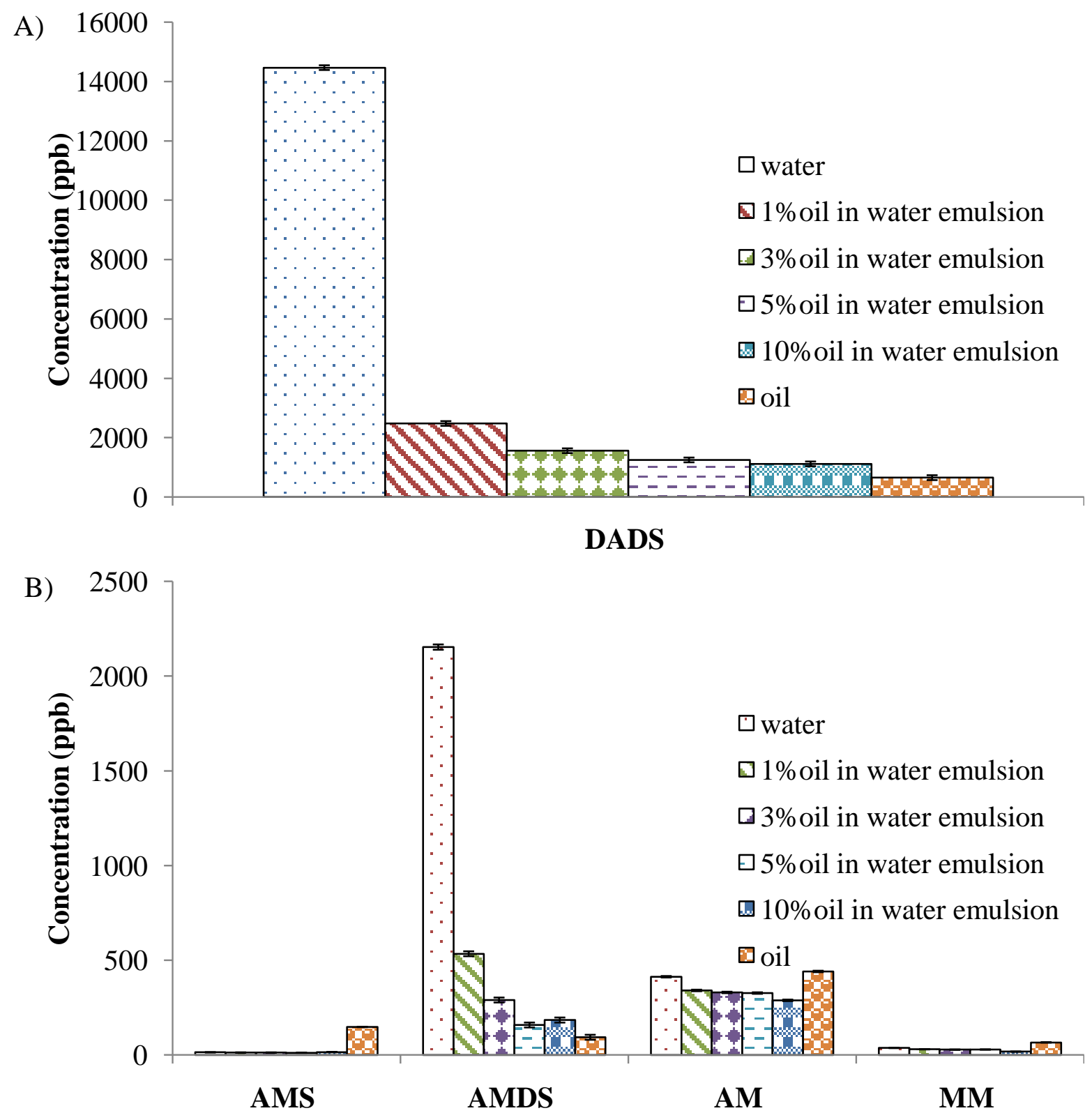

Figure A.1 Concentrations of A) diallyl disulfide (DADS), B) allyl methyl sulfide (AMS), allyl methyl disulfide (AMDS), allyl mercaptan (AM), and methyl mercaptan (MM) in the headspace of chopped unblanched garlic. 1\%Tween 80 was added in all oilin-water emulsions. Distilled water and pure canola oil were used as controls. Values represent least square mean \pm standard error $(n=3)$. 
Table A.2 Concentrations of diallyl disulfide (DADS), allyl methyl sulfide (AMS), allyl methyl disulfide (AMDS), allyl mercaptan (AM), and methyl mercaptan (MM) in the headspace of chopped blanched garlic. Chopped garlic was heated in $99^{\circ} \mathrm{C}$ water bath for $10 \mathrm{~min}$ and cooled in ice for $5 \mathrm{~min}$. $1 \%$ Tween 80 was added in all oil-in-water emulsions. Distilled water and pure canola oil were used as controls. Values represent least square mean \pm standard error $(n=3)$.

\begin{tabular}{|c|c|c|c|c|c|}
\hline \multirow{2}{*}{ Treatments } & \multicolumn{5}{|c|}{ Concentration (ppb) } \\
\cline { 2 - 7 } & DADS & AMS & AMDS & AM & MM \\
\hline water & $280288.50 \pm 1226.16$ & $274.13 \pm 5.30$ & $21045.16 \pm 97.90$ & $946.96 \pm 11.71$ & $1.13 \pm 0.17$ \\
\hline 1\%oil in water emulsion & $8621.20 \pm 1213.38$ & $82.77 \pm 4.37$ & $1675.76 \pm 98.06$ & $258.93 \pm 11.43$ & $1.21 \pm 0.17$ \\
\hline 3\%oil in water emulsion & $9079.21 \pm 1218.16$ & $91.99 \pm 4.49$ & $1653.18 \pm 103.85$ & $285.21 \pm 11.68$ & $1.36 \pm 0.17$ \\
\hline $\mathbf{5 \%}$ oil in water emulsion & $6327.83 \pm 1213.07$ & $61.40 \pm 4.42$ & $698.65 \pm 98.00$ & $249.80 \pm 11.45$ & $0.97 \pm 0.17$ \\
\hline $\mathbf{1 0 \%}$ oil in water emulsion & $4930.03 \pm 1218.55$ & $39.41 \pm 4.17$ & $478.14 \pm 98.11$ & $272.90 \pm 11.42$ & $1.47 \pm 0.17$ \\
\hline & $3540.64 \pm 1220.75$ & $540.89 \pm 4.40$ & $340.64 \pm 98.91$ & $1749.86 \pm 11.47$ & $3.05 \pm 0.17$ \\
\hline
\end{tabular}



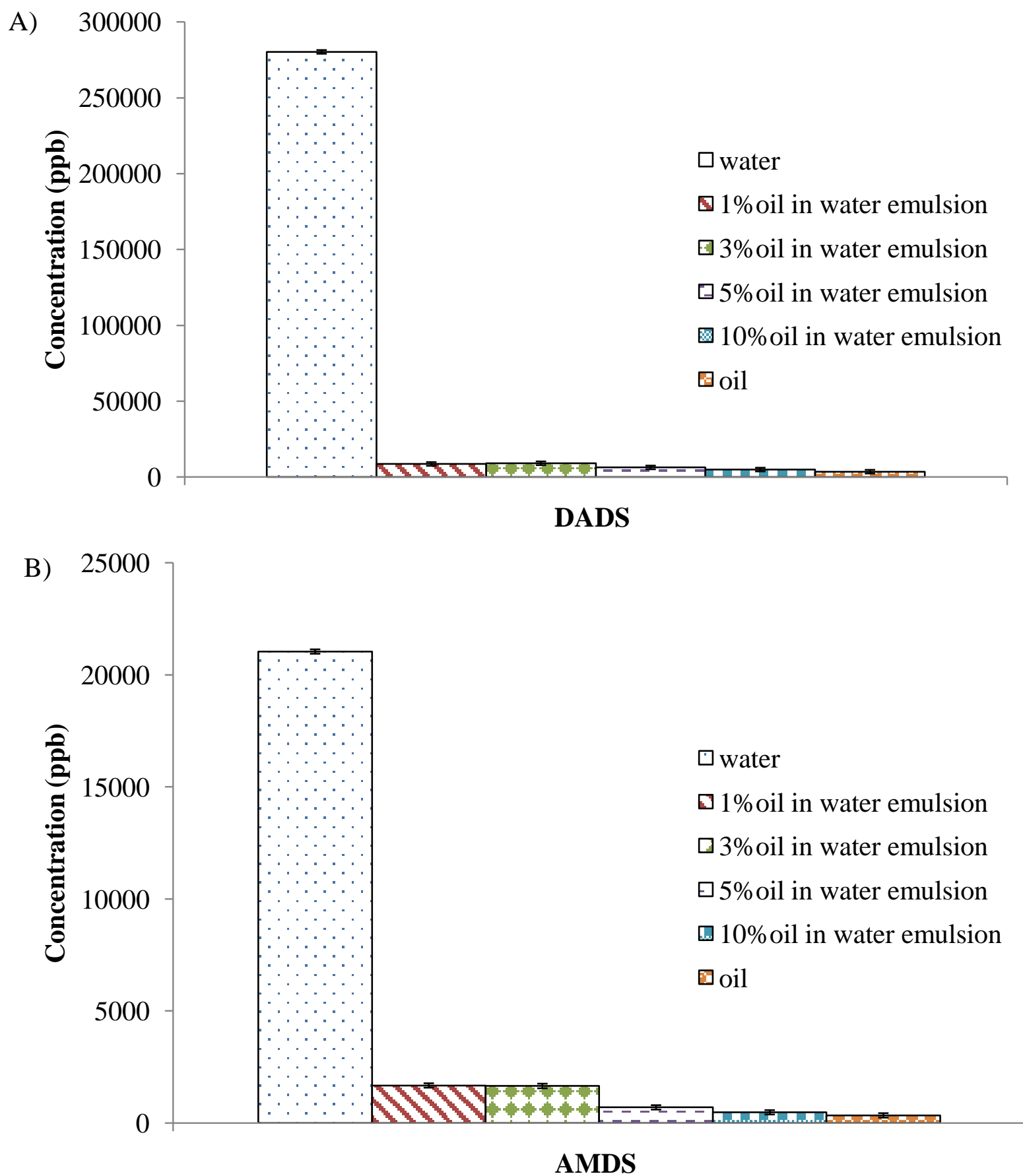


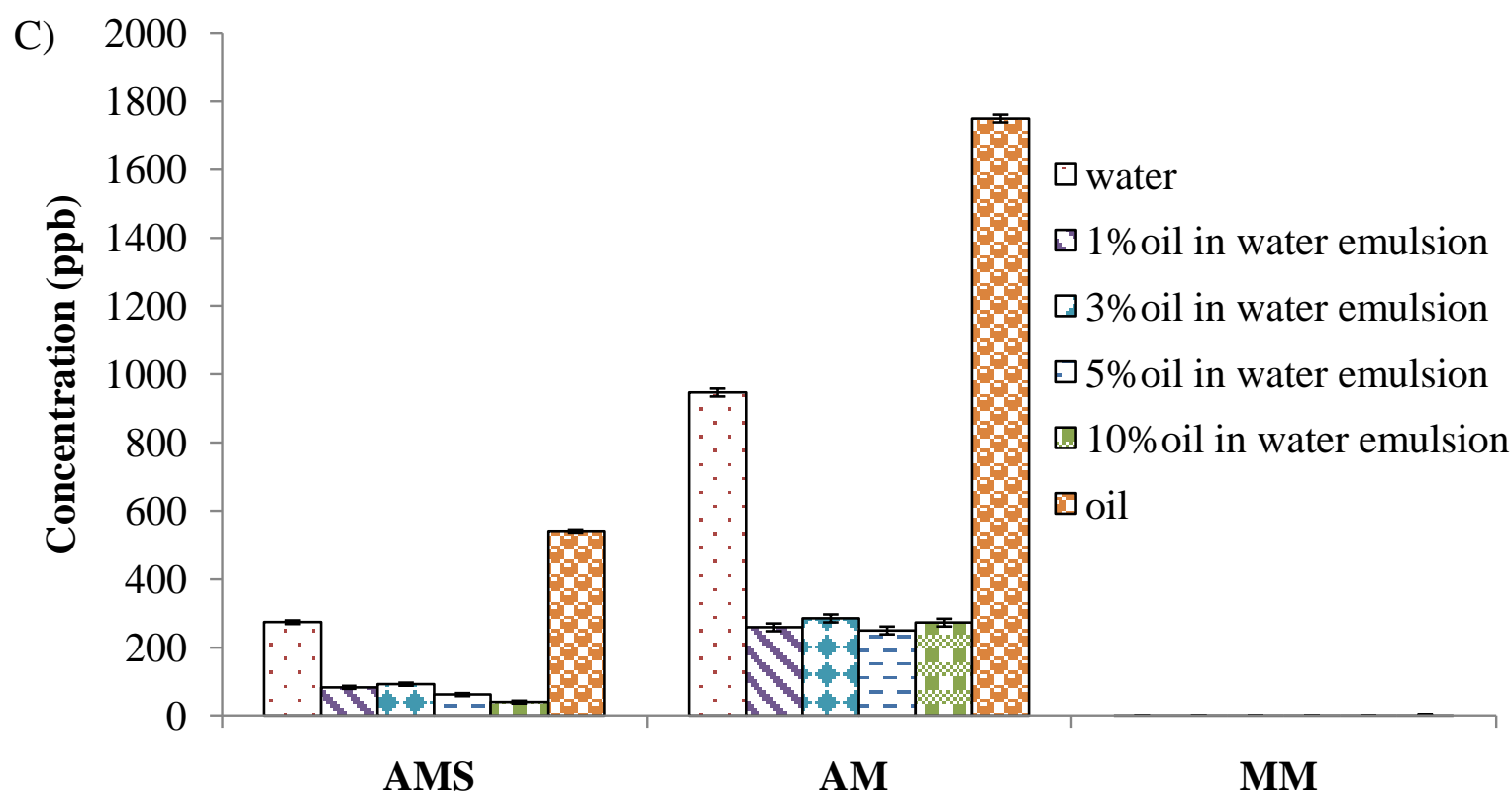

Figure A.2 Concentrations of A) diallyl disulfide (DADS), B) allyl methyl disulfide (AMDS), C) allyl methyl sulfide (AMS), allyl mercaptan (AM), and methyl mercaptan (MM) in the headspace of chopped blanched garlic. Chopped garlic was heated in $99^{\circ} \mathrm{C}$ water bath for $10 \mathrm{~min}$ and cooled in ice for $5 \mathrm{~min}$. 1\% Tween 80 was added in all oil-in-water emulsions. Distilled water and pure canola oil were used as controls. Values represent least square mean \pm standard error $(n=3)$. 
Table A.3 Concentrations of diallyl disulfide (DADS), allyl methyl sulfide (AMS), allyl methyl disulfide (AMDS), allyl mercaptan (AM), and methyl mercaptan (MM) in the headspace of chopped unblanched garlic. 1\% Tween 80 was added in all samples. Values represent least square mean \pm standard error $(n=3)$.

\begin{tabular}{|c|c|c|c|c|c|}
\hline \multirow{2}{*}{ Treatments } & \multicolumn{5}{|c|}{ Concentration (ppb) } \\
\cline { 2 - 6 } & DADS & AMS & AMDS & AM & MM \\
\hline 1\% Tween80 in water & $3592.18 \pm 59.59$ & $18.57 \pm 7.01$ & $1063.20 \pm 9.14$ & $311.15 \pm 4.52$ & $26.32 \pm 0.58$ \\
\hline 1\%oil in water emulsion & $2375.55 \pm 59.34$ & $14.31 \pm 6.99$ & $618.43 \pm 9.04$ & $352.30 \pm 4.67$ & $21.06 \pm 0.59$ \\
\hline 3\% oil in water emulsion & $1687.90 \pm 61.16$ & $18.37 \pm 7.01$ & $360.30 \pm 9.61$ & $280.41 \pm 4.92$ & $27.83 \pm 0.63$ \\
\hline 5\%oil in water emulsion & $2595.32 \pm 59.70$ & $23.16 \pm 7.01$ & $548.86 \pm 9.31$ & $336.13 \pm 4.55$ & $23.97 \pm 0.59$ \\
\hline $\mathbf{1 0 \%}$ il in water emulsion & $1382.81 \pm 61.03$ & $10.58 \pm 7.01$ & $261.70 \pm 9.44$ & $283.53 \pm 4.88$ & $18.87 \pm 0.63$ \\
\hline 1\% Tween80 in oil & $665.82 \pm 59.40$ & $607.46 \pm 7.00$ & $64.91 \pm 9.04$ & $694.43 \pm 4.80$ & $59.04 \pm 0.78$ \\
\hline
\end{tabular}




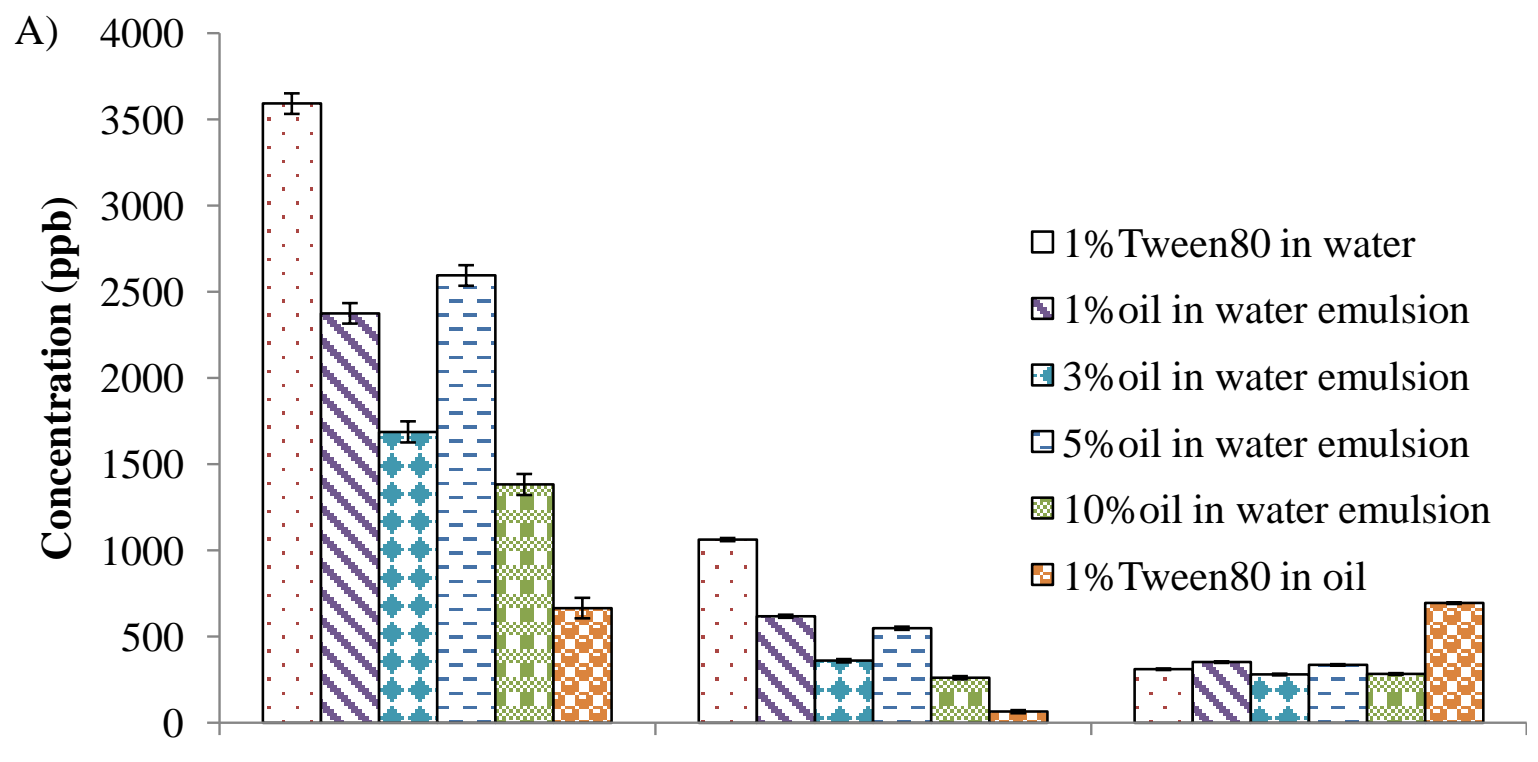

DADS AMDS

AM

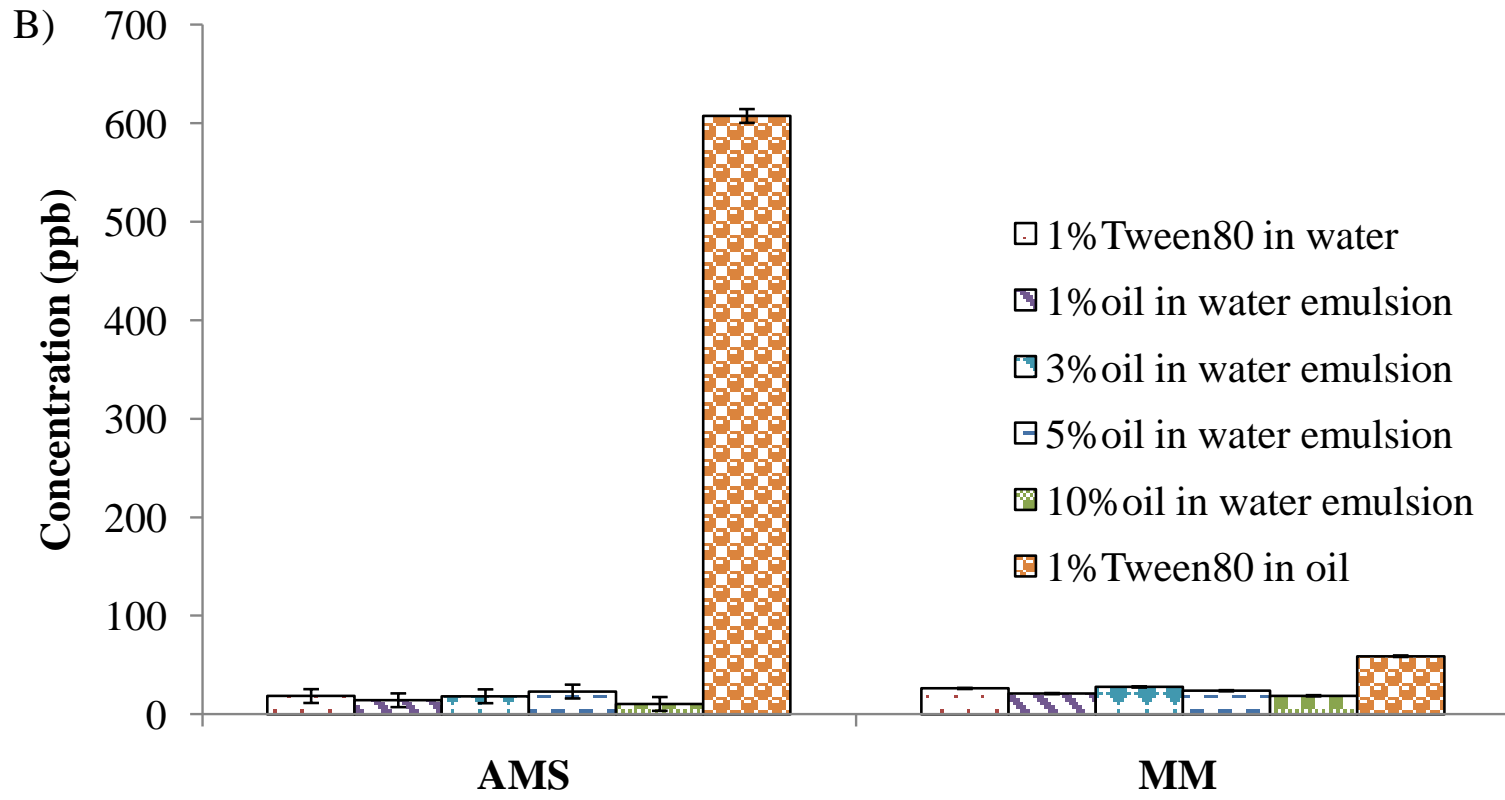

Figure A.3 Concentrations of A) diallyl disulfide (DADS), allyl methyl disulfide (AMDS), allyl mercaptan (AM), B) allyl methyl sulfide (AMS), and methyl mercaptan (MM) in the headspace of chopped unblanched garlic. 1\% Tween 80 was added in all samples. Values represent least square mean \pm standard error $(n=3)$. 
Table A.4 Concentrations of diallyl disulfide (DADS), allyl methyl sulfide (AMS), allyl methyl disulfide (AMDS), allyl mercaptan (AM), and methyl mercaptan (MM) in the headspace of chopped blanched garlic. Chopped garlic was heated in $99^{\circ} \mathrm{C}$ water bath for $10 \mathrm{~min}$ and cooled in ice for $5 \mathrm{~min} .1 \%$ Tween 80 was added in all samples. Values represent least square mean \pm standard error $(n=3)$.

\begin{tabular}{|c|c|c|c|c|c|}
\hline \multirow{2}{*}{ Treatments } & \multicolumn{5}{|c|}{ Concentration (ppb) } \\
\cline { 2 - 6 } & DADS & AMS & AMDS & AM & MM \\
\hline 1\% Tween80 in water & $18386.87 \pm 254.72$ & $109.07 \pm 2.01$ & $4406.93 \pm 50.33$ & $386.41 \pm 10.60$ & $1.52 \pm 0.16$ \\
\hline 1\%oil in water emulsion & $11556.79 \pm 260.28$ & $83.91 \pm 2.01$ & $2331.3 \pm 50.81$ & $390.67 \pm 10.61$ & $1.63 \pm 0.16$ \\
\hline $\mathbf{3 \%}$ oil in water emulsion & $8465.16 \pm 258.18$ & $76.76 \pm 2.00$ & $1399.2 \pm 50.33$ & $358.27 \pm 10.77$ & $1.96 \pm 0.16$ \\
\hline $\mathbf{5 \%}$ oil in water emulsion & $8641.54 \pm 255.07$ & $55.08 \pm 2.04$ & $832.61 \pm 50.36$ & $408.27 \pm 10.89$ & $1.73 \pm 0.16$ \\
\hline $\mathbf{1 0 \%}$ oil in water emulsion & $8303.05 \pm 254.87$ & $47.35 \pm 2.01$ & $769.69 \pm 50.66$ & $367.43 \pm 10.59$ & $1.12 \pm 0.16$ \\
\hline 1\%Tween80 in oil & $5210.41 \pm 273.04$ & $256.27 \pm 2.07$ & $253.86 \pm 52.31$ & $1520.37 \pm 10.58$ & $2.6 \pm 0.16$ \\
\hline
\end{tabular}



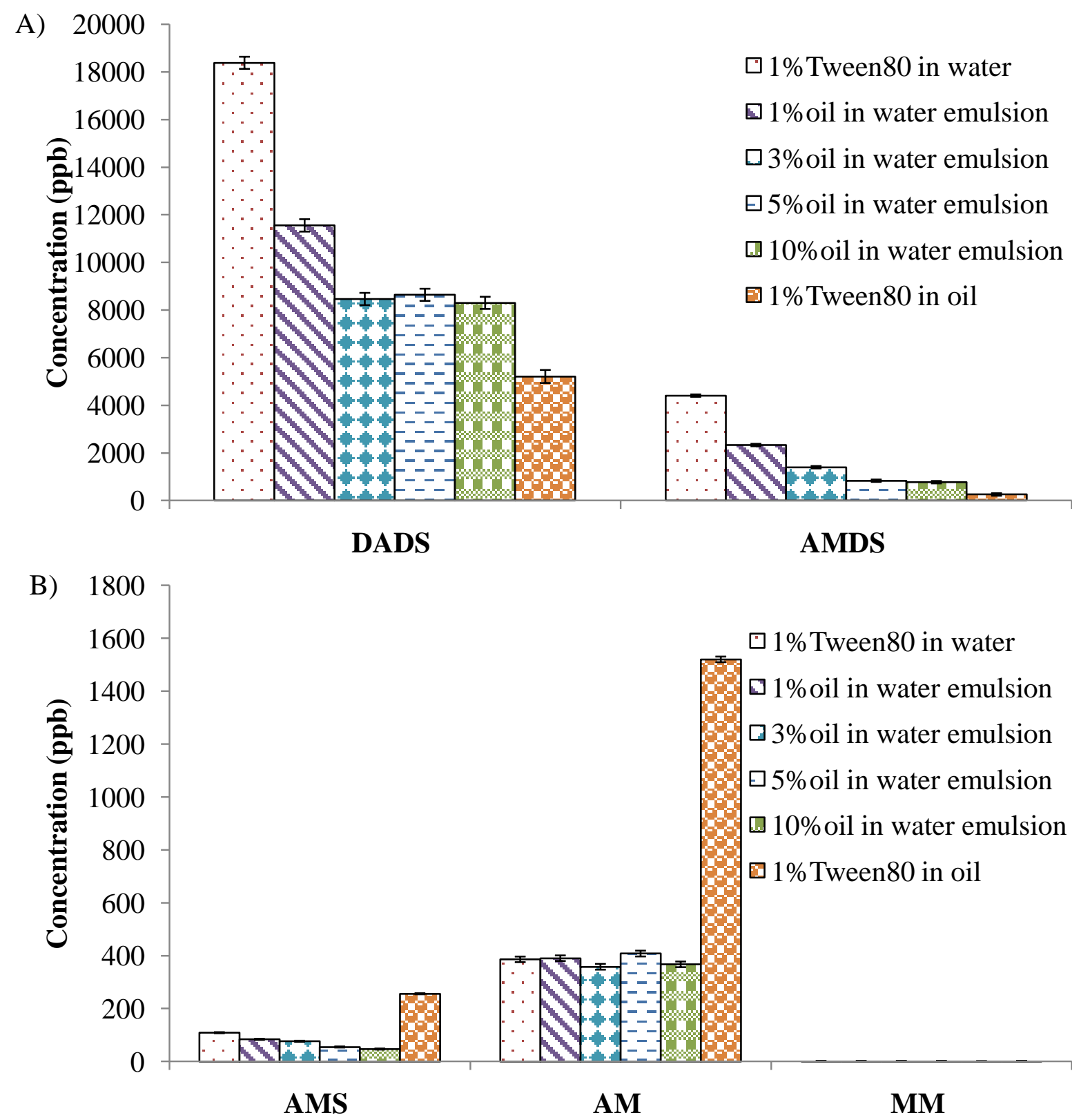

Figure A.4 Concentrations of A) diallyl disulfide (DADS), allyl methyl disulfide (AMDS), B) allyl methyl sulfide (AMS), allyl mercaptan (AM), and methyl mercaptan (MM) in the headspace of chopped blanched garlic. Chopped garlic was heated in $99^{\circ} \mathrm{C}$ water bath for $10 \mathrm{~min}$ and cooled in ice for $5 \mathrm{~min} .1 \%$ Tween 80 was added in all samples. Values represent least square mean \pm standard error $(n=3)$. 
A)

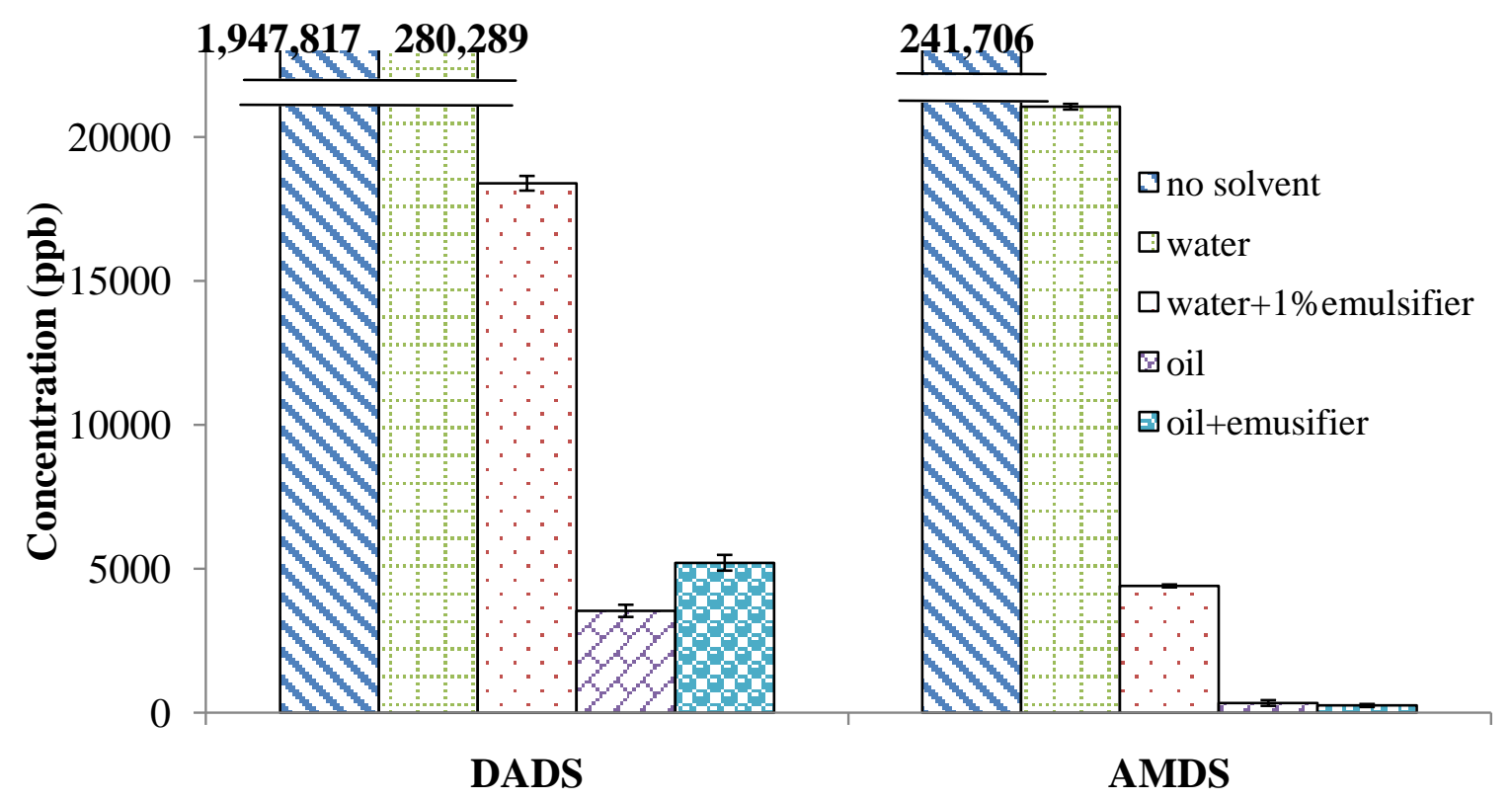

B)

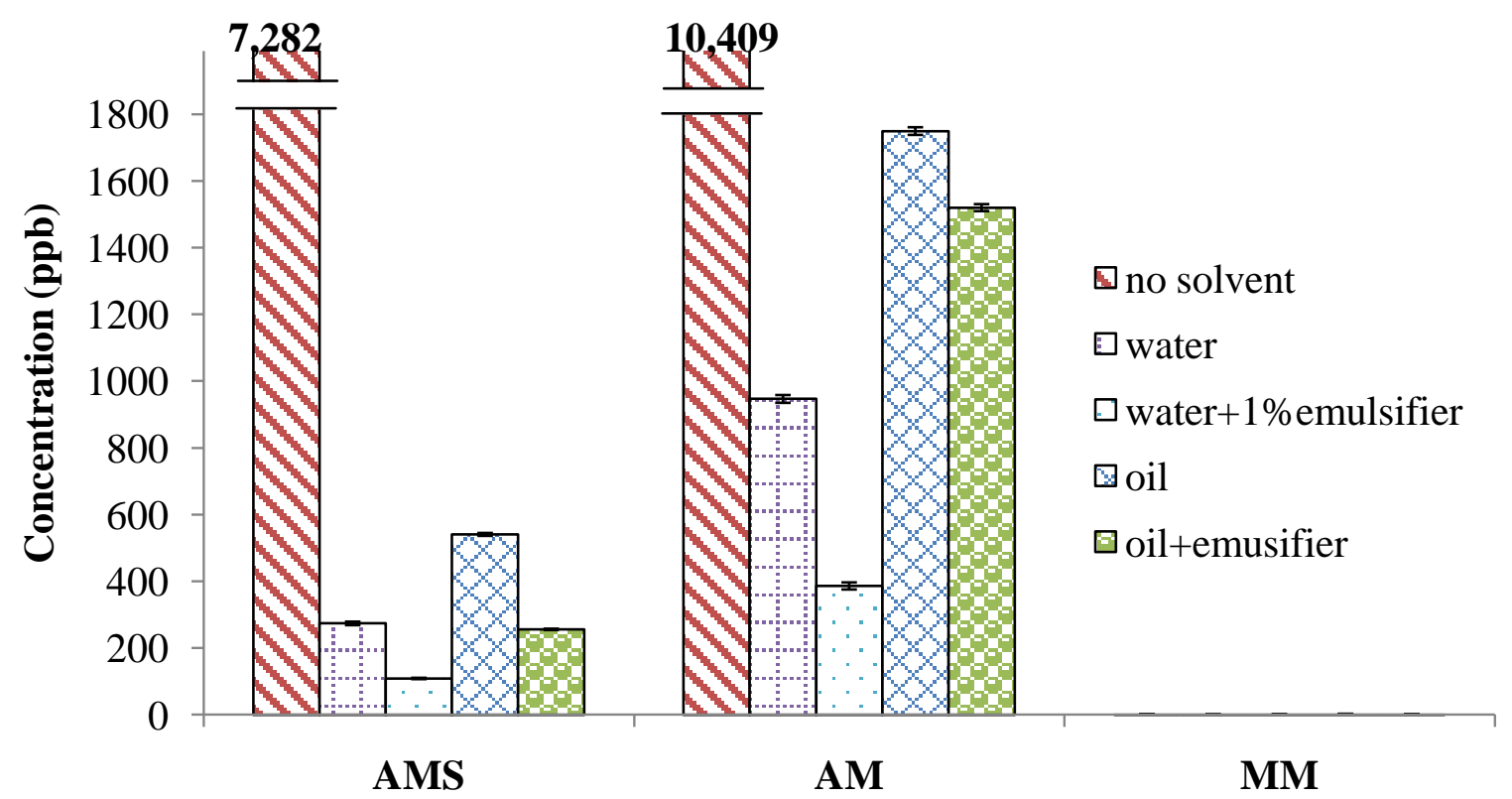

Figure A.5 Effect of solutions with different polarity on the concentrations of A) diallyl disulfide (DADS), allyl methyl disulfide (AMDS), B) allyl methyl sulfide (AMS), allyl mercaptan (AM), and methyl mercaptan (MM) in the headspace of chopped blanched garlic. 

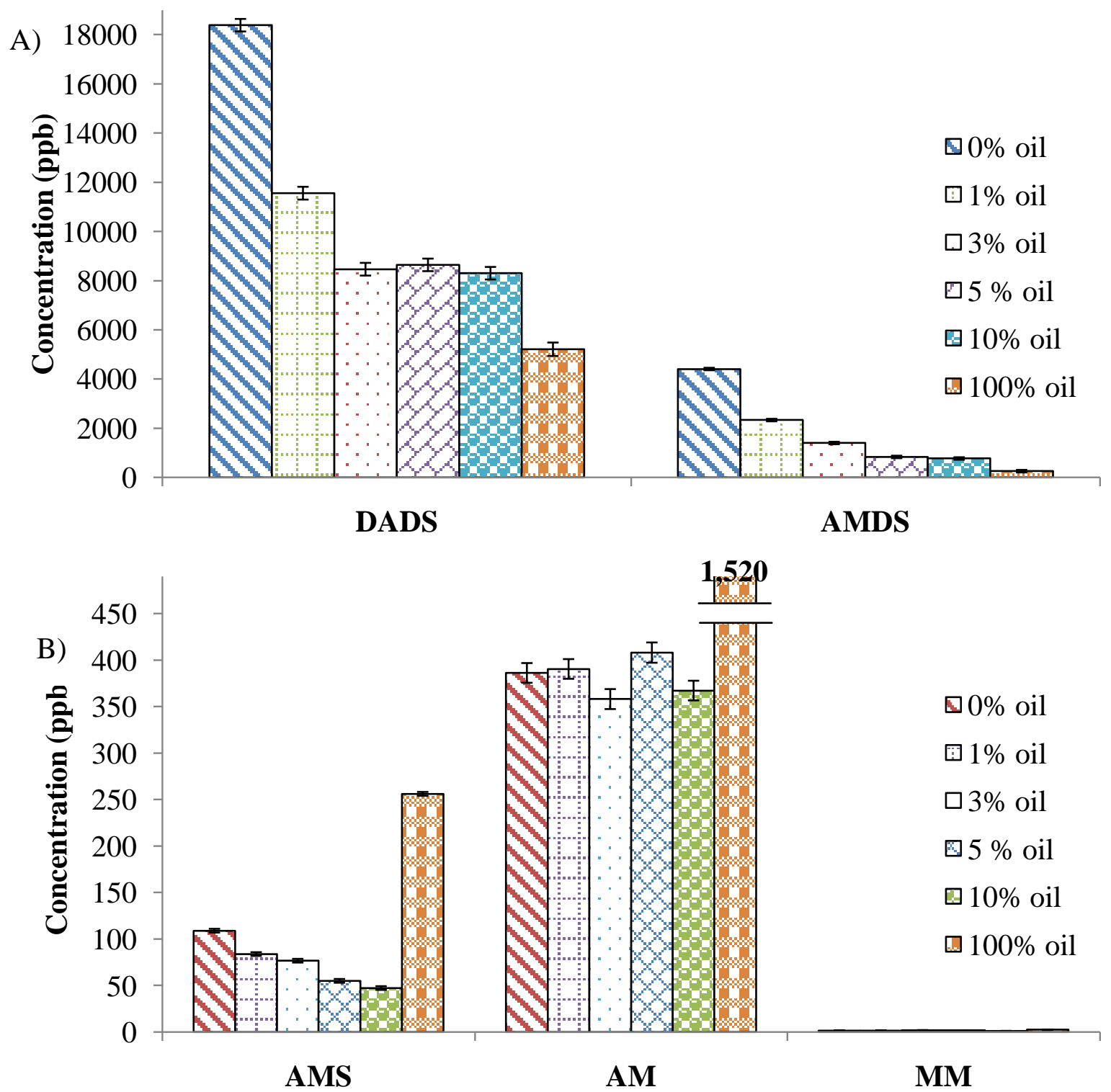

Figure A.6 Effect of canola oil concentration on the concentrations of A) diallyl disulfide (DADS), allyl methyl disulfide (AMDS), B) allyl methyl sulfide (AMS), allyl mercaptan (AM), and methyl mercaptan (MM) in the headspace of chopped blanched garlic in oilin-water emulsions. 
Table A.5 Effect of sodium caseinate concentrations on the reduction of diallyl disulfide (DADS), allyl methyl sulfide (AMS), allyl methyl disulfide (AMDS), allyl mercaptan (AM), and methyl mercaptan (MM) in the headspace of chopped unblanched garlic. Values represent least square mean \pm standard error $(n=3)$.

\begin{tabular}{|c|c|c|c|c|c|}
\hline \multirow{2}{*}{ Treatments } & \multicolumn{5}{|c|}{ Concentration (ppb) } \\
\cline { 2 - 6 } & DADS & AMS & AMDS & AM & MM \\
\hline water & $17123.11 \pm 159.50$ & $23.04 \pm 0.68$ & $2223.2 \pm 18.60$ & $381.69 \pm 5.17$ & $23.87 \pm 0.59$ \\
\hline 1\% sodium caseinate & $16321.71 \pm 157.67$ & $24.85 \pm 0.71$ & $2232.91 \pm 18.81$ & $465.54 \pm 5.21$ & $25.52 \pm 0.59$ \\
\hline 3\% sodium caseinate & $15246.72 \pm 174.33$ & $25.31 \pm 0.71$ & $2205.42 \pm 20.24$ & $459.81 \pm 5.31$ & $24.42 \pm 0.59$ \\
\hline $\mathbf{5 \%}$ sodium caseinate & $13457.35 \pm 158.16$ & $21.99 \pm 0.68$ & $2022.64 \pm 18.63$ & $388.16 \pm 5.16$ & $22.95 \pm 0.59$ \\
\hline $\mathbf{1 0 \%}$ sodium caseinate & $12487.06 \pm 167.36$ & $30.13 \pm 0.74$ & $2097.53 \pm 21.41$ & $423.93 \pm 5.44$ & $31.37 \pm 0.60$ \\
\hline
\end{tabular}

Table A.6 Effect of sodium caseinate concentrations on the reduction of diallyl disulfide (DADS), allyl methyl sulfide (AMS), allyl methyl disulfide (AMDS), allyl mercaptan (AM), and methyl mercaptan (MM) in the headspace of chopped blanched garlic. Values represent least square mean \pm standard error $(n=3)$.

\begin{tabular}{|c|c|c|c|c|c|}
\hline \multirow{2}{*}{ Treatments } & \multicolumn{5}{|c|}{ Concentration (ppb) } \\
\cline { 2 - 7 } & DADS & AMS & AMDS & \multicolumn{1}{c|}{ AM } & \multicolumn{1}{c|}{ MM } \\
\hline water & $247367.67 \pm 4128.88$ & $358.71 \pm 5.48$ & $17300.64 \pm 252.98$ & $1549.86 \pm 25.55$ & $1.26 \pm 0.20$ \\
\hline 1\% sodium caseinate & $241859.96 \pm 4074.75$ & $283.62 \pm 5.81$ & $16713.34 \pm 244.58$ & $1546.87 \pm 25.59$ & $1.5 \pm 0.20$ \\
\hline 3\% sodium caseinate & $109981.1 \pm 4344.26$ & $241.81 \pm 5.52$ & $10859.34 \pm 261.43$ & $773.47 \pm 25.58$ & $1.6 \pm 0.20$ \\
\hline 5\% sodium caseinate & $205003.72 \pm 4540.71$ & $371.79 \pm 5.40$ & $15381.2 \pm 298.71$ & $1357.31 \pm 25.06$ & $1.71 \pm 0.20$ \\
\hline 10\% sodium caseinate & $116095.18 \pm 4065.21$ & $291.56 \pm 5.67$ & $11065.95 \pm 245.69$ & $912.8 \pm 25.75$ & $1.57 \pm 0.20$ \\
\hline
\end{tabular}




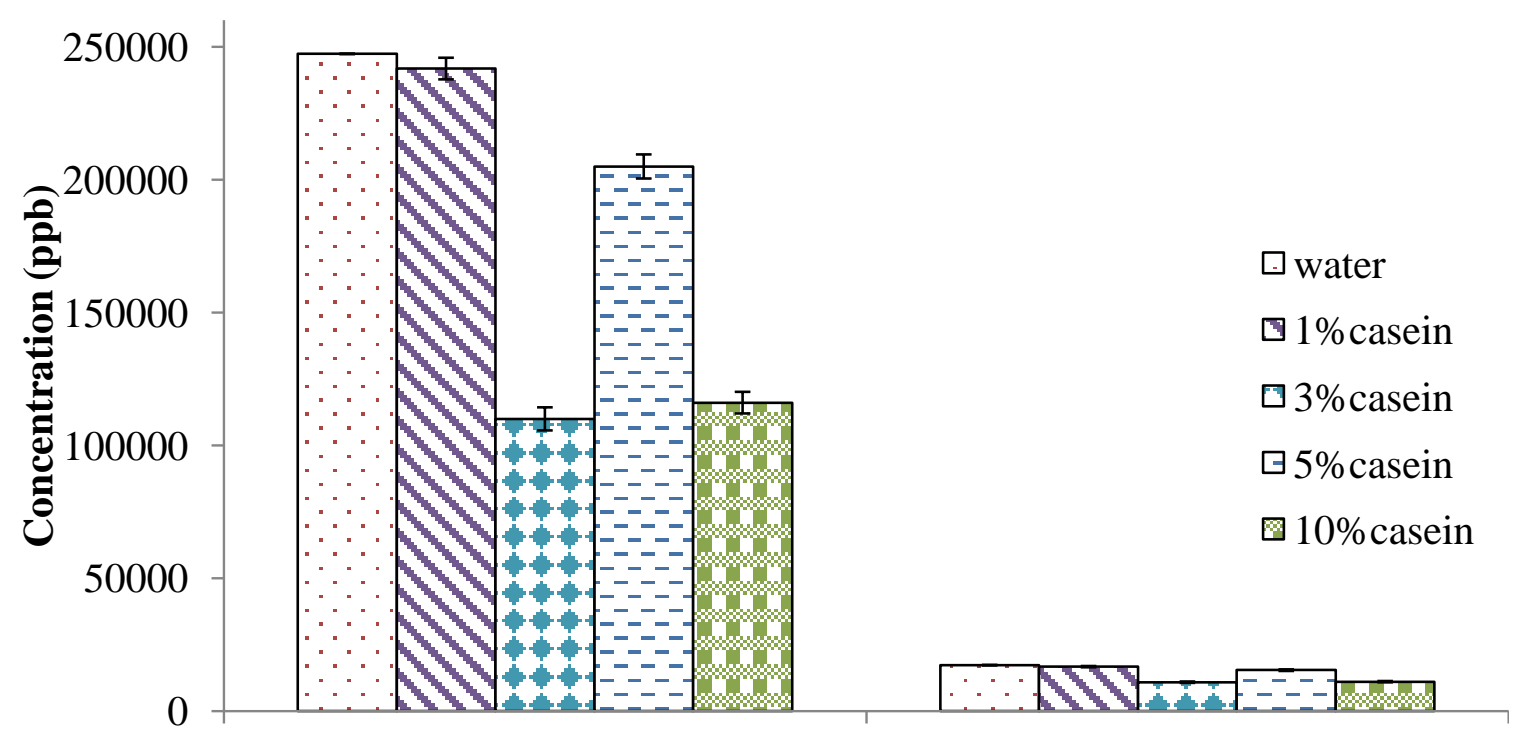

DADS

AMDS

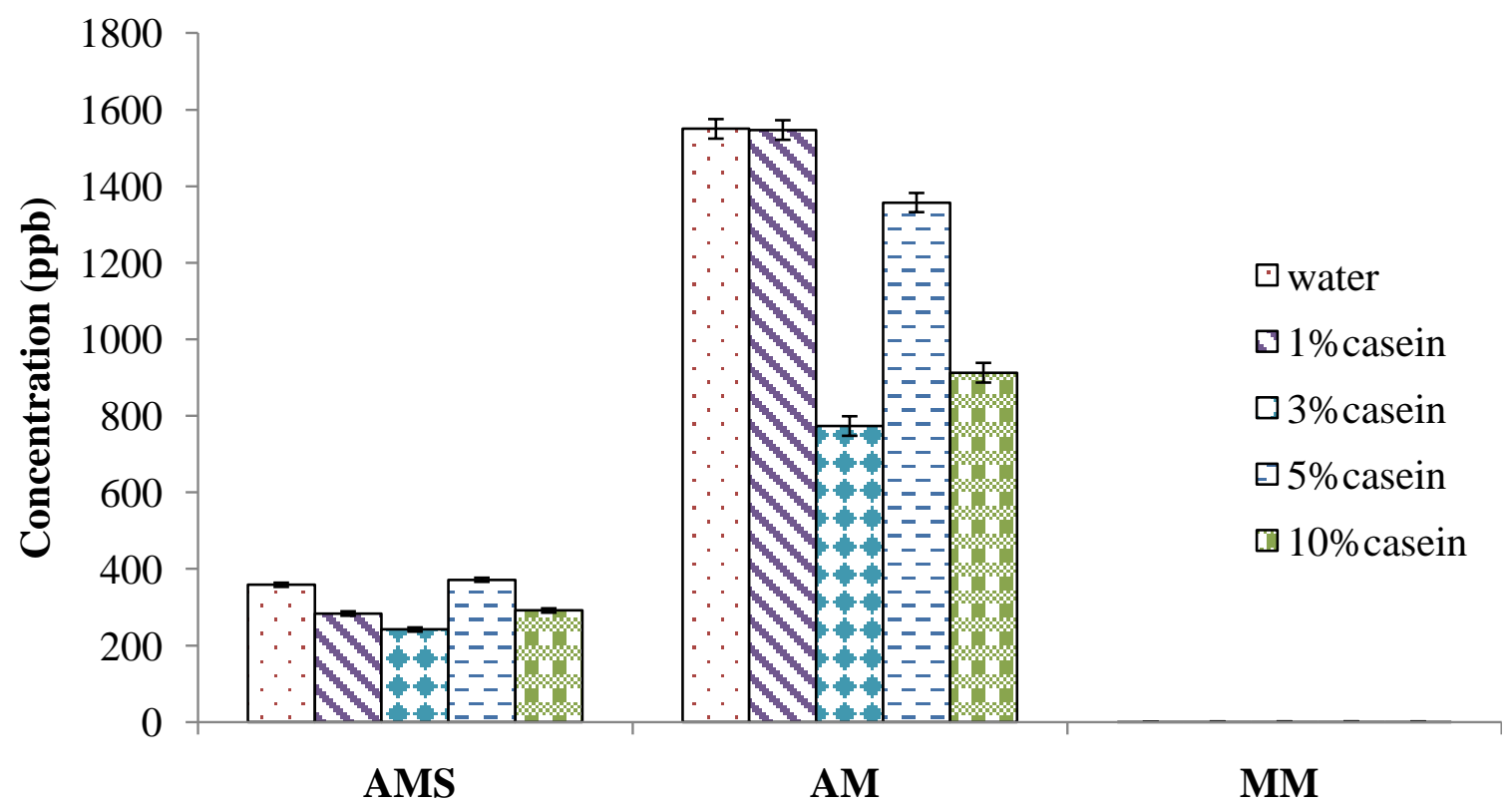

Figure A.7 Effect of sodium caseinate on the concentrations of the more hydrophobic compounds: diallyl disulfide (DADS) and allyl methyl disulfide (AMDS) and the more hydrophilic compounds: allyl methyl sulfide (AMS), allyl mercaptan (AM), and methyl mercaptan (MM) in the headspace of blanched chopped garlic in aqueous solutions. 
Table A.7 Effect of lactose concentrations on the reduction of diallyl disulfide (DADS), allyl methyl sulfide (AMS), allyl methyl disulfide (AMDS), allyl mercaptan (AM), and methyl mercaptan (MM) in the headspace of chopped unblanched garlic. Values represent least square mean \pm standard error $(n=3)$.

\begin{tabular}{|c|c|c|c|c|c|}
\hline \multirow{2}{*}{ Treatments } & \multicolumn{5}{|c|}{ Concentration (ppb) } \\
\cline { 2 - 6 } & DADS & AMS & AMDS & AM & MM \\
\hline water & $47897.3 \pm 488.10$ & $101.07 \pm 2.22$ & $5793.52 \pm 49.88$ & $1576.56 \pm 21.08$ & $70.22 \pm 1.42$ \\
\hline $\mathbf{1 \% l a c t o s e}$ & $48614.78 \pm 503.59$ & $82.64 \pm 2.20$ & $5130.26 \pm 50.57$ & $1143.32 \pm 18.80$ & $57.64 \pm 1.47$ \\
\hline 3\%lactose & $49084.12 \pm 492.26$ & $87.21 \pm 2.23$ & $5462.33 \pm 50.72$ & $1394.49 \pm 19.46$ & $59.71 \pm 1.36$ \\
\hline 5\%lactose & $46398 \pm 525.33$ & $66.77 \pm 2.64$ & $5377.06 \pm 51.04$ & $1503 \pm 20.34$ & $64.69 \pm 1.39$ \\
\hline $\mathbf{1 0 \% l a c t o s e}$ & $42684.05 \pm 505.89$ & $62.21 \pm 2.24$ & $4784.46 \pm 50.12$ & $1399.06 \pm 19.82$ & $58.07 \pm 1.35$ \\
\hline
\end{tabular}

Table A.8 Effect of lactose concentrations on the reduction of diallyl disulfide (DADS), allyl methyl sulfide (AMS), allyl methyl disulfide (AMDS), allyl mercaptan (AM), and methyl mercaptan (MM) in the headspace of chopped blanched garlic. Values represent least square mean \pm standard error $(n=3)$.

\begin{tabular}{|c|c|c|c|c|c|}
\hline \multirow{2}{*}{ Treatments } & \multicolumn{5}{|c|}{ Concentration (ppb) } \\
\cline { 2 - 6 } & DADS & AMS & AMDS & AM & MM \\
\hline water & $138908.38 \pm 2905.41$ & $150.99 \pm 2.78$ & $10427.83 \pm 186.81$ & $364.93 \pm 14.08$ & $0.97 \pm 0.15$ \\
\hline 1\%lactose & $209076.04 \pm 2874.06$ & $177.01 \pm 2.70$ & $13674.13 \pm 186.04$ & $653.07 \pm 13.80$ & $0.59 \pm 0.15$ \\
\hline 3\%lactose & $193241.32 \pm 2873.27$ & $139.7 \pm 2.68$ & $11937.99 \pm 186.24$ & $505.8 \pm 13.80$ & $0.79 \pm 0.15$ \\
\hline 5\%lactose & $227052.64 \pm 2870.72$ & $195.02 \pm 2.67$ & $13594.79 \pm 185.88$ & $850.63 \pm 13.92$ & $0.69 \pm 0.15$ \\
\hline $\mathbf{1 0 \% l a c t o s e}$ & $155556.65 \pm 2874.07$ & $121.27 \pm 2.85$ & $9908.34 \pm 185.86$ & $541.8 \pm 13.82$ & $1.17 \pm 0.15$ \\
\hline
\end{tabular}



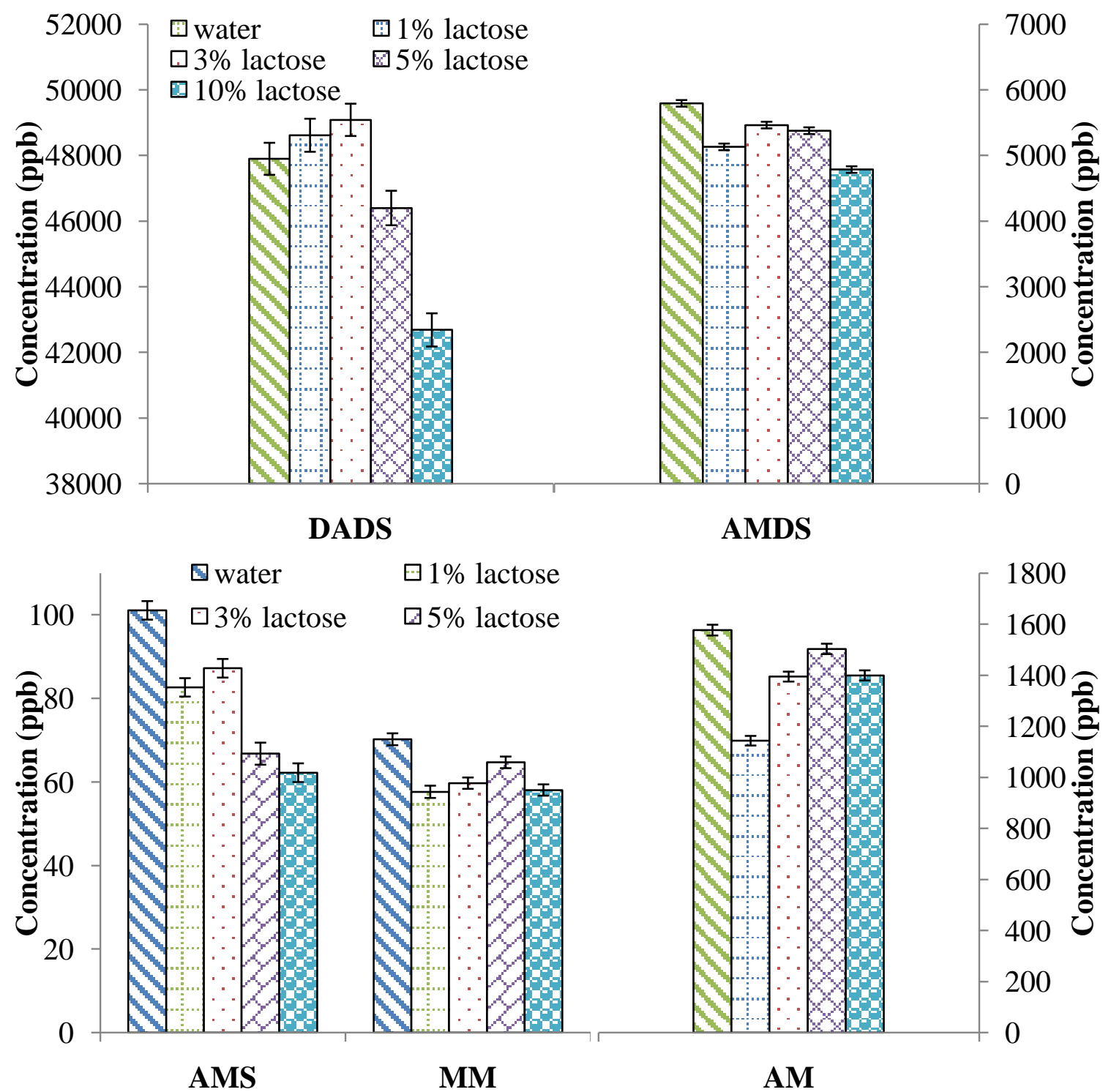

Figure A. 8 Effect of lactose on the concentrations of A) diallyl disulfide (DADS), allyl methyl disulfide (AMDS), B) allyl mercaptan (AM), allyl methyl sulfide (AMS), and methyl mercaptan (MM) in the headspace of chopped unblanched garlic in aqueous solutions. Allyl methyl disulfide (AMDS) and allyl mercaptan (AM) are on the secondary axis. 


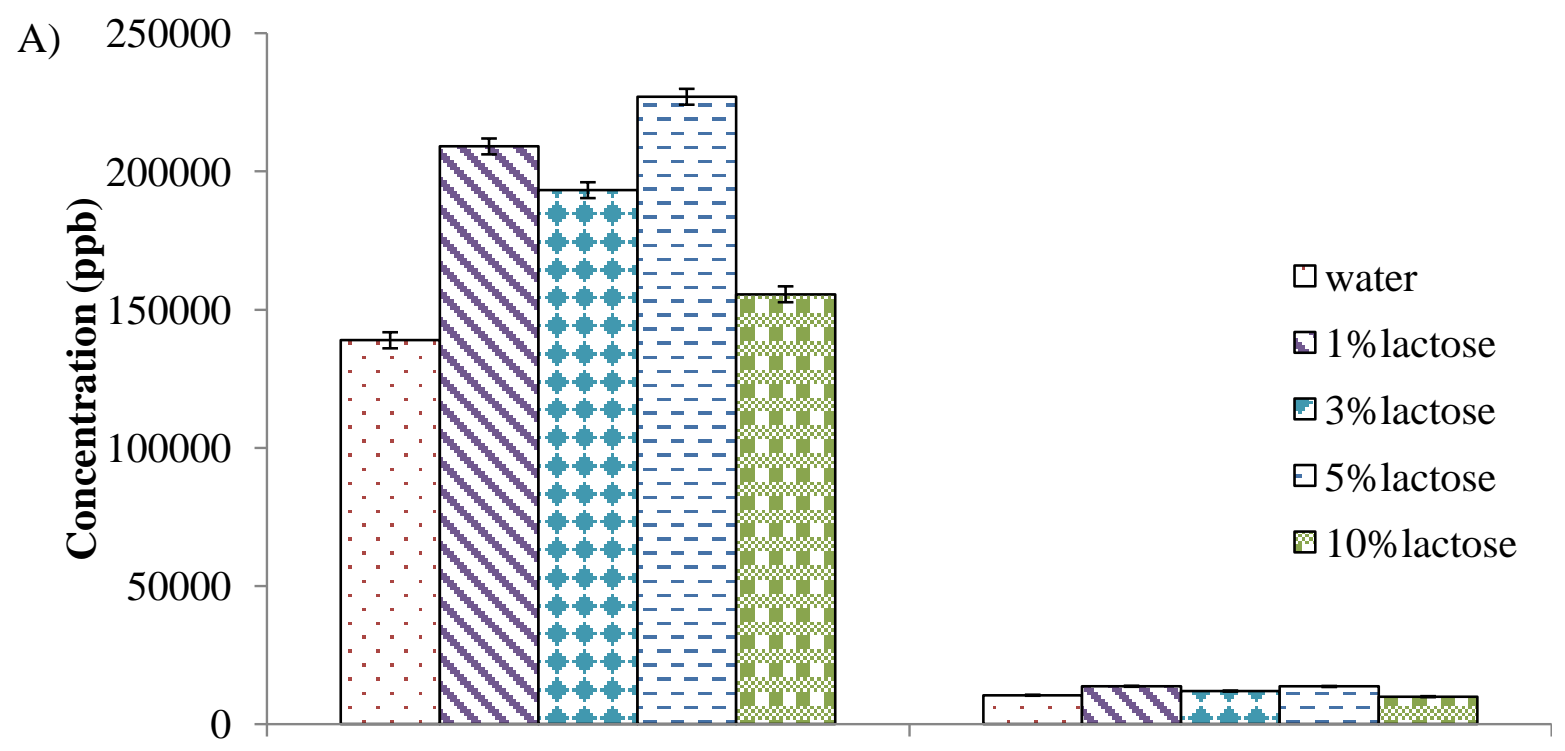

DADS

AMDS

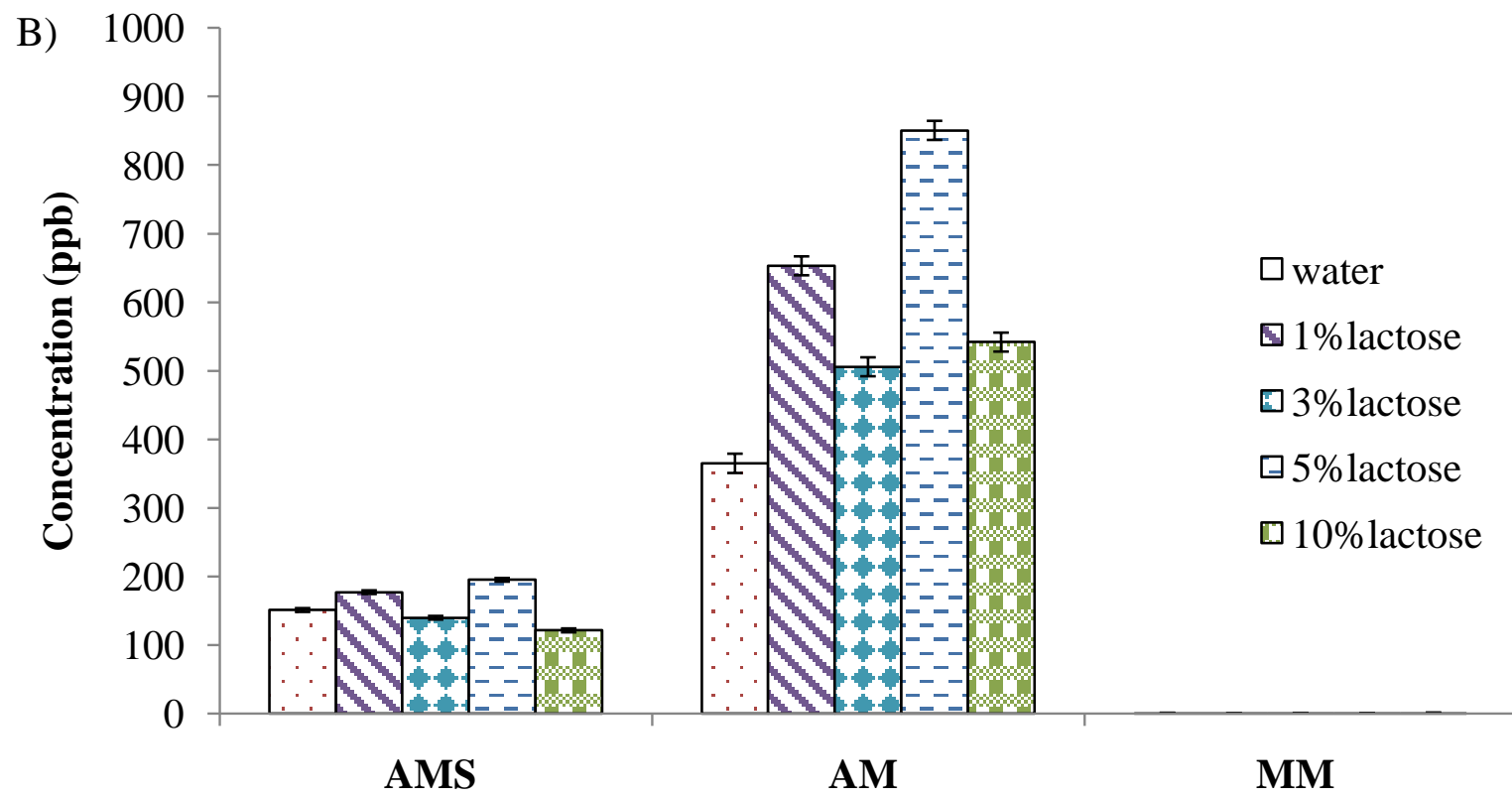

Figure A.9 Effect of lactose on the concentrations of A) diallyl disulfide (DADS), allyl methyl disulfide (AMDS), B) allyl methyl sulfide (AMS), allyl mercaptan (AM), and methyl mercaptan (MM) in the headspace of chopped blanched garlic in aqueous solutions. 
Table A.9 Effect of milk on the reduction of diallyl disulfide (DADS), allyl methyl sulfide (AMS), allyl methyl disulfide (AMDS), allyl mercaptan (AM), and methyl mercaptan (MM) in the headspace of chopped unblanched garlic. Values represent least square mean \pm standard error $(n=3)$.

\begin{tabular}{|c|c|c|c|c|c|c|}
\hline & \multicolumn{7}{|c|}{ concentration (ppb) } \\
\cline { 2 - 7 } & no solvent & water & fat-free milk & whole milk & 3\% oil & 3\% casein \\
\hline DADS & $53004 \pm 686$ & $17322 \pm 192$ & $17142 \pm 192$ & $12963 \pm 187$ & $1688 \pm 174$ & $15247 \pm 492$ \\
\hline AMS & $1709 \pm 40$ & $22 \pm 1$ & $25 \pm 1$ & $27 \pm 1$ & $-6 \pm 1$ & $25 \pm 2$ \\
\hline AMDS & $8064 \pm 96$ & $2203 \pm 20$ & $2101 \pm 20$ & $1001 \pm 20$ & $360 \pm 20$ & $2205 \pm 51$ \\
\hline AM & $2345 \pm 22$ & $371 \pm 5$ & $337 \pm 5$ & $458 \pm 5$ & $280 \pm 5$ & $460 \pm 19$ \\
\hline MM & $95 \pm 2$ & $23 \pm 1$ & $20 \pm 1$ & $30 \pm 1$ & $28 \pm 1$ & $24 \pm 1$ \\
\hline
\end{tabular}

Table A.10 Concentration of diallyl disulfide (DADS) in the mouth for 60 minutes after ingestion of garlic or chopped garlic in water, fat-free milk, whole milk, or $10 \%$ casein. Values represent least square mean \pm standard error $(n=3)$.

\begin{tabular}{|c|c|c|c|c|c|c|c|}
\hline \multirow{2}{*}{$\begin{array}{c}\text { Treatments/ } \\
\text { time (min) }\end{array}$} & \multicolumn{7}{|c|}{ Concentration of DADS (ppb) } \\
\cline { 2 - 9 } & $\mathbf{3}$ & $\mathbf{6}$ & $\mathbf{9}$ & $\mathbf{1 2}$ & $\mathbf{1 5}$ & $\mathbf{3 0}$ & $\mathbf{6 0}$ \\
\hline no solvent & $924.24 \pm 22.27$ & $503.48 \pm 14.72$ & $366.95 \pm 11.55$ & $280.33 \pm 9.82$ & $214.41 \pm 6.73$ & $90.97 \pm 3.01$ & $21.14 \pm 0.93$ \\
\hline water & $52.37 \pm 2.91$ & $13.67 \pm 1.07$ & $4.94 \pm 1.04$ & $3.46 \pm 0.51$ & $1.73 \pm 0.83$ & $0.75 \pm 0.42$ & $0.8 \pm 0.56$ \\
\hline $\begin{array}{c}\text { fat-free } \\
\text { milk }\end{array}$ & $74.65 \pm 2.91$ & $19.49 \pm 1.07$ & $12.61 \pm 1.04$ & $7.26 \pm 0.51$ & $4.95 \pm 0.83$ & $1.22 \pm 0.42$ & $1.67 \pm 0.56$ \\
\hline whole milk & $40.95 \pm 2.91$ & $7.57 \pm 1.07$ & $4.51 \pm 1.04$ & $2.15 \pm 0.51$ & $2.08 \pm 0.83$ & $0.94 \pm 0.42$ & $0.46 \pm 0.56$ \\
\hline $\mathbf{1 0 \%}$ casein & $35.96 \pm 2.91$ & $9.98 \pm 1.07$ & $3.86 \pm 1.04$ & $1.69 \pm 0.51$ & $0.62 \pm 0.83$ & $0.36 \pm 0.42$ & $0.24 \pm 0.56$ \\
\hline
\end{tabular}


Table A.11 Concentration of allyl mercaptan (AM) in the mouth for 60 minutes after ingestion of garlic or chopped garlic in water, fat-free milk, whole milk, or $10 \%$ casein. Values represent least square mean \pm standard error $(n=3)$.

\begin{tabular}{|c|c|c|c|c|c|c|c|}
\hline \multirow{2}{*}{$\begin{array}{l}\text { Treatments/ } \\
\text { time (min) }\end{array}$} & \multicolumn{7}{|c|}{ AM LSMEAN (ppb) } \\
\hline & 3 & 6 & 9 & 12 & 15 & 30 & 60 \\
\hline no solvent & $699.62 \pm 24.63$ & $463.54 \pm 21.30$ & $367.1 \pm 17.16$ & $267.28 \pm 13.77$ & $211.32 \pm 9.61$ & $94.04 \pm 4.59$ & $24.03 \pm 1.13$ \\
\hline water & $57.94 \pm 12.67$ & $21.7 \pm 5.46$ & $12.48 \pm 3.16$ & $7.64 \pm 1.77$ & $2.12 \pm 1.51$ & $0.55 \pm 0.72$ & $0.78 \pm 0.62$ \\
\hline $\begin{array}{c}\text { fat-free } \\
\text { milk }\end{array}$ & $92.65 \pm 12.67$ & $36.37 \pm 5.46$ & $20.38 \pm 3.16$ & $9.88 \pm 1.77$ & $7.65 \pm 1.51$ & $1.71 \pm 0.72$ & $1.27 \pm 0.62$ \\
\hline whole milk & $59.06 \pm 12.67$ & $17.29 \pm 5.46$ & $7.9 \pm 3.16$ & $4.13 \pm 1.77$ & $2.74 \pm 1.51$ & $1.44 \pm 0.72$ & $1.00 \pm 0.62$ \\
\hline $10 \%$ casein & $45.53 \pm 12.67$ & $17.9 \pm 5.46$ & $9.48 \pm 3.16$ & $4.66 \pm 1.77$ & $2.74 \pm 1.51$ & $1.68 \pm 0.72$ & $0.49 \pm 0.62$ \\
\hline
\end{tabular}

Table A.12 Concentration of allyl methyl disulfide (AMDS) in the mouth for 60 minutes after ingestion of garlic or chopped garlic in water, fat-free milk, whole milk, or $10 \%$ casein. Values represent least square mean \pm standard error $(n=3)$.

\begin{tabular}{|c|c|c|c|c|c|c|c|}
\hline \multirow{2}{*}{ Treatments/time (min) } & \multicolumn{5}{|c|}{ AMDS LSMEAN (ppb) } \\
\cline { 2 - 8 } & $\mathbf{3}$ & $\mathbf{6}$ & $\mathbf{9}$ & $\mathbf{1 2}$ & $\mathbf{1 5}$ & $\mathbf{3 0}$ & $\mathbf{6 0}$ \\
\hline no solvent & $113.7 \pm 3.47$ & $49.7 \pm 1.65$ & $34.1 \pm 1.33$ & $27.03 \pm 1.04$ & $22.88 \pm 0.94$ & $13.47 \pm 0.57$ & $9.01 \pm 0.41$ \\
\hline water & $9.22 \pm 1.47$ & $6.21 \pm 1.74$ & $2.48 \pm 1.62$ & $2.71 \pm 1.93$ & $4.42 \pm 2.22$ & $4.16 \pm 3.74$ & $3.94 \pm 2.55$ \\
\hline fat-free milk & $10.62 \pm 1.47$ & $5.24 \pm 1.74$ & $4.75 \pm 1.62$ & $5.65 \pm 1.93$ & $5.2 \pm 2.22$ & $3.71 \pm 3.74$ & $4.31 \pm 2.55$ \\
\hline whole milk & $7.21 \pm 1.47$ & $8.97 \pm 1.74$ & $3.77 \pm 1.62$ & $4.52 \pm 1.93$ & $7.12 \pm 2.22$ & $5.96 \pm 3.74$ & $4.76 \pm 2.55$ \\
\hline $\mathbf{1 0 \%}$ casein & $6.7 \pm 1.47$ & $5.07 \pm 1.74$ & $2.34 \pm 1.62$ & $1.97 \pm 1.93$ & $4.11 \pm 2.22$ & $10.73 \pm 3.74$ & $3.8 \pm 2.55$ \\
\hline
\end{tabular}


Table A.13 Concentration of allyl methyl sulfide (AMS) in the mouth for 60 minutes after ingestion of garlic or chopped garlic in water, fat-free milk, whole milk, or $10 \%$ casein. Values represent least square mean \pm standard error $(n=3)$.

\begin{tabular}{|c|c|c|c|c|c|c|c|c|}
\hline \multirow{2}{*}{$\begin{array}{l}\text { Treatments/ } \\
\text { time (min) }\end{array}$} & \multicolumn{8}{|c|}{ AMS LSMEAN (ppb) } \\
\hline & 3 & 6 & 9 & 12 & 15 & 30 & 60 & 70 \\
\hline no solvent & $120.21 \pm 1.79$ & $109.95 \pm 1.98$ & $107.62 \pm 1.83$ & $102.01 \pm 1.83$ & $97.98 \pm 1.83$ & $81.74 \pm 1.79$ & $63.08 \pm 1.83$ & $60.91 \pm 0.94$ \\
\hline water & $42.47 \pm 0.91$ & $53.53 \pm 1.07$ & $58.07 \pm 1.19$ & $56.74 \pm 1.19$ & $55.11 \pm 1.04$ & $47.56 \pm 0.96$ & $50.54 \pm 1.00$ & $45.96 \pm 0.96$ \\
\hline $\begin{array}{c}\text { fat-free } \\
\text { milk }\end{array}$ & $38.19 \pm 0.92$ & $34.19 \pm 1.08$ & $31.51 \pm 1.20$ & $28.05 \pm 1.20$ & $29.11 \pm 1.03$ & $23.07 \pm 0.94$ & $24.99 \pm 0.99$ & $25.96 \pm 0.94$ \\
\hline whole milk & $32.39 \pm 0.91$ & $28.23 \pm 1.07$ & $28.52 \pm 1.22$ & $28.19 \pm 1.19$ & $29.06 \pm 1.03$ & $32.44 \pm 0.96$ & $34.24 \pm 1.01$ & $36.79 \pm 0.96$ \\
\hline $10 \%$ casein & $26.91 \pm 0.91$ & $25.63 \pm 1.07$ & $27.92 \pm 1.20$ & $29.21 \pm 1.20$ & $32.16 \pm 1.04$ & $38.08 \pm 0.96$ & $44.73 \pm 1.01$ & $45.60 \pm 0.96$ \\
\hline
\end{tabular}

Table A.14 Concentration of diallyl disulfide (DADS) in the mouth for 60 minutes after ingestion of garlic followed by $2 \%$ fat milk, green tea, or none. Values represent least square mean \pm standard error $(n=8)$.

\begin{tabular}{|c|c|c|c|c|c|c|c|}
\hline $\begin{array}{c}\text { Treatments/ } \\
\text { time (min) }\end{array}$ & \multicolumn{7}{|c|}{ Concentration of DADS (ppb) } \\
\cline { 2 - 8 } & $\mathbf{3}$ & $\mathbf{6}$ & $\mathbf{9}$ & $\mathbf{1 2}$ & $\mathbf{1 5}$ & $\mathbf{3 0}$ & $\mathbf{6 0}$ \\
\hline garlic & $924.24 \pm 22.27$ & $503.48 \pm 14.72$ & $366.95 \pm 11.55$ & $280.33 \pm 9.82$ & $214.41 \pm 6.73$ & $90.97 \pm 3.01$ & $21.14 \pm 0.93$ \\
\hline $\begin{array}{c}\text { garlic } \\
\text { followed by } \\
\mathbf{2 \%} \text { fat milk }\end{array}$ & $506.38 \pm 21.53$ & $406.23 \pm 14.53$ & $314.42 \pm 11.65$ & $228.40 \pm 9.80$ & $186.96 \pm 6.77$ & $68.2 \pm 2.86$ & $18.63 \pm 0.98$ \\
\hline $\begin{array}{c}\text { garlic } \\
\text { followed by } \\
\text { green tea }\end{array}$ & $531.19 \pm 23.09$ & $378.88 \pm 15.78$ & $265.35 \pm 12.39$ & $209.18 \pm 10.39$ & $162.11 \pm 7.17$ & $55.17 \pm 2.99$ & $19.86 \pm 0.97$ \\
\hline
\end{tabular}


Table A.15 Concentration of allyl mercaptan (AM) in the mouth for 60 minutes after ingestion of garlic followed by $2 \%$ fat milk, green tea, or none. Values represent least square mean \pm standard error $(n=8)$.

\begin{tabular}{|c|c|c|c|c|c|c|c|}
\hline $\begin{array}{c}\text { Treatments/ } \\
\text { time (min) }\end{array}$ & \multicolumn{7}{|c|}{ Concentration of AM (ppb) } \\
\cline { 2 - 8 } & $\mathbf{3}$ & $\mathbf{6}$ & $\mathbf{9}$ & $\mathbf{1 2}$ & $\mathbf{1 5}$ & $\mathbf{3 0}$ & $\mathbf{6 0}$ \\
\hline garlic & $699.62 \pm 24.63$ & $463.54 \pm 21.30$ & $367.1 \pm 17.16$ & $267.28 \pm 13.77$ & $211.32 \pm 9.61$ & $94.04 \pm 4.59$ & $24.03 \pm 1.13$ \\
\hline $\begin{array}{c}\text { garlic } \\
\text { followed by } \\
\mathbf{2 \%} \text { fat milk }\end{array}$ & $494.89 \pm 23.96$ & $472.89 \pm 21.03$ & $382.02 \pm 17.35$ & $285.09 \pm 13.77$ & $215.62 \pm 9.59$ & $71.12 \pm 4.32$ & $22.63 \pm 1.19$ \\
\hline $\begin{array}{c}\text { garlic } \\
\text { followed by } \\
\text { green tea }\end{array}$ & $500.75 \pm 25.46$ & $439.41 \pm 22.84$ & $314.49 \pm 18.44$ & $259.55 \pm 14.60$ & $201.03 \pm 10.30$ & $63.19 \pm 4.51$ & $17.41 \pm 1.17$ \\
\hline
\end{tabular}

Table A.16 Concentration of allyl methyl disulfide (AMDS) in the mouth for 60 minutes after ingestion of garlic followed by $2 \%$ fat milk, green tea, or none. Values represent least square mean \pm standard error $(n=8)$.

\begin{tabular}{|c|c|c|c|c|c|c|c|}
\hline \multirow{2}{*}{$\begin{array}{c}\text { Treatments/ } \\
\text { time (min) }\end{array}$} & \multicolumn{7}{|c|}{ Concentration of AMDS (ppb) } \\
\cline { 2 - 8 } & $\mathbf{3}$ & $\mathbf{6}$ & $\mathbf{9}$ & $\mathbf{1 2}$ & $\mathbf{1 5}$ & $\mathbf{3 0}$ & $\mathbf{6 0}$ \\
\hline garlic & $113.7 \pm 3.47$ & $49.7 \pm 1.65$ & $34.1 \pm 1.33$ & $27.03 \pm 1.04$ & $22.88 \pm 0.94$ & $13.47 \pm 0.57$ & $9.01 \pm 0.41$ \\
\hline $\begin{array}{c}\text { garlic } \\
\text { followed by } \\
\mathbf{2 \%} \text { fat milk }\end{array}$ & $58.69 \pm 3.37$ & $42.73 \pm 1.64$ & $32.61 \pm 1.32$ & $25.03 \pm 1.04$ & $20.63 \pm 0.95$ & $10.41 \pm 0.54$ & $7.46 \pm 0.43$ \\
\hline $\begin{array}{c}\text { garlic } \\
\text { followed by } \\
\text { green tea }\end{array}$ & $56.17 \pm 3.60$ & $37.48 \pm 1.78$ & $26.41 \pm 1.40$ & $22.13 \pm 1.10$ & $19.93 \pm 1.01$ & $10.86 \pm 0.57$ & $8.53 \pm 0.42$ \\
\hline
\end{tabular}


Table A.17 Concentration of allyl methyl sulfide (AMS) in the mouth for 60 minutes after ingestion of garlic followed by $2 \%$ fat milk, green tea, or none. Values represent least square mean \pm standard error $(\mathrm{n}=8)$.

\begin{tabular}{|c|c|c|c|c|c|c|c|}
\hline \multirow{2}{*}{$\begin{array}{c}\text { Treatments/ } \\
\text { time (min) }\end{array}$} & \multicolumn{7}{|c|}{ Concentration of AMS (ppb) } \\
\cline { 2 - 8 } & $\mathbf{3}$ & $\mathbf{6}$ & $\mathbf{9}$ & $\mathbf{1 2}$ & $\mathbf{1 5}$ & $\mathbf{3 0}$ & $\mathbf{6 0}$ \\
\hline garlic & $120.21 \pm 1.79$ & $109.95 \pm 1.98$ & $107.62 \pm 1.83$ & $102.01 \pm 1.83$ & $97.98 \pm 1.83$ & $81.74 \pm 1.79$ & $63.08 \pm 1.83$ \\
\hline $\begin{array}{c}\text { garlic } \\
\text { followed by } \\
\mathbf{2 \%} \text { fat milk }\end{array}$ & $101.21 \pm 1.14$ & $102.11 \pm 1.18$ & $101.74 \pm 1.20$ & $97.43 \pm 1.20$ & $90.13 \pm 1.17$ & $67.93 \pm 1.10$ & $53.42 \pm 0.90$ \\
\hline $\begin{array}{c}\text { garlic } \\
\text { followed by } \\
\text { green tea }\end{array}$ & $94.22 \pm 1.45$ & $90.76 \pm 1.50$ & $91.93 \pm 1.51$ & $90.05 \pm 1.52$ & $86.63 \pm 1.46$ & $74.99 \pm 1.37$ & $56.59 \pm 1.07$ \\
\hline
\end{tabular}

